\title{
GEORG-AUGUST-UNIVERSITÄT
} GÖTTINGEN

\section{Characterization of Npl3-mediated RNA quality control in Saccharomyces cerevisiae}

\section{Dissertation}

\author{
for the award of the degree \\ "Doctor rerum naturalium" \\ of the Georg-August-Universität Göttingen
}

within the doctoral program "Molecular Biology of Cells"

of the Georg-August University School of Science (GAUSS)

submitted by

Ulla-Maria Schneider

from Wolfhagen, Germany

Göttingen, December 2017 


\section{Members of the Thesis Committee}

Prof. Dr. Heike Krebber

Department of Molecular Genetics

Institute for Microbiology and Genetics

Dr. Oliver Valerius

Department of Molecular Microbiology and Genetics

Institute for Microbiology and Genetics

Prof. Dr. Ralf Ficner

Department of Molecular Biology

Institute for Molecular Biology

\section{Members of the Examination Board}

Referee: Prof. Dr. Heike Krebber

Department of Molecular Genetics

Institute for Microbiology and Genetics

\section{2nd Referee:}

Dr. Oliver Valerius

Department of Molecular Microbiology and Genetics

Institute for Microbiology and Genetics

\section{Further Members of the Examination Board}

Prof. Dr. Ralf Ficner

Department of Molecular Biology

Institute for Molecular Biology

Prof. Dr. Jörg Stülke

Department of Molecular Microbiology and Genetics

Institute for Microbiology and Genetics

Prof. Dr. Stefanie Pöggeler

Department of Molecular Structural Biology

Institute for Microbiology and Genetics

PD Dr. Wilfried Kramer

Department of Molecular Genetics

Institute for Microbiology and Genetics

Date of oral examination: $20^{\text {th }}$ February 2018 


\section{Affidavit}

I hereby declare that this doctoral thesis entitled "Characterization of Npl3-mediated RNA quality control in Saccharomyces cerevisiae" has been written independently with no other sources and aids than quoted.

Göttingen, December 2017

Ulla-Maria Schneider 


\section{Table of contents}

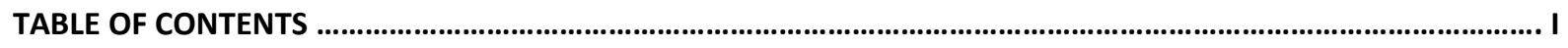

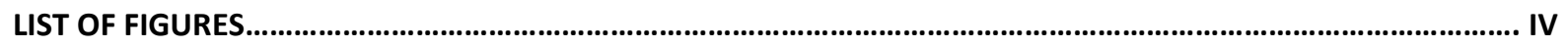

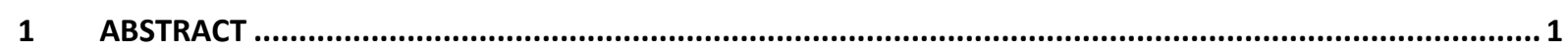

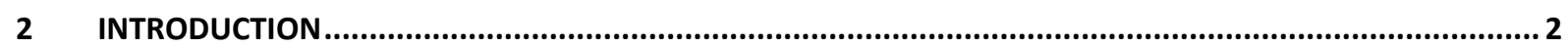

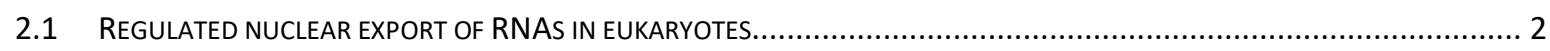

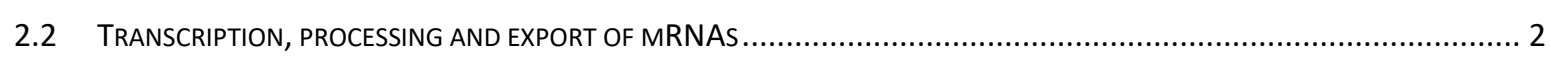

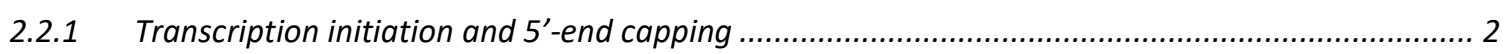

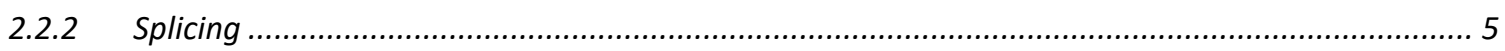

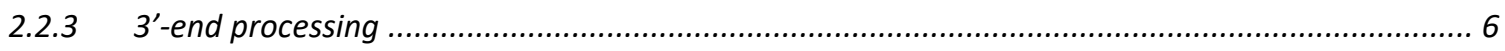

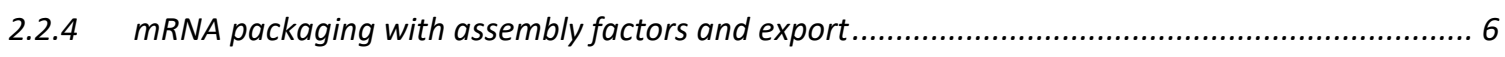

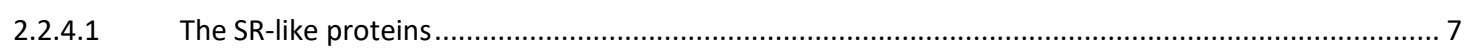

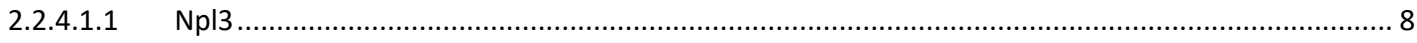

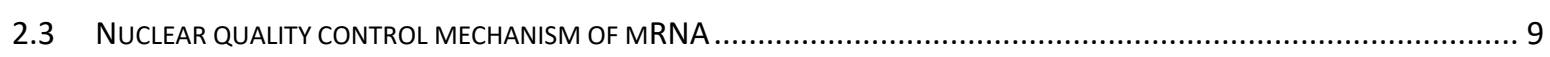

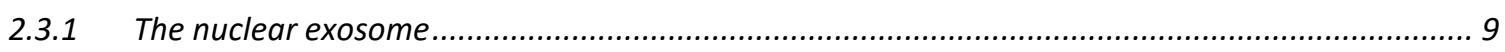

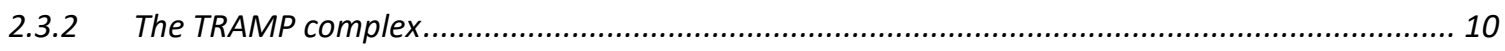

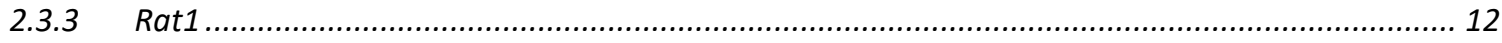

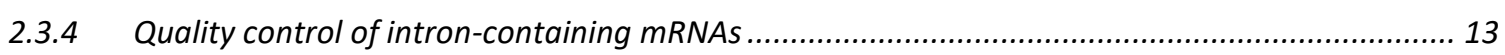

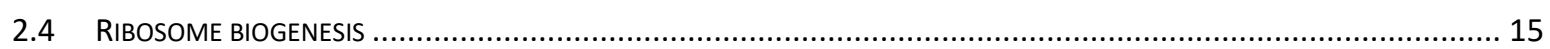

2.4.1 rRNA transcription initiation and pre-rRNA processing ...................................................... 16

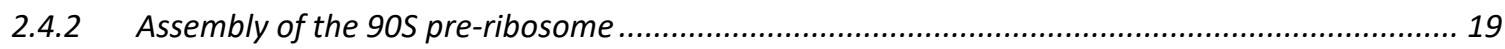

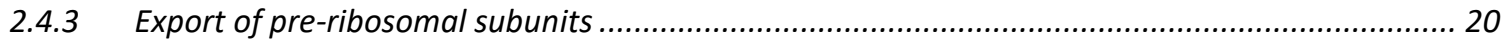

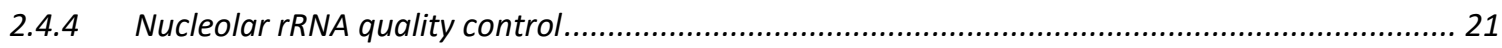

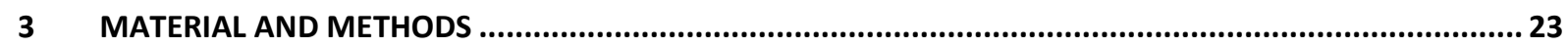

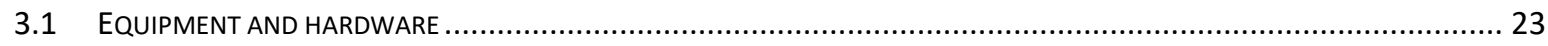

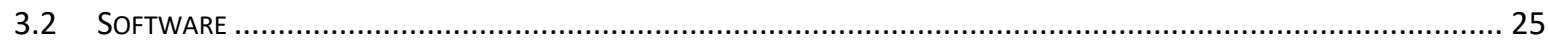

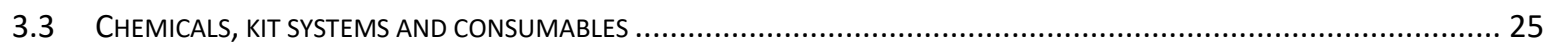

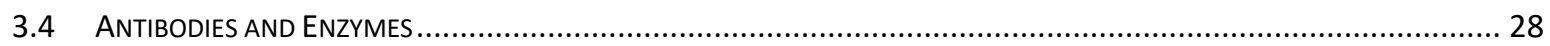

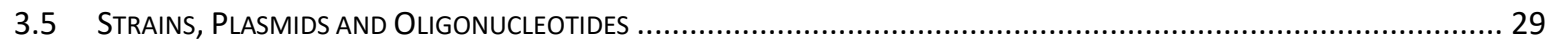

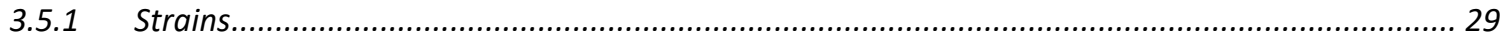

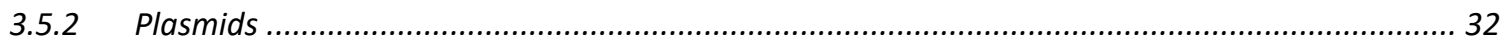

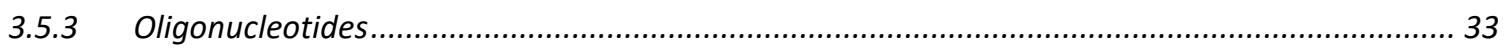

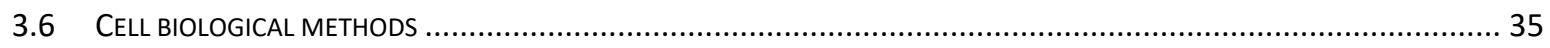

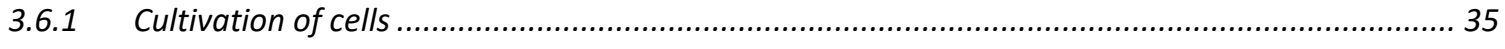

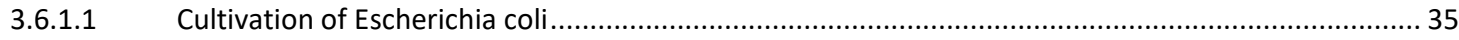

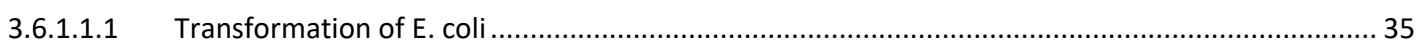




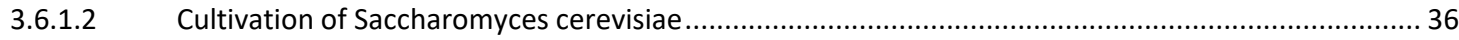

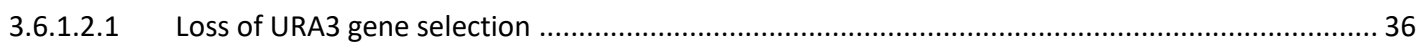

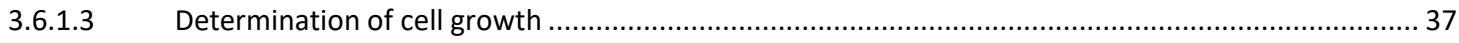

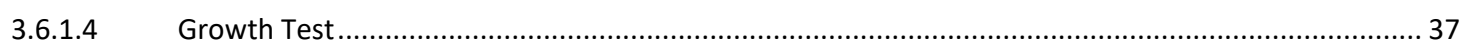

3.6.1.5 Sporulation and tetrad dissection of S.cerevisiae ...................................................................... 37

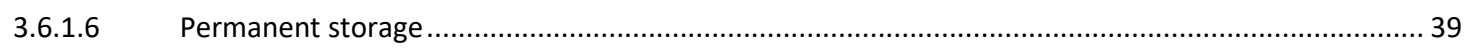

3.6.1.7 High-Efficient Lithium Acetat Transformation of S. cerevisiae ...................................................... 39

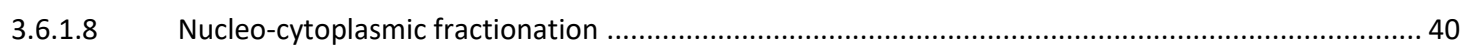

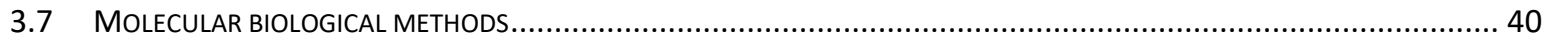

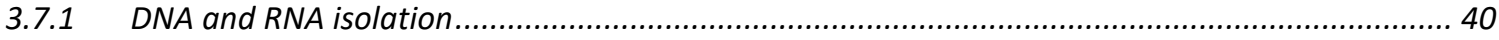

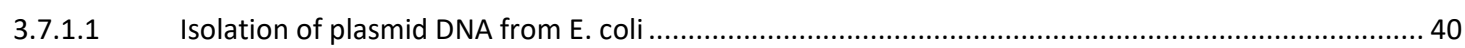

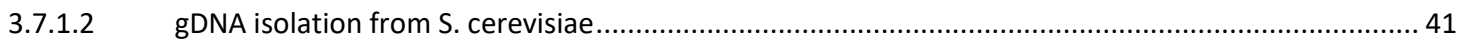

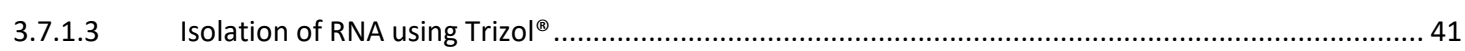

3.7.1.4 Isolation of RNA using the NucleoSpin RNA Kit system ............................................................... 42

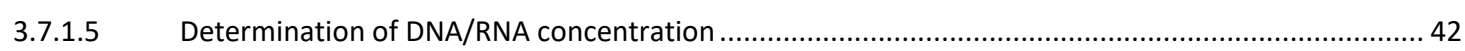

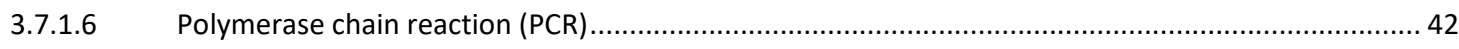

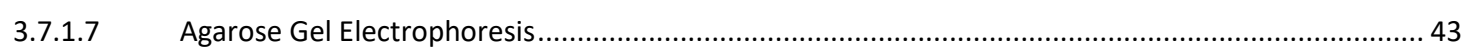

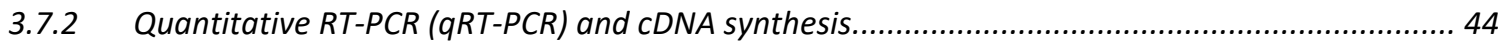

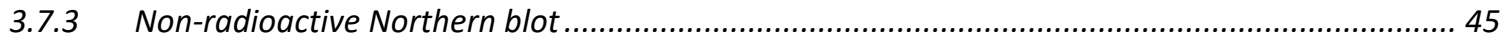

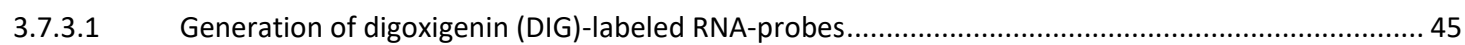

3.7.3.2 Denaturing RNA-formaldehyde agarose gel electrophoresis ........................................................ 46

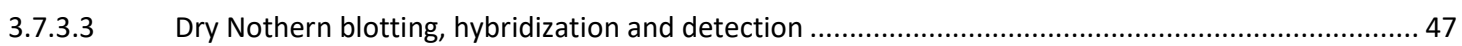

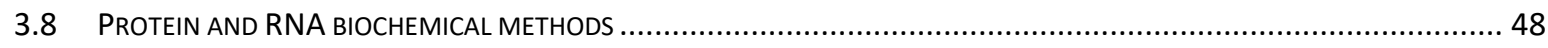

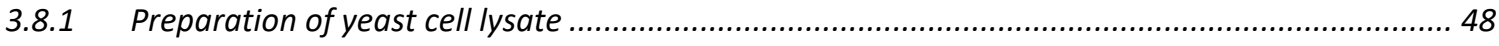

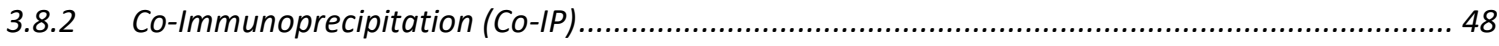

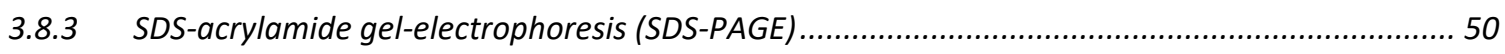

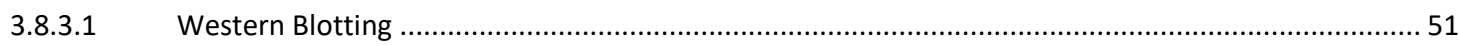

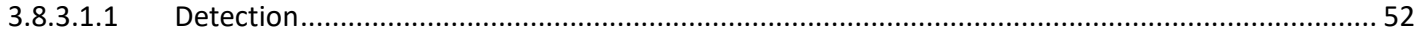

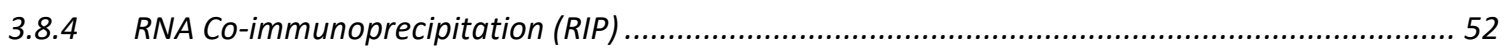

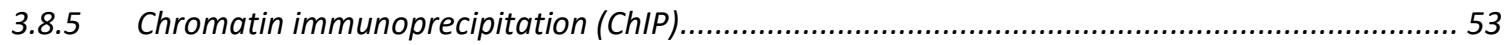

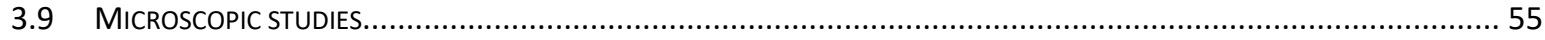

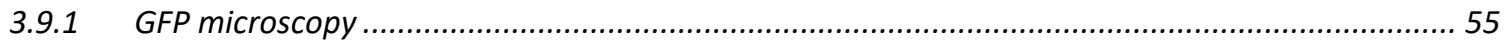

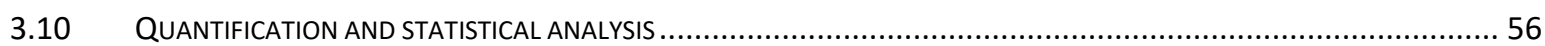

4 RESULTS

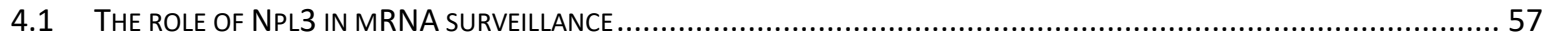

4.1.1 Npl3 is loaded to pre-mRNA after capping is completed ...................................................5 57

4.1.2 Npl3 prevents leakage of uncapped pre-mRNAs into the cytoplasm ...........................................58

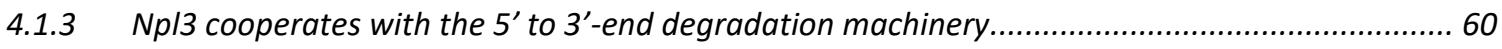

4.1.3.1 Npl3 genetically interacts with the $5^{\prime}$ to $3^{\prime}$-end degradation machinery .......................................6 60

4.1.3.2 Npl3 physically interacts with the $5^{\prime}$ to $3^{\prime}$ exonuclease Rat1 and its cofactor Rai1 in vivo .................6 61 
4.1.4 Npl3 is required to recruit the 5'-3'-end degradation machinery.

4.1.5 Binding between the export receptor Mex67 and Np/3 is impaired upon disturbed capping ....... 62

4.1.6 Np/3 cooperates with the TRAMP-complex mediated degradation machinery of false mRNAs ... 64

4.1.6.1 Npl3 physically interacts with factors of the TRAMP complex, but not with the exosome factor Rrp6 65

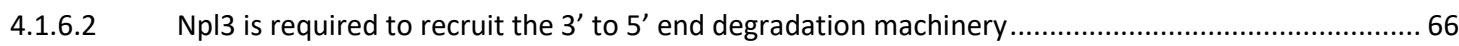

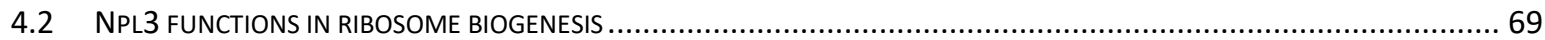

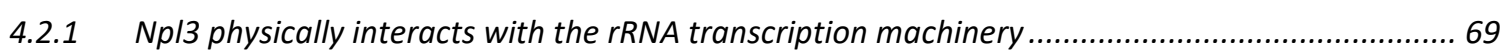

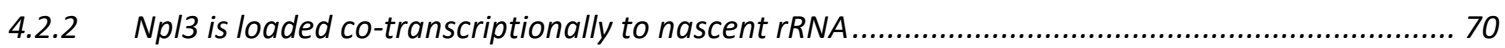

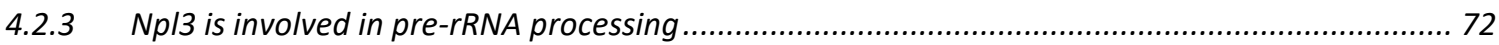

4.2.4 Np/3 cooperates with the exosome and the TRAMP complex in pre-rRNA processing and surveillance

4.2.5 Np/3 is important to recruit the TRAMP/exosome machinery to the processing sites in ETS1...... 74

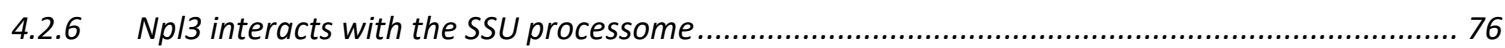

4.2.7 Np/3 physically interacts with several factors of the SSU processome in vivo............................. 77

4.2.8 Npl3 is required to recruit the SSU processome component Rcl1 to pre-rRNA.......................... 78

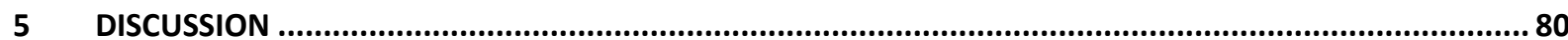

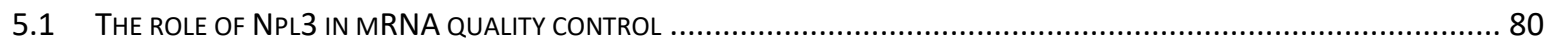

5.1.1 Np/3 is a surveillance factor for pre-mRNA capping ......................................................... 80

5.1.2 Npl3 cooperates with the 3' to 5' TRAMP mediated degradation machinery............................ 84

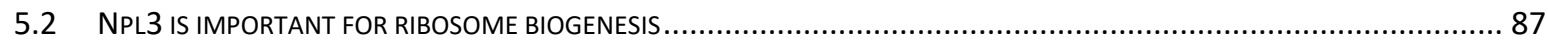

5.2.1 Np/3 is co-transcriptionally loaded to the $5^{\prime}$-end of pre-rRNAs and involved in rRNA processing

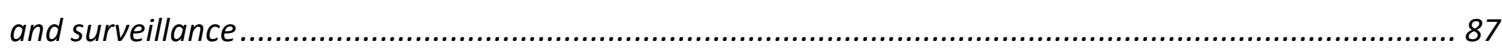

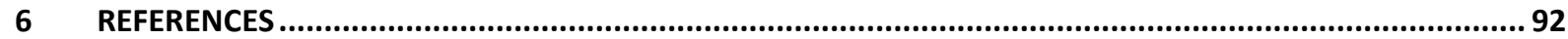

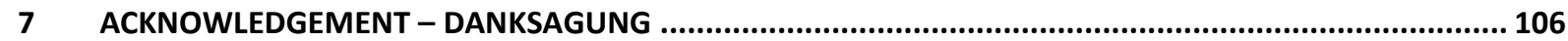

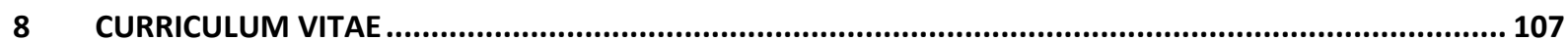




\section{List of figures}

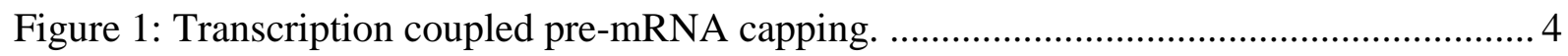

Figure 2: Domain structures and similarities of the SR-like proteins Hrb1, Gbp2 and Npl3... 8

Figure 3: Composition of the nuclear/nucleolar exosome in S.cerevisiae ............................. 10

Figure 4: Schematic representation of the functional mechanism of the exosome.................. 11

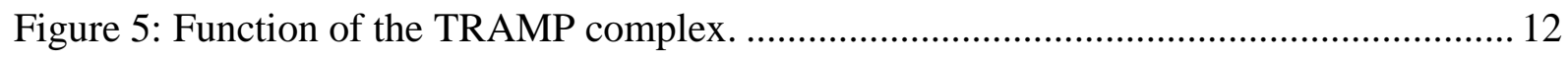

Figure 6: Model for surveillance of spliced transcripts...................................................... 13

Figure 7: Schematic representation of the 35S rRNA precursor.......................................... 15

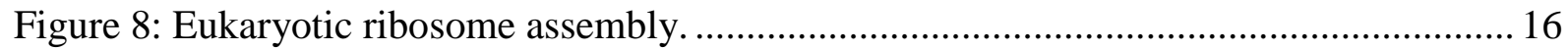

Figure 9: Schematic representation of the rDNA locus in S.cerevisiae .................................. 17

Figure 10: Pre-rRNA processing in S.cerevisiae. ................................................................. 18

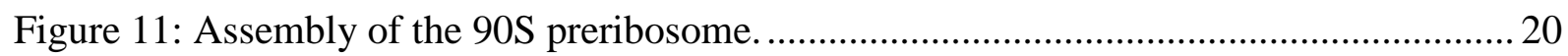

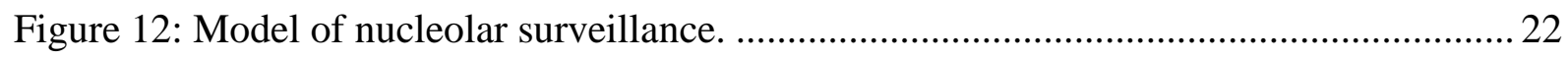

Figure 13: Npl3 does not physically interact with the capping enzyme in vivo......................58

Figure 14: Deletion of NPL3 leads to a leakage of uncapped mRNAs into the cytoplasm. .... 59

Figure 15: Deletion of NPL3 combined with a mutant of the nuclear 5' exonuclease RAT1 or a deletion of its co-factor RAIl lead to severe growth defects.

Figure 16: Np13 physically interacts with the 5'-3' degradation machinery Rat1-Rai1 in vivo.

Figure 17: Npl3 is required to recruit the 5'-3' mRNA degradation machinery.

Figure 18: Reduced binding between Npl3 and Mex67 upon generation of aberrant capped transcripts.

Figure 19: Npl3 physically interacts with Air1 and Air2 RNA-independently and in dependence of RNA with Trf4 and Trf5, but not with Mtr4 and Rrp6. 66

Figure 20: Npl3 is required to recruit the TRAMP-exosome degradation machinery to mRNAs.

Figure 21: Npl3 interacts with the rRNA transcription machinery..................................... 70

Figure 22: Npl3 interacts with the rRNA transcription machinery....................................... 71

Figure 23: Npl3 is co-transcriptionally loaded to pre-rRNA. .............................................. 72

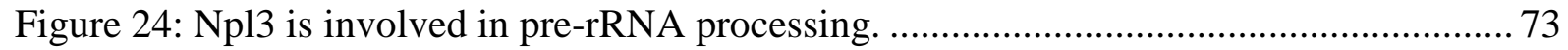

Figure 25: Npl3 is required for proper rRNA processing and surveillance. ............................ 75

Figure 26: Npl3 is important to recruit the TRAMP-exosome degradation machinery to rRNAs. 
Figure 27: Npl3 genetically interacts with SSU processome components............................. 77

Figure 28: Npl3 physically interacts with SSU processome components in vivo. .................. 78

Figure 29: Npl3 is important for the SSU processome assembly....................................... 79

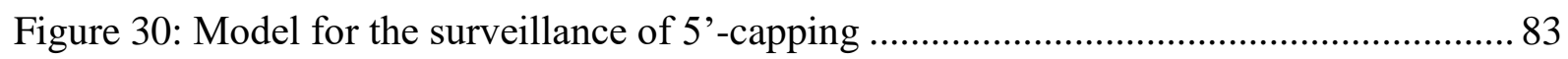

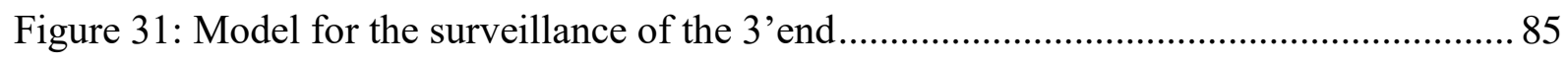

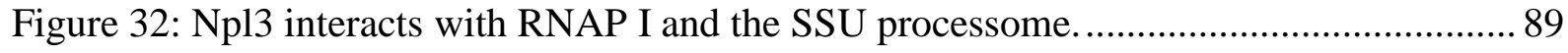

Figure 33: Npl3 in ribosome biogenesis and quality control of rRNA. ................................. 91 


\section{Abstract}

During all steps of nuclear RNA maturation, aberrant RNAs can be generated. However, nuclear quality control mechanisms ensure that immature or aberrant RNAs are retained in the nucleus and subsequently degraded to prevent faulty transcripts from being exported into the cytoplasm and participate in cellular processes. In this study, the multifunctional RNA-binding protein Np13 was identified to be a general key surveillance factor for mRNAs and rRNAs. Here we show, that the protein binds to pre-mRNAs after the 5'-capping is completed. A properly processed 5'-cap is bound by the cap binding complex (CBC). This is detected by $\mathrm{Npl3}$ and correctly capped pre-mRNAs are further processed. However, if the 5'-cap was not properly added, Npl3 prevents the export of these faulty transcripts by recruiting the 5 ' to 3 ' degradation machinery Rat1-Rai1 via interaction with Rai1. Interestingly, the quality control of $\mathrm{Npl} 3$ does not seem to be restricted to the 5'-end of an mRNA, because we could also show that Npl3 is required to recruit the 3' to 5' degradation machinery. In this case, Npl3 loads the TRAMP complex component Air2 to the 3'-end of mRNAs, inducing the subsequent TRAMP complex formation and therefore the degradation by the nuclear exosome.

Strikingly, Npl3 functions also in ribosome biogenesis. Here, we show that Npl3 is loaded cotranscriptionally to the 5'-end of emerging pre-rRNAs and it is important for early rRNA processing and surveillance. Npl3 interacts with the SSU processome and is important for its assembly. Furthermore, Npl3 is required to load the 3' to 5' degradation machinery to prerRNAs. This is important for the rRNA degradation during regular processing and for degradation of aberrant precursors especially the 23S rRNA.

Remarkably, the functions of Npl3 in mRNA and rRNA biogenesis are quite similar, as Npl3 in both cases is required for RNA processing and surveillance to ensure that only high-quality RNAs can exit the nucleus and engage in protein synthesis. Npl3 prevents the nuclear export of aberrant transcripts and recruits the $5^{\prime}$ to $3^{\prime}$ and the 3 'to 5 ' degradation machineries. Their recruitment requires co-factors as the TRAMP complex or Rai1, which Npl3 loads to the RNA, before it is released, and the RNA is degraded. Thus, our work has uncovered Npl3 as a general guard protein for mRNA and rRNA processing that determines whether an RNA is further processed or eliminated from the cell. 


\section{Introduction}

\subsection{Regulated nuclear export of RNAs in eukaryotes}

In eukaryotic cells, the nuclear and cytoplasmic sub compartments are separated by the nuclear envelope and thereby isolating the messenger RNA (mRNA) transcription from its translation into a protein. During transcription, mRNAs are co-transcriptionally processed and loaded with assembly factors, resulting in an export competent messenger ribonucleoprotein particle (mRNP) (Fasken and Corbett, 2009). Once an mRNP reaches the cytoplasm, it is translated into a protein by the ribosomes. Nuclear pore complexes (NPCs), which are channels through the nuclear envelope, facilitate a regulated exchange of molecules and complexes (Sommer and Nehrbass, 2005). Nuclear quality control mechanisms ensure that immature or aberrant mRNAs are not exported into the cytoplasm for subsequent translation, but rather are retained and degraded in the nucleus (Fasken and Corbett, 2009). Otherwise, export of such defective mRNAs and their translation might result in gene products that are harmful to the cell and could lead to diseases including cancer or neurodegenerative diseases in higher eukaryotes (Lukong et al., 2008) . Likewise, the selective nuclear export of properly assembled pre-ribosomal subunits, consisting of ribosomal RNA (rRNA) and ribosomal proteins is necessary for cell viability. Improper processing of rRNA or incomplete assembly of ribosomal factors can result in structurally defective ribosomes and therefore lead to a number of diseases in higher eukaryotes (Freed et al., 2010). Similar to mRNA, cells have evolved several quality control mechanisms that prevent nucleolar or nuclear export of defective pre-ribosomal subunits (Lafontaine, 2010).

\subsection{Transcription, processing and export of mRNAs}

\subsubsection{Transcription initiation and 5'-end capping}

In eukaryotes three RNA polymerases (RNAPs) are responsible for the synthesis of different kinds of RNA. RNAP I is required to transcribe rRNA, RNAP II synthesizes all mRNAs and a number of non-conding RNAs (ncRNAs) and RNAP III generates among others transfer RNAs (tRNAs), small nucleolar RNAs (snoRNAs) and the 5S rRNA. RNAP II is composed of 12 subunits including its largest and catalytic active protein Rpb1. Furthermore, Rpb1 exhibits a C-terminal domain (CTD) built up of 26 tandem heptad repeats in yeast, which is unique for RNAP II and conserved from fungi to human. The CTD serves as recruitment platform for 
transcription and processing factors and plays an important role in regulating transcriptional processes, whereby its phosphorylation state is relevant in determining its activity (Cramer, 2004; Hsin and Manley, 2012). For transcription initiation, the general transcription factors TFIIA, TFIIB, TFIID, TFIIE, TFIIH; the mediator complex and RNAP II with an unphosphorylated CTD assemble and built the preinitiation complex (PIC). Simultaneously with transcription initiation the CTD gets highly phosphorylated, especially at serine2 (Ser2) and serine5 (Ser5) positions of the heptad (Hsin and Manley, 2012). Soon after transcription initiation, the first co-transcriptional processing event of pre-mRNAs, the capping, occurs. Capping of pre-mRNAs is essential for the viability of eukaryotic cells. The mature 5 ' guanineN7 cap plays a critical role during an mRNA life cycle. It is involved in coordinating the subsequent co-transcriptional pre-mRNA processing steps and it is required for nuclear export and efficient translation and stabilization (Jove and Manley, 1982; Rasmussen and Lis, 1993; Ghosh and Lima, 2010). The capping process is performed in three enzymatic activities. Initially, the first phosphate is removed by the RNA triphosphatase Cet1 to generate diphosphate-terminated pre-mRNA (Tsukamoto et al., 1997). After that, the guanylyltransferase Ceg1 transfers a GMP nucleoside to this diphosphate-terminated premRNA resulting in a 5'-5' link (Shibagaki et al., 1992). Finally, the terminal guanine base is methylated at the N7 position by the guanine N7 methyltransferase Abd1 to form a mature mRNA cap structure (Mao, Schwer and Shuman, 1995). After the capping reaction has been completed, the cap binding complex (CBC), which is a heterodimeric complex composed of Cbp80 and Cbp20, binds to the mature cap structure and thereby promotes the subsequent nuclear export (Lewis and Izaurflde, 1997) (Figure1). It has been shown, that the capping event occurs already upon synthesis of an approximately 20 nucleotide long transcript (Coppola, Field and Luse, 1983). The capping enzyme consisting of Ceg1 and Cet1 is recruited to the CTD when it is phosphorylated at Ser5, however the interaction with the CTD seems to be mediated by Ceg1 (Ho and Shuman, 1999; Takase et al., 2000). Ceg1 and Cet1 form a stable complex, whereby a Cet 1 dimer binds to either a single Ceg1 or a Ceg1 dimer resulting in a heterotrimeric or heterotetrametric complex (Fabrega et al., 2003; Gu, Rajashankar and Lima, 2010). It was shown by chromatin immunoprecipitation analyses, that the capping enzyme subunits are Abd1 is loaded100 nucleotides further downstream (Mayer et al., 2010; Lidschreiber, Leike and Cramer, 2013). As the generation of a mature cap structure is the first processing step in loaded 


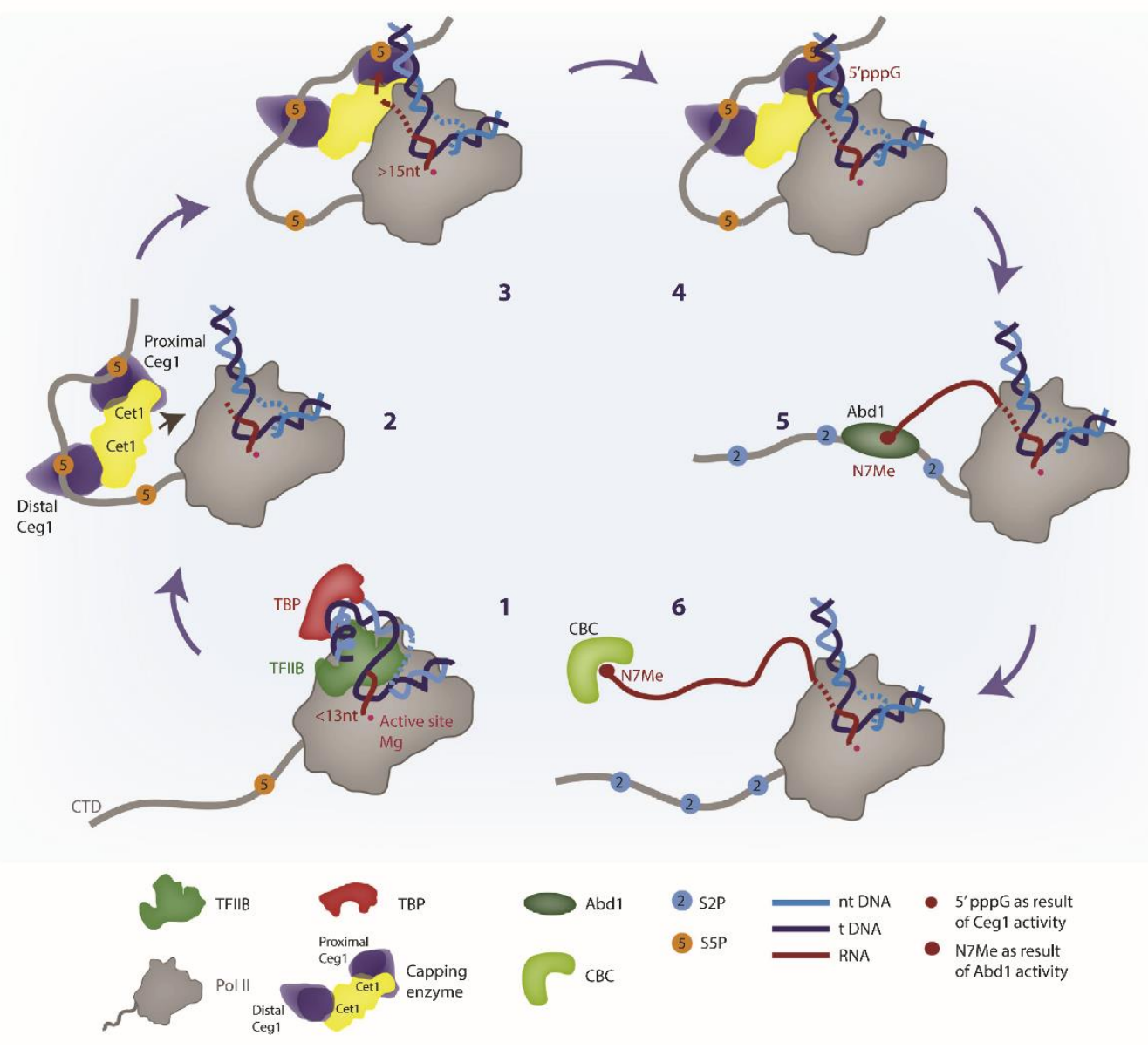

Figure 1: Transcription coupled pre-mRNA capping.

Unphosphorylated RNAP II assembles with general transcription factors on the promoter region during transcription initiation and RNA synthesis begins (1). When the emerging RNA reaches a length of about $13 \mathrm{nt}$ the general transcription factors are released and the Ser5-phophorylated CTD can bind the capping enzyme composed of Cet1 and Ceg1 (2). Subsequently, the capping enzyme docks onto the RNAP II surface at the end of the RNA exit tunnel (3). Cet1 hydrolyzes the 5'-triphosphate end of the nascent RNA resulting in a diphosphate end, which is then transferred to the Ceg1 active site and coupled to a GMP moiety (4). Guanylation triggers dissociation of the capping enzyme from the RNAP II surface and a decrease in Ser5 phosphorylation of the CTD results in a complete release of the capping enzymes from RNAP II. The methyltransferase Abd1 binds subsequently to the Ser2-phospophrylated CTD and catalyzes the addition of the methyl group of the cap structure (5). The cap-binding complex (CBC) binds to a proper processed cap structure to stabilize the RNA and further stimulate processive elongation (6)

(Martinez-Rucobo et al., 2015)

immediately downstream of the transcription start site, while the methyltransferase the life cycle of an mRNA and because it is important among others for further mRNA maturation and export, quality control mechanisms are required to recognize and degrade uncapped or aberrant pre-mRNAs. Although the precise mechanisms is still unclear, it was shown that Rai1, which is a nuclear factor with decapping endonuclease activity, is involved in recognition and subsequent degradation of uncapped or unmethylated mRNAs (Jiao et al., 2010). Moreover, 
the serine-arginine rich (SR) protein Npl3 was shown to be recruited to mRNA very early during transcription via the CTD (Lei, Krebber and Silver, 2001) and interacts with the CBC (Shen et al., 2000). To facilitate splicing, which is the next mRNA processing event, the presence of the $\mathrm{CBC}$ and $\mathrm{Npl3}$ are required and help to recruit the splicing machinery (Görnemann et al., 2005; Kress, Krogan and Guthrie, 2008).

\subsubsection{Splicing}

After capping is successfully completed, splicing is initiated if the transcript contains noncoding regions. During splicing, these non-coding introns are removed from pre-mRNAs and the exons are ligated together to a continuous coding strand. This process is carried out by the spliceosome, a dynamic ribonucleoprotein particle, which is composed of 5 small nuclear RNAs (snRNAs) termed U1, U2, U4, U5 and U6 and additionally over 80 proteins in S. cerevisiae (Will \& Lührmann, 2011). Indeed, in S. cerevisiae only 5\% of all genes contain introns. However, these genes are highly expressed, so that about $25 \%$ of all transcripts derive from intron-containing genes (Ares, Grate and Pauling, 1999; Davis et al., 2000). Intron containing pre-mRNAs exhibit short consensus sequences at the exon-intron transitions to allow recognition by the spliceosome. These consensus sequences are found at the 5' splice site with the conserved dinucleotide GU and at the 3' splice site with the conserved dinucleotide AG. Furthermore, a third consensus sequence termed branch point sequence is located within the intron. Spliceosome assembly takes place by stepwise interaction of the snRNPs and numerous other splicing factors (Matlin and Moore, 2007). It is initiated by binding of the U1 snRNP to the 5' splice site of the intron, which is mediated by ATP independent base-pairing between U1 and the 5' splice site. Next, U2 associates with the branch point site, forming a complex termed complex A or pre-spliceosome. After that, the U4-U6-U5 tri-snRNP complex is recruited to complex A, resulting in complex B. Conformational rearrangements lead to the dissociation of $\mathrm{U} 1$ and U4. This dissociation and the subsequent recruitment of the DEAD-box RNA helicase Prp2 results in an active complex B, which carries out the first two reactions of splicing (Will and Lührmann, 2011). First, pre-mRNA is cleaved at the 5' splice site and subsequently an adenosine of the branch point sequence attacks the phosphodiester bond at the 5' splice site, which leads to a free $5^{\prime}$ end of exon 1 . This results in lariat formation by the ligation of the 5 , end of the intron with the adenosine of the branch point sequence. Afterwards, mRNA is cleaved at the 3' splice site and the two exons are ligated (Wahl, Will and Lührmann, 2009; 
Will and Lührmann, 2011). Finally, the spliced mRNA is released and the snRNPs are recycled for further splicing reactions (Matlin and Moore, 2007).

\subsubsection{3'-end processing}

The final step of mRNA processing is polyadenylation of the 3'-end, including the poly(A) site cleavage, subsequent polyadenylation, and the binding of poly(A) binding proteins. In this final phase of transcription, RNAP II generates polyadenylation signal sequences within the premRNAs. These signal sequences are recognized by the poly(A) complex, which is also recruited by the CTD (Moore and Proudfoot, 2009). Poly(A) signals include efficiency elements (EE), positioning elements (PE) and U-rich elements that are located around the cleavage site (Tian and Graber, 2012). Once the poly(A) complex is successfully associated with these poly(A) signal sequences the cleavage at the poly(A) site is carried out by the poly(A) complex component Ydh1 (Moore and Proudfoot, 2009). Subsequently, a 70-90 nt long adenosine tail is added to the 3' end by the poly(A) complex subunit Pap1 (Moore and Proudfoot, 2009; Chan, Choi and Shi, 2011). After successful polyadenylation, the tail is immediately bound by the poly(A) binding proteins Nab2 and Pab1. This binding is crucial for stability of the poly(A) tail and these proteins control furthermore its quality and length (Dunn et al., 2005; Soucek, Corbett and Fasken, 2012). Finally, the 5' exonuclease Rat1 degrades the RNA downstream of the cleavage site which is still associated with RNAP II (Kim et al., 2004). It was proposed, that the 3'-end processing machinery is already recruited by RNAP II during transcription initiation (Chan, Choi and Shi, 2011). Moreover, it is assumed, that Npl3, which is also loaded early while transcription initiation, antagonizes 3 '-end processing when not accomplished in time by competition with the polyadenylation and cleavage factors (Bucheli and Buratowski, 2005).

\subsection{4 mRNA packaging with assembly factors and export}

Parallel to the processing events, maturing mRNAs are also co-transcriptionally loaded with mRNP assembly factors, such as several factors important for mRNA, including the essential factors Sub2 and Yra1, and the THO complex, which is formed by Tho2, Hpr1, Mft1 and Thp2 Tex1. Together with Sub2 and Yra1 the THO complex forms the so called TREX (transcription and mNNA export) complex (Rougemaille et al., 2008; Meinel and Sträßer, 2015). The THO complex is proposed to facilitate transcription elongation by preventing DNA-RNA hybrid formation and to help recruiting other factors, such as Sub2, for correct mRNP assembly (Huertas and Aguilera, 2003; Meinel and Sträßer, 2015). Subsequently, the TREX complex 
together with $\mathrm{Npl3}$ is proposed to bring mRNPs to the nuclear pore complex (NPC) (Meinel and Sträßer, 2015). Properly processed, export competent mRNPs can be recognized and bound by the essential export-receptor heterodimer Mex67-Mtr2 and are finally translocated trough the NPC into the cytoplasm. For that, mRNA binding proteins, such as the SR-proteins Npl3, Gbp2, and Hrb1 as well as the poly(A) binding protein Nab2, function as adaptors for Mex67Mtr2 (Lei and Silver, 2002; Häcker and Krebber, 2004). Mex67 facilitates the export of mRNPs via interaction with the NPC (Hobeika et al., 2009). The NPC is an octagonally symmetrical cylinder consisting of nucleoporins (Nups), which form an inner and an outer ring. Phenylalanine-glycine (FG)-rich repeats of the nucleoporins coat the inner ring of the NPC and thus present a hydrophobic meshwork that prevents diffusion of higher molecular particles (Aitchison and Rout, 2012). Mex67 binds to the FG-rich repeats of the nucleoporins and in this way facilitate the transport of the mRNP through this hydrophobic meshwork (Hobeika et al., 2009). Once an mRNP has reached the cytoplasm, the helicase activity of Dbp5 results in remodeling of the mRNP, which results in the release of Mex67 from the particle to ensure directionality of the transport event (Tieg and Krebber, 2013).

\subsubsection{The SR-like proteins}

In S. cerevisiae, three shuttling SR-like proteins exist: Npl3, Gbp2 and Hrb1. In general, SR proteins are a conserved family of mRNA-binding proteins that are important factors of the premRNA processing machinery. In higher eukaryotes, SR proteins are required for pre-mRNA splicing and are also regulators for alternative splicing (Jeong, 2017). In S. cerevisiae, the three SR-proteins are highly homologous. Each of them contains RNA recognition motifs (RRMs) and a serine/arginine rich region termed SR domain, which are essential for the protein function. The RRMs are crucial for its binding to RNAs, whereas the SR-rich domain is required for protein interaction. Npl3 additionally exhibits a APQE (ala- nine/proline/glutamine/glutamic acid) rich domain with unknown function (Windgassen and Krebber, 2003; Häcker and Krebber, 2004). Gbp2 and Hrb1 share $47 \%$ of their amino acid residues, whereas Npl3 and Gbp2 share $27 \%$ of the amino acid residues and Npl3 and Hrb1 share $23 \%$ of the amino acid residues (Windgassen and Krebber, 2003) (Figure 2). While Npl3 interacts with bulk mRNAs and is early loaded onto the emerging transcript via RNAP II (Lei, Krebber and Silver, 2001; Kim Guisbert et al., 2005), Gbp2 and Hrb1 are recruited at a late stage of transcription by the THO complex (Häcker and Krebber, 2004; Hurt et al., 2004). It was shown, that Gbp2 and Hrb1 are key surveillance factors for intron-containing pre-mRNAs (Hackmann et al., 2014). 


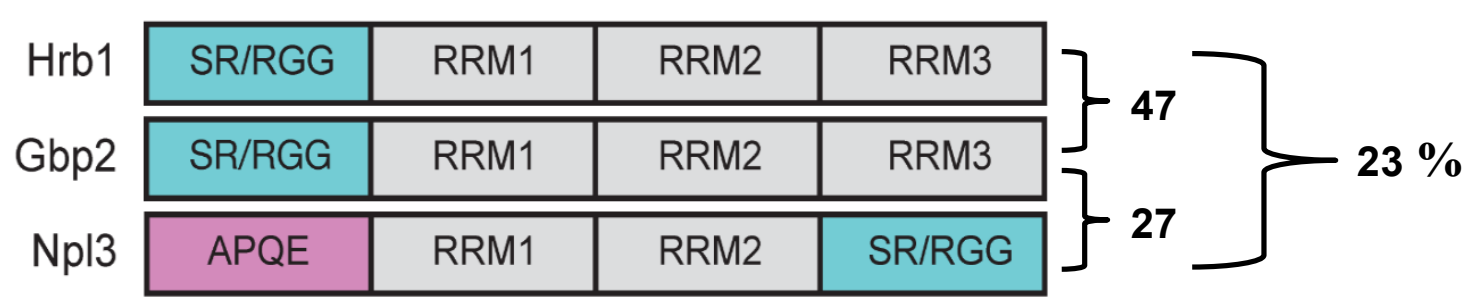

Figure 2: Domain structures and similarities of the SR-like proteins Hrb1, Gbp2 and Npl3. The SR-like proteins Hrb1 and Gbp2 contain three RRMs (RNA Recognition Motifs) and an N-terminal SR domain (serine/arginine rich domain). They share $47 \%$ of their amino acid residues. Npl3 exhibits two RRMs, a C-terminal SR domain and additionally a N-terminal APQE domain (alanine/proline/glutamine/glutamic acid) rich domain. Np13 and Gbp2 share $27 \%$ of their amino acid residues and $\mathrm{Npl} 3$ and $\mathrm{Hrb} 1$ share $23 \%$ of their amino acid residues.

(Adapted from Häcker \& Krebber, 2004)

They predominantly bind to unspliced transcripts and retain them in the nucleus until splicing is completed. When unspliced or aberrant spliced pre-mRNAs are recognized, Gbp2 and Hrb1 interact with the TRAMP complex to promote mRNA degradation by the nuclear exosome (Wolin, Sim and Chen, 2012; Hackmann et al., 2014).

\subsection{Npl3}

The multifunctional protein Npl3 participates in diverse RNA-related processes such as transcription, splicing, export of mRNPs and the large ribosomal subunit (LSU) as well as translation (Hackmann et al., 2011b; Santos-Pereira et al., 2014). Npl3 is loaded to pre-mRNAs during transcription initiation via the CTD of RNAP II (Lei, Krebber and Silver, 2001) and interacts with the CBC (Shen et al., 2000). Furthermore, binding of Npl3 promotes transcription elongation and prevent premature termination by competing with the CF1A cleavage and polyadenylation complex (Bucheli and Buratowski, 2005). Timely transcription termination is achieved by casein kinase (CKII)-dependent phosphorylation of RNAP II, which enables the action of termination factors. Finally, a dephosphorylation of Npl3 by Glc7 supports the nuclear export of the mRNP (Gilbert and Guthrie, 2004; Dermody et al., 2008). As an adaptor for the export receptor heterodimer Mex67-Mtr2, Npl3 shuttles with mRNPs into the cytoplasm (Lee, Henry and Pamela, 1996; Gilbert and Guthrie, 2004). In the cytoplasm, Npl3 is dephosphorylated by Sky1 and re-transported into the nucleus via its import receptor Mtr10 (Gilbert, Siebel and Guthrie, 2001). Besides its functions in the mRNA life cycle, Npl3 has also been found to be important for the nuclear export of large ribosomal subunits (LSU) independently of Mex67 (Hackmann et al., 2011). Additionally, Npl3 co-purifies with the 18S, 
25S and 5S rRNA (Krogan et al., 2004) and its downregulation affects the processing of the $27 \mathrm{~S}$ precursor rRNA to mature $25 \mathrm{~S}$ rRNA as well as the processing of the $20 \mathrm{~S}$ precursor rRNA to 18S rRNA (Russell and Tollervey, 1992). However, the function of Npl3 in rRNA processing was never addressed. Moreover, in addition to its manifold nuclear functions, Npl3 plays also a role in translation initiation. Here, it is required for proper subunit joining (Baierlein et al., 2013).

\subsection{Nuclear quality control mechanism of mRNA}

At all steps of nuclear mRNA maturation aberrant mRNAs can be produced. Nevertheless, these aberrant mRNAs are recognized and eliminated by the nuclear surveillance machinery. In the nucleus, mRNA quality control and degradation are realized by distinct factors including the exosome, which exhibit a 3' to 5' exonuclease activity, and the 5' to 3' exonuclease Rat1. The nuclear exosome functions in processing and degrading several classes of defective RNAs and requires co-factors for its activity. In the nucleus, general co-factors are the TRAMP (Trf4/5Air1/2-Mtr4-Polyadenlytaion) complex, the Nrd1-complex, Rrp47, Mpp6 and Nop53 (Bernstein and Toth, 2012). These factors have all in common that they recruit the nuclear exosome to their target RNAs. The 5' to 3' exonuclease activity of Rat1 requires the binding of the pyrophosphohydrolase Rai1 (Xue et al., 2000; Xiang et al., 2009).

\subsubsection{The nuclear exosome}

The exosome is a highly conserved RNA metabolism machinery that plays a key role in RNA surveillance, degradation and processing. In fact, it provides the major 3'-5'exoribonucleolytic activity in all eukaryotes (Mitchell et al., 1997; Houseley, LaCava and Tollervey, 2006). In S.cerevisiae, the exosome consists of a nine-subunit core complex and the nuclear/cytoplasmic endo-exoribonuclease Dis3/Rrp44. In the nucleus, the exosome additionally associates with the riboexonuclease Rrp6. The 'core' complex is built up of nine subunits: Rrp4, Rrp40, Rrp41, Rrp42, Rrp43, Rrp45, Rrp46, Mtr3 and Cs14. Six of these subunits form a hexameric ring, which is bound by three RNA-binding subunits on top (Wolin, Sim and Chen, 2012) (Figure 3). The nuclear exosome functions in degrading and processing of several classes of RNAs such as mRNAs, rRNAs, tRNAs, snRNA, and small nucleolar RNAs (snoRNAs) (Callahan and Butler, 2010). Aberrant RNA is channeled through the core and subsequently degraded by the exoribonuclease Dis3/Rrp44 or it is guided to the second exoribonuclease Rrp6. For its activity, the exosome requires distinct cofactors including Mtr4/TRAMP, Rrp47, Mpp6, Nrd1/Nab3 and 
Nop53 that promote specificity or recruit the exosome to a site of processing. The exosome exhibits weak exonuclease activity in vitro, but rapid degradation is seen in vivo, indicating that cofactors are required for its activity. Moreover, RNA helicases are required to remove secondary structure to allow proper processing or degradation (Bernstein and Toth, 2012) (Figure 4). In case of mRNAs, degradation by the exosome requires the recruitment of the TRAMP complex, which strongly enhances the activity of Rrp6. The exosome/TRAMP machinery does not only degrade byproducts of mRNA maturation, it is also crucial for the turnover of mRNAs that were not processed correctly (Callahan and Butler, 2010; Bernstein

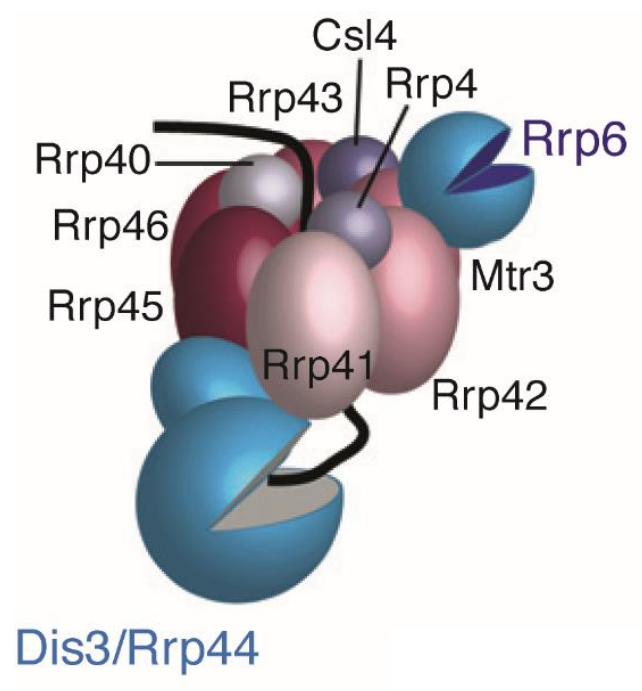

Figure 3: Composition of the nuclear/nucleolar exosome in S.cerevisiae.

The "core" exosome is composed of 9 subunits. Six of them form a hexameric ring: (Rrp41, Rrp42, Rrp43, Rrp45, Rrp46 and Mtr3. This ring structure is bound by three RNA-binding proteins Rrp40, Rrp4 and Cs14. The 5'-3' exoribonuclease interacts with the bottom of the channel, while the nuclear specific 5'-3' exoribonuclease Rrp6 is proposed to be located at the channel entrance. (Wolin, Sim, \& Chen, 2012)

and Toth, 2012).

\subsubsection{The TRAMP complex}

The TRAMP complex, as the major cofactor for the nuclear exosome, is important for processing and surveillance of several kinds of RNAs including mRNAs, rRNAs, tRNAs, snRNA, snoRNAs and cryptic unstable transcripts (CUTs). It consists of three components, which are conserved in eukaryotes: a non-canonical poly(A) polymerase $\operatorname{Trf} 4$ or $\operatorname{Trf5}$, a zincknuckle RNA binding protein, either Air1 or Air2, and the RNA helicase Mtr4 (Bernstein and Toth, 2012; Schmidt and Butler, 2013). It is proposed, that the TRAMP complex recognizes 


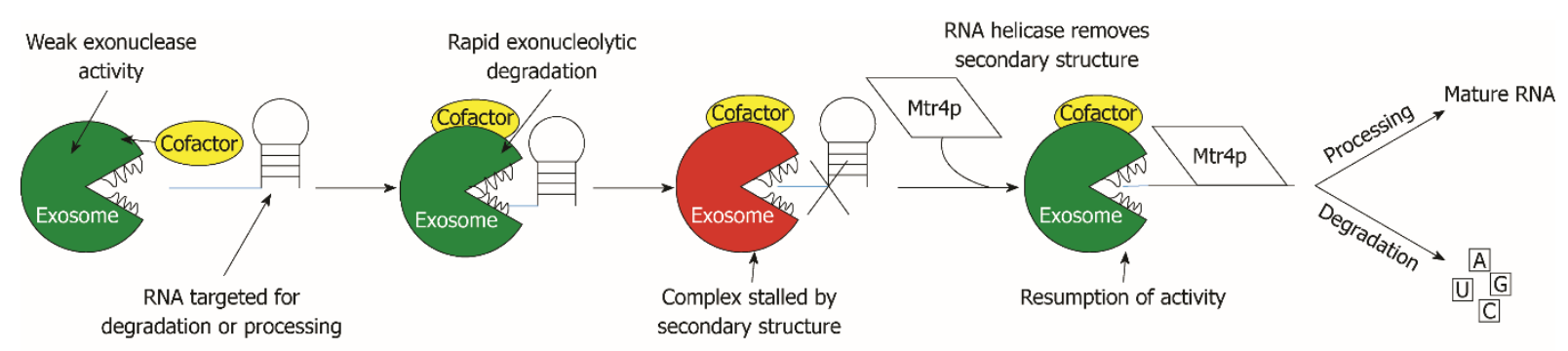

Figure 4: Schematic representation of the functional mechanism of the exosome.

The figure depicts the requirement for a cofactor to stimulate the exonuclease activity of the exosome and furthermore the necessity for an RNA helicase to eliminate secondary structure to allow proper processing or degradation. Here, a representative stem loop structure is shown, but any RNA with secondary structure could undergo the same unwinding to complete processing or degradation. The cofactor shown stands representative for all known and unknown cofactors. (Bernstein \& Toth, 2012)

aberrant RNAs via Air1 or Air2 and labels them with a short (4-5 nt) oligo(A) tail at their 3'ends by either Trf4 or Trf5 (Wlotzka et al., 2011; Jia et al., 2012). Furthermore, it is suggested that these RNAs are subsequently bound by Mtr4 and guided through its helical core to unwind the RNA. This oligo(A) labeled and unwound RNA is finally accessible for the degradation by the nuclear exosome (Jia et al., 2012) (Figure 5). Air1 and Air2 are required for RNA binding and have similar but non-redundant functions. It is supposed, that Air1 and Air2 control the substrate specificity within the TRAMP complex (Schmidt et al., 2012). Trf4 and Trf5 are likewise assumed to have overlapping but not redundant functions (San Paolo et al., 2009). RNA binding of Trf4 is thought to be mediated by Air1/2 via interaction of two zinc knuckle domains with the central domain of Trf4 (Hamill, Wolin and Reinisch, 2010). The essential RNA-helicase Mtr4 belongs to the Ski2 family of DExH-box containing proteins and functions in unwinding duplex RNA like secondary structures in 3' to 5' direction in an ATP dependent manner. Furthermore, it exhibits an RNA binding activity of single-stranded RNAs, on which it preferentially binds to short poly(A) substrates (Bernstein et al., 2008). Moreover, it was shown, that Mtr4 controls and restricts adenylation accomplished by the non-canonical TRAMP polymerases Trf4 or Trf5 (Jia et al., 2011). Aside from its role in the TRAMP complex, Mtr4 also has TRAMP independent functions, such as in the processing of rRNAs (Bernstein and Toth, 2012). It is proposed, that there are two different types of complexes: TRAMP4 composed of Trf4, Air2, and Mtr4, and TRAMP5 composed of Trf5, Air1, and Mtr4. Each complex is competent for oligoadenylation of various pre-rRNA, snRNA, snoRNA, tRNAs, mRNAs, and small non-coding RNAs and both complexes can stimulate degradation by Rrp6 and the exosome. Functional redundancy of the complexes can only be observed in specific circumstances, in which one of the complexes is defective. TRAMP5 is assumed to be localized 
mainly to the nucleolus, where it is involved in the surveillance of rRNAs. TRAMP4 localizes to the nucleus and is supposed to be approximately three fold more prevalent as TRAMP5 and controls the quality of several classes of RNAs including mRNAs, tRNAs, snRNAs, and snoRNAs (Bernstein et al., 2008; Tutucci and Stutz, 2011; Bernstein and Toth, 2012).

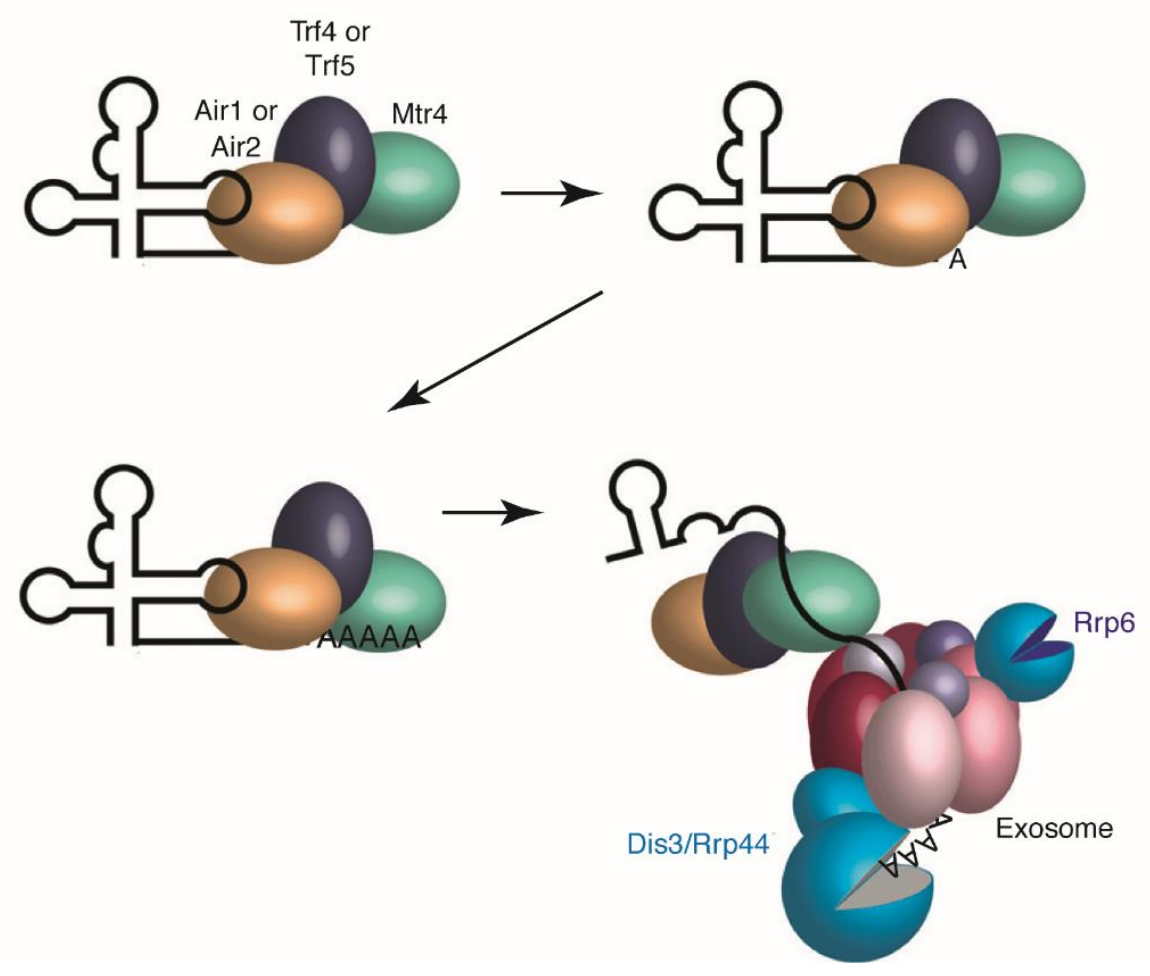

Figure 5: Function of the TRAMP complex.

The RNA-binding protein, either Air1 or Air2, together with the poly(A) polymerase Trf4 or Trf5 recognize protein-free 3' extension on RNAs. This leads to a subsequent oligoadenylation by Trf4, which is length restricted by Mtr4. Furthermore, Mtr4 is proposed to be involved in recruiting the exosome to its substrate. Once the exosome is recruited, Mtr4 unwinds RNA secondary structures via its helicase activity to make it accessible for degradation (Wolin, Sim, \& Chen, 2012)

\subsubsection{Rat1}

Rat1 is an essential nuclear 5' to 3' RNA exonuclease, which is involved in a variety of RNA metabolism steps including rRNA and snoRNA processing and degradation of aberrant premRNAs. For its activity, Rat1 requires its co-factor Rai1. During mRNA biogenesis, Rat1 together with Rail is responsible for the 5' - 3' degradation of uncapped mRNA (Jiao et al., 2010; Jimeno-González et al., 2010). Furthermore, Rat1 is involved in poly(A) dependent transcription termination and degrades RNA downstream of the cleavage site. Thereby, the Rat1-Rai1 complex is required for both, binding and degrading the RNA, resulting in release of RNAP II (Kim et al., 2004; Bernstein and Toth, 2012). Moreover, Rat1 together with Rai is 
required for proper 5 '-end processing of $5.8 \mathrm{~S}$ and $25 \mathrm{~S}$ pre-rRNA and for the degradation of the $\operatorname{poly}(\mathrm{A})^{+}$pre-rRNAs from their 5 ' -ends. The complex is co-transcriptionally loaded onto prerRNAs after cleavage by the endonuclease Rnt1, which generates a loading site for Rat1-Rai1 (Fang, Phillips and Butler, 2005; Bernstein and Toth, 2012).

\subsubsection{Quality control of intron-containing mRNAs}

The two SR proteins Gbp2 and Hrb1 have been found to be key surveillance factors for spliced transcripts. While Np13 binds to bulk mRNAs, Gbp2 and Hrb1 are preferentially loaded to
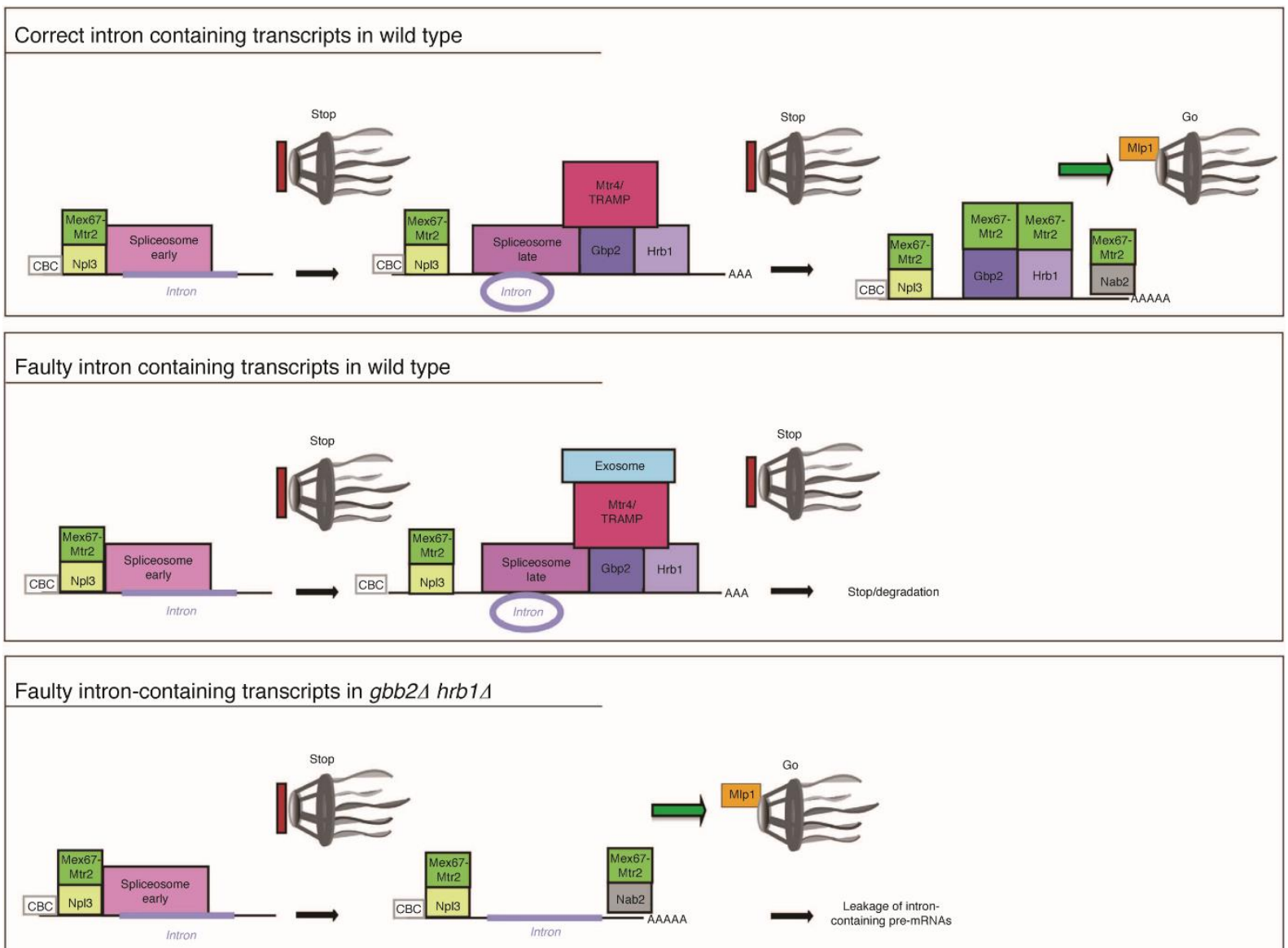

Figure 6: Model for surveillance of spliced transcripts.

Npl3 is loaded early to the nascent transcript, binds to the cap-binding complex (CBC) and promotes the recruitment of the early spliceosome. It interacts with the export receptor Mex67-Mtr2, but the presence of the spliceosome prevents export. Gbp2 and Hrb1 are loaded to intron-containing transcripts via the THO complex during late steps of splicing and recruit the TRAMP complex. If mRNAs are correctly spliced, the TRAMP complex can dissociate and Mex67-Mtr2 binds to these mRNAs, which are then exported (top). In case mRNAs are inadequatly spliced, they are marked by the TRAMP complex and subsequently degraded by the exosome (middle). In the absence of $\mathrm{Gbp} 2$ and $\mathrm{Hrb} 1$, the surveillance machinery is not recruited to intron-containing premRNAs and thus intron-containing transcripts can exit the nucleus (Hackmann et al., 2014). 
intron-containing mRNAs. Npl3 is loaded early to the emerging transcripts and aids to recruit the spliceosome (Lei, Krebber and Silver, 2001; Kress, Krogan and Guthrie, 2008). At late steps of splicing, Gbp2 and Hrb1 are recruited to the transcript via the THO complex (Hackmann et al., 2014). Here, Gbp2 and Hrb1 monitor splicing and mostly Gpb2 interacts with the TRAMP complex component Mtr4. A model was suggested that upon correct splicing, the TRAMP complex is released and Gbp2 and Hrb1 can bind the export receptor heterodimer Mex67-Mtr2. This leads to the subsequent transport of the mRNA into the cytoplasm. In contrast, when transcripts are not or aberrantly spliced, The TRAMP complex is not released from Gbp2, gets the chance to add an oligo(A) tail, and subsequently recruits the exosome for degradation of this faulty transcript. Therefore, in the case that Gbp2 and Hrb1 are missing, there is no quality control and degradation of intron-containing transcript, which results in a leakage of introncontaining pre-mRNAs into the cytoplasm (Hackmann et al., 2014) (Figure 6). 


\subsection{Ribosome biogenesis}

Generation of ribosomes is a fundamental process providing cells with molecular complexes for protein preparation. Ribosomes are very complex molecular machines built up of a small $40 \mathrm{~S}$ and large 60S subunits. In S.cerevisiae, the small 40S subunit is composed of the $18 \mathrm{~S}$ rRNA and 33 ribosomal proteins ( $\mathrm{r}$ proteins) and the large 60S subunit consist of the $25 \mathrm{~S}$ rRNA, 5.8S rRNA, 5S rRNA and $46 \mathrm{r}$ proteins. Accordingly, ribosome biogenesis comprises the processing and modification of rRNAs and their correct structural assembly with $\mathrm{r}$ proteins. For that, about 200 conserved non-ribosomal assembly factors are required such as RNA-binding proteins, RNA helicases, endo- and exonucleases, GTPases and ATPases. Moreover, about 75 snoRNAs are required for processing and assembly. Together, these factors realize folding and processing of pre-rRNA, rearrangement of protein-protein or protein-RNA networks as well as export and surveillance (Kressler, Hurt and Baßler, 2010; Peña, Hurt and Panse, 2017). Biogenesis of both subunits starts with the transcription of the 35S rRNA primary transcript by RNAP II. This $35 \mathrm{~S}$ rRNA precursor contains the sequences for the 18S, 25S and 5.8S rRNA, whose are separated by internal transcribed spacer (ITS) and flanked by external transcribed spacer $(E T S)$ regions. The 18S rRNA is flanked by the 5' ETS/ETS1, the 18S rRNA and 5.8S rRNA are separated by ITS1, the 5.8S rRNA and 25S rRNA are separated by the ITS2 and the 25S rRNA is flanked by the 3' ETS/ETS2 (Figure7). By many processing and cleavage events at the specific cleavage

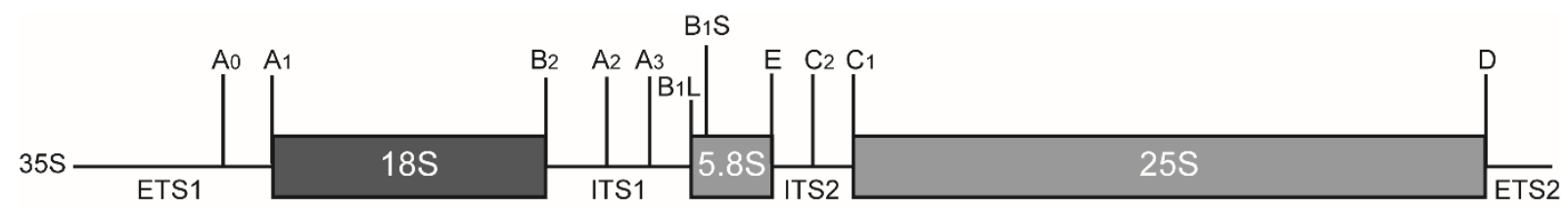

Figure 7: Schematic representation of the 35S rRNA precursor.

The 35S rRNA precursor contains the sequences for the mature 18S rRNA, which is part of the small ribosomal subunit, and the sequences for the mature $5.8 \mathrm{~S}$ and $25 \mathrm{~S}$ rRNA, whose are part of the large ribosomal subunit. These sequences are flanked by external transcribed spacer (5'-ETS and 3'-ETS) and separated by internal transcribed spacer (ITS1 and ITS2). To reach maturity, the ETS and ITS regions are removed. For that, cleavage events occur in a stepwise manner at the indicated cleavage sites from A-D.

sites the spacer regions are removed resulting in the mature $18 \mathrm{~S}, 25 \mathrm{~S}$ and $5.8 \mathrm{~S}$ rRNA. In contrast, the 5S pre-rRNA is transcribed indepentently of the 35S rRNA precursor by RNAP III (Fernández-Pevida, Kressler and de la Cruz, 2015a). A subset of 40S-specific r proteins as well as non-ribosomal factors and snoRNAs including the U3 assembles co-transcriptional with 


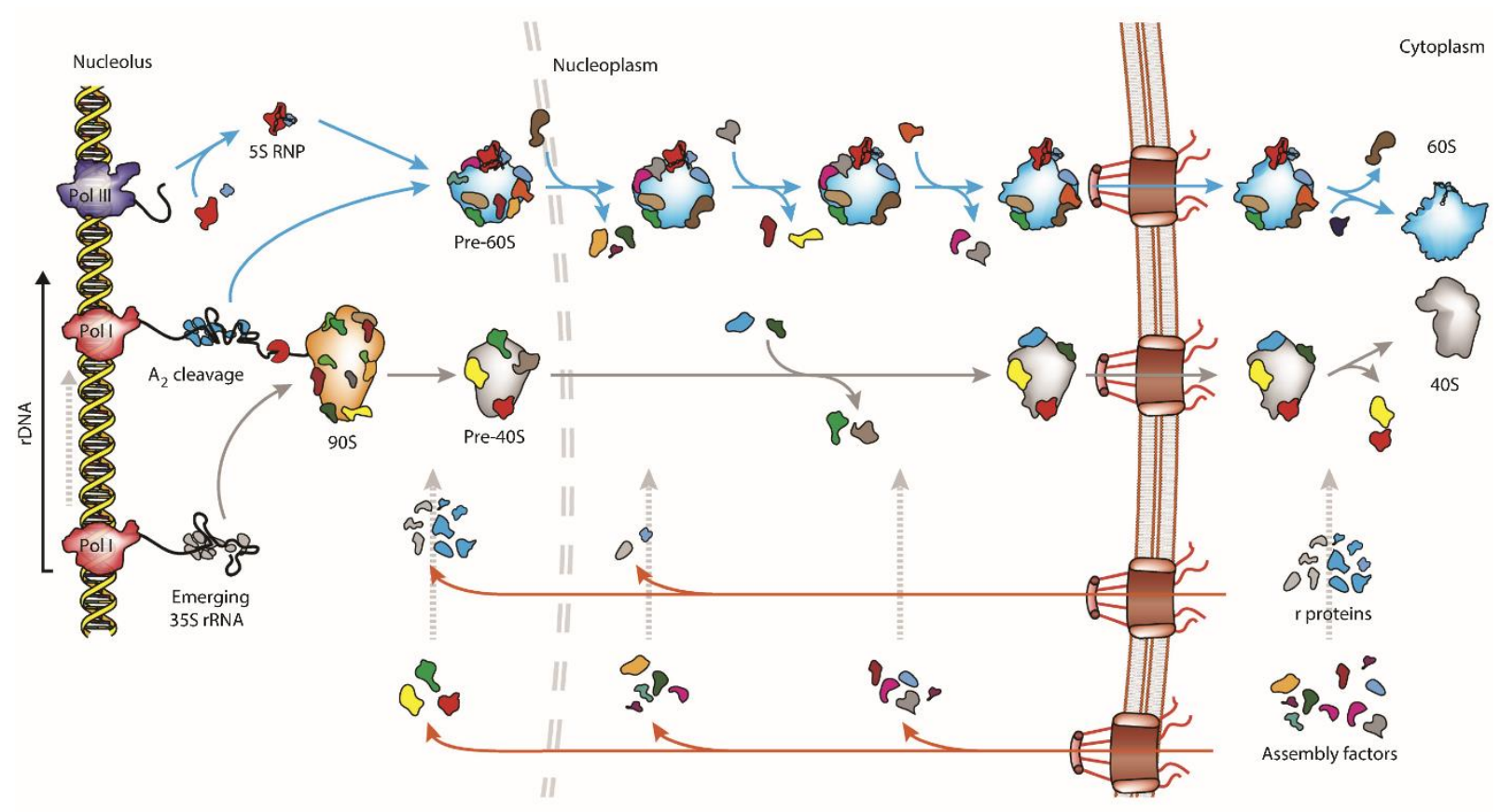

Figure 8: Eukaryotic ribosome assembly.

Transcription of the 35S rRNA precursor by RNAP I occurs in the nucleolus. Multiple 40S-specific $r$ proteins as well as non-ribosomal factors and snoRNAs assemble co-transcriptionally with the 35S pre-rRNA and form the $90 \mathrm{~S}$ preribosome. Cleavage at the site A2 results in the separation of the pre-40S subunit and the pre-60S subunit, which undergo different pathways to reach maturity. The 5S rRNA, which is transcribed by RNAP III indepently from the $35 \mathrm{~S}$ rRNA, joins the pre-60S subunit in the nucleolus. Both preribosomal subunits are further processed and are transported from the nucleolus into the cytoplasm, where transiently associating factors promote the maturation during their transfer into the nucleoplasm. Export receptors facilitate the transport into the cytoplasm via the NPC, where remaining assembly and transport factors are released during a quality check and finally the subunits are competent for translation. (Peña et al., 2017)

the emerging $35 \mathrm{~S}$ pre-rRNA and form the $90 \mathrm{~S}$ preribosome. Cleavage at the site $\mathrm{A}_{2}$ results in the separation of the pre-40S subunit and the pre-60S subunit that both undergo different pathways to reach maturity. Subsequently, the preribosomal subunits are further processed and are transported from the nucleolus into the cytoplasm. For that, transiently associating factors promote the maturation during their way in the nucleoplasm and furthermore export receptors facilitate the transport into the cytoplasm via the NPC. Here, remaining assembly and transport factors are released during a quality check and finally the subunits are competent for translation (Peña, Hurt and Panse, 2017) (Figure 8).

\subsection{1 rRNA transcription initiation and pre-rRNA processing}

In eukaryotic cells, RNAP I is responsible for transcribing pre-rRNAs that result in the mature 18S, 5.8S, 25S rRNA. Pre-rRNA transcription accounts for $60 \%$ of cellular transcription and in 


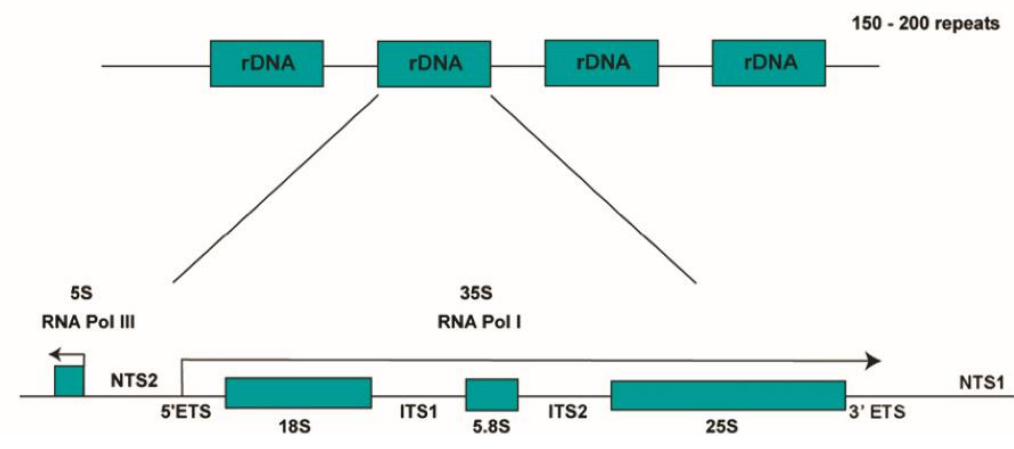

Figure 9: Schematic representation of the rDNA locus in S.cerevisiae.

S.cerevisiae exhibits about 150-200 tandem repeats of the rDNA transcription unit on chromosome 12. A single unit is composed of the 35S pre-rRNA trancribed by RNAPI and the pre-5S rRNA trancribed by RNAP III. (Woolford \& Baserga, 2013)

a single cell generation about 200,000 ribosomes are generated. In S. cerevisiae, pre-rRNA transcription occur in the nucleolus, which is a nuclear sub compartment and is formed around the rDNA. The rDNA is located on chromosome XII and contains about $150-200$ tandem repeats of the rDNA transcription unit. A single unit contain the both the $35 \mathrm{~S}$ rRNA precursor synthesized by RNAP I and the 5S rRNA precursor that is synthesized by RNAP III. The 35S pre-rRNA contains the sequences for three rRNAs, which are transcripts for $18 \mathrm{~S}, 5.8 \mathrm{~S}$ and $25 \mathrm{~S}$. These transcripts are separated by two internal transcribed spacers (ITSs) and flanked by two external transcribed spacers (ETSs) (Thiry and Lafontaine, 2005; Woolford and Baserga, 2013)(Figure 9). RNAP I in S.cerevisiae is built up of 14 subunits: Rpa190, Rpa135, Rpc40, Rpc19, Rpb5, Rpo26, Rpb8, Rpb10, Rpc10, Rpa12, Rpa43, Rpa14, Rpa49, Rpa34. Of these subunits, all except Rpa34 and Rpa49 are either shared with the two other polymerases ore are homologous to their subunits. There are four general transcription factors complexes or single transcription factors that support the recruitment of RNAPI to the site of transcription. Besides the upstream activity factor (UAF), the TATA binding protein (TBP) and the core factor (CF) there are the factor Rrn3, which is highly important for recruitment of RNAP I and transcription initiation (Milkereit and Tschochner, 1998; Woolford and Baserga, 2013). Processing of the 6.6 kb sized $35 \mathrm{~S}$ rRNA precursor starts with the cleavage events at the site $\mathrm{A}_{0}, \mathrm{~A}_{1}$ and $\mathrm{A}_{2}$. Thus, cleavage at site $\mathrm{A}_{2}$ in the ITS1 region results in the 20S and 27SA2 pre-rRNA and thereby separating the pre-40S and pre-60S ribosomal subunit. Those processing events can occur either co-transcriptionally or post-transcriptionally, whereby about $70 \%$ of pre-rRNAs undergo cotranscriptional cleavage (Koš and Tollervey, 2010; Fernández-Pevida, Kressler and de la Cruz, 2015). 


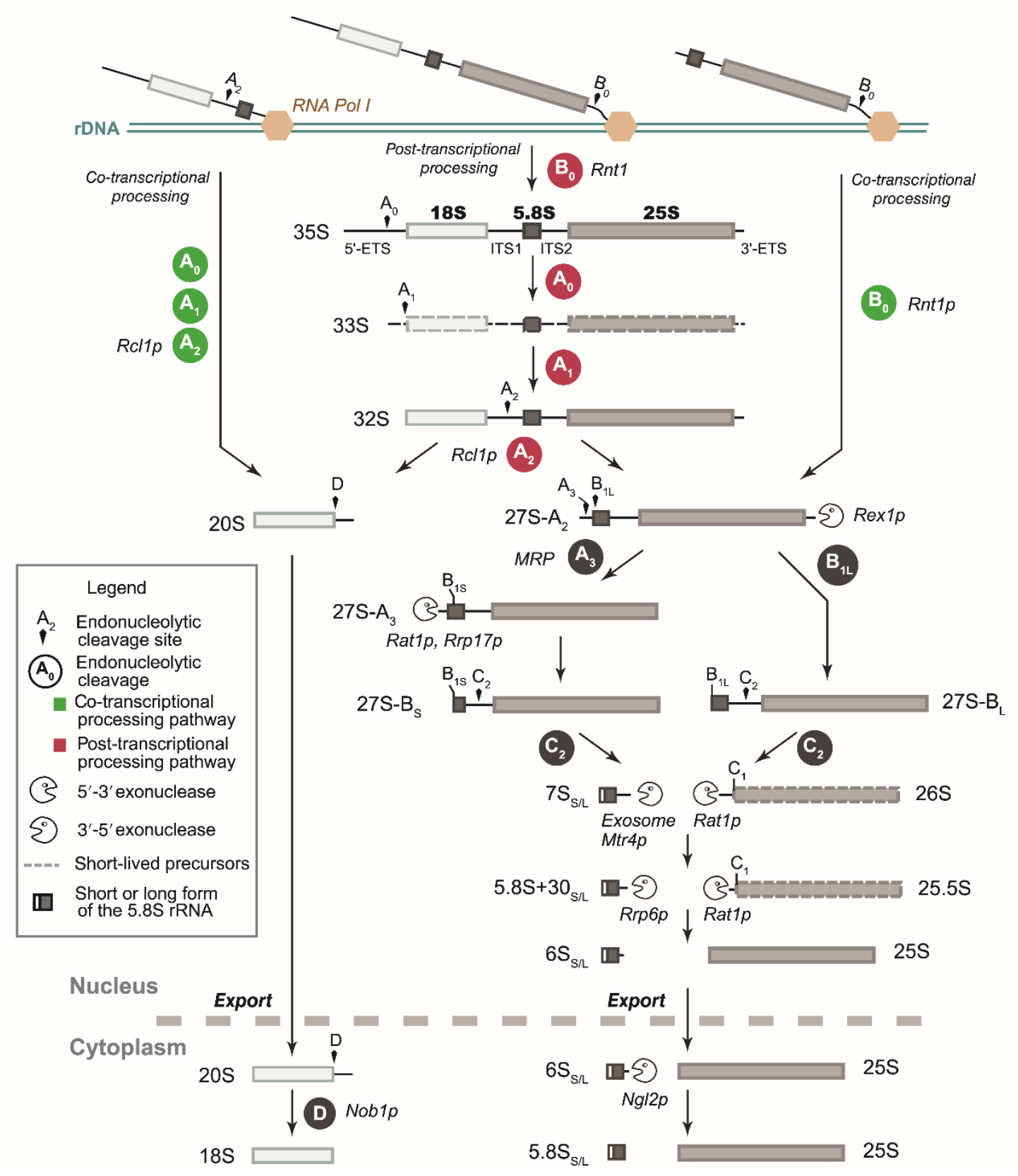

\section{Figure 10: Pre-rRNA processing in S.cerevisiae.}

The 35S rRNA precursor is transcribed by RNAP I and is processed either co-transcriptionally (green) or posttranscriptionally (red). Most of the emerging transcripts are processed co-transcriptionally, whereby first the $\mathrm{A}_{0}$, $A_{1}$ and $A_{2}$ sites are cleaved. These cleavage events result in the $20 \mathrm{~S}$ and 27S- $A_{2}$ rRNA precursor and thus cleavage at site $\mathrm{A}_{2}$ separates the pre-40S particle from the pre-60S particle. Maturation of the $18 \mathrm{~S}$ rRNA occurs in the cytoplasm by a endonucleolytic cleavage step carried out by Nob2. Processing of the $27 \mathrm{SA}_{2}$ precursor is performed in two alternative pathways. In the major pathway, the $27 \mathrm{SA}_{2}$ is cleaved at site $\mathrm{A}_{3}$ by the RNAse MRP and then rapidly trimmed to site $\mathrm{B}_{1 \mathrm{~s}}$ by Rat1 and Rrp17, whereas in the minor pathway $27 \mathrm{SA}_{2}$ is cleaved directly at site BIL resulting in $27 \mathrm{~S}_{\mathrm{BLL}}$. Subsequently, the $27 \mathrm{~S}_{\mathrm{BIL}} /$ Is is initially cleaved at site $\mathrm{C}_{2}$, resulting in $7 \mathrm{~S}$ and $26 \mathrm{~S}$ rRNA precursors. The 7S pre-rRNA is trimmed stepwise by the exosome together with Mtr4 to the $6 \mathrm{~S}$ rRNA precursor, which is transported in the cytoplasm and finally processed by Ngl2 to the mature 5.8S rRNA. The 26S pre-rRNA is trimmed by Rat 1 to the mature $25 \mathrm{~S}$ rRNA in the nucleus. (Henras, Plisson-Chastang, O'Donohue, Chakraborty, \& Gleizes, 2015) 
Co-transcriptional cleavage at the $\mathrm{A}_{2}$ site proceed when RNAP I reach about $1.5 \mathrm{~kb}$ downstream. After successful cleavage at site $\mathrm{A}_{2}$, the $20 \mathrm{~S}$ pre-rRNA is further processed in the cytoplasm. Therefore, the $\mathrm{A}_{2-\mathrm{D}}$ region is endonucleolytically removed by Nob1 resulting in the mature $18 \mathrm{~S}$ rRNA. The further processing of the $27 \mathrm{SA}_{2}$ precursor is carried out by two alternative pathways. In the major pathway $(\sim 85 \%)$, the $27 \mathrm{SA}_{2}$ is cleaved at site $\mathrm{A}_{3}$ by the RNAse MRP and then rapidly trimmed to site $\mathrm{B} 1 \mathrm{~S}$ by Rat 1 and $\operatorname{Rrp} 17$, whereas $15 \%$ of $27 \mathrm{SA}_{2}$ is cleaved directly at site $\mathrm{BIL}$ resulting in $27 \mathrm{SB}_{\mathrm{IL}}$. After that, the $27 \mathrm{SB}_{\mathrm{IL} / \mathrm{IS}}$ is initially cleaved at site $\mathrm{C}_{2}$, resulting in 7S and 26S rRNA precursors. The 7S pre-rRNA is trimmed stepwise by the exosome together with Mtr4 to the 6S rRNA precursor, which is transported in the cytoplasm and finally processed by $\mathrm{Ng} 12$ to the mature 5.8S rRNA. Additionally, the 26S pre-rRNA is trimmed by Rat1 to the mature 25S rRNA in the nucleus (Fernández-Pevida, Kressler and de la Cruz, 2015b; Henras et al., 2015) (Figure 10).

\subsubsection{Assembly of the 90S pre-ribosome}

Already during transcription, the $35 \mathrm{~S}$ pre-rRNA assembles co-transcriptionally with multiple trans-acting factors and predominantly small ribosomal proteins to form a large macromolecular complex, which is either called the $90 \mathrm{~S}$ pre-ribosome or small-subunit (SSU) processome (Dragon et al., 2002; Thomson, Ferreira-Cerca and Hurt, 2013) . Additionally, small nucleolar ribonucleoprotein (snoRNP) particles covalently modify the pre-rRNAs, for that 2'-O-methylation is mediated by C/D box containing snoRNPs and pseudiuridinylation by H/ACA box containing snoRNPs (Thomson, Ferreira-Cerca and Hurt, 2013). Aside from the different snoRNPs, the assembly machinery is built up of 60-70 non-ribosomal proteins, whose structurally assemble in subcomplexes. Up to now, six subcomplexes of the SSU processome have been described: UTP-A (Utp4, 5, 8, 9, 10, 15, 17 and Pol5), UTP-B (Utp1, 6, 12, 13, 18 and 21), UTP-C (Utp22, Rrp7 and the four subunits of casein kinase II: cka1, Cka2, Ckb1 and Ckb2), Mpp10-Imp3-Imp4, U3 snoRNP, and Bms1-Rc11. These subcomplexes interact cotranscriptionally with the emerging pre-rRNA in a hierarchical manner (Pérez-Fernández, Martín-Marcos and Dosil, 2011; Chaker-Margot et al., 2015; Zhang et al., 2016). First, the UTP-A and UTP-B complexes assemble on the nascent 5' ETS region, whereas the UTP-C and Bms1-Rcl1 complex bind afterwards when the pre-18S rRNA becomes available (ChakerMargot et al., 2015; Zhang et al., 2016). To coordinate these binding events, the U3 snoRNP, together with the Mpp10-Imp3-Imp4 complex, is required. For that, the U3 snoRNP mediates the binding events by hybridization to several complementary binding sites within the 5 '-ETS 


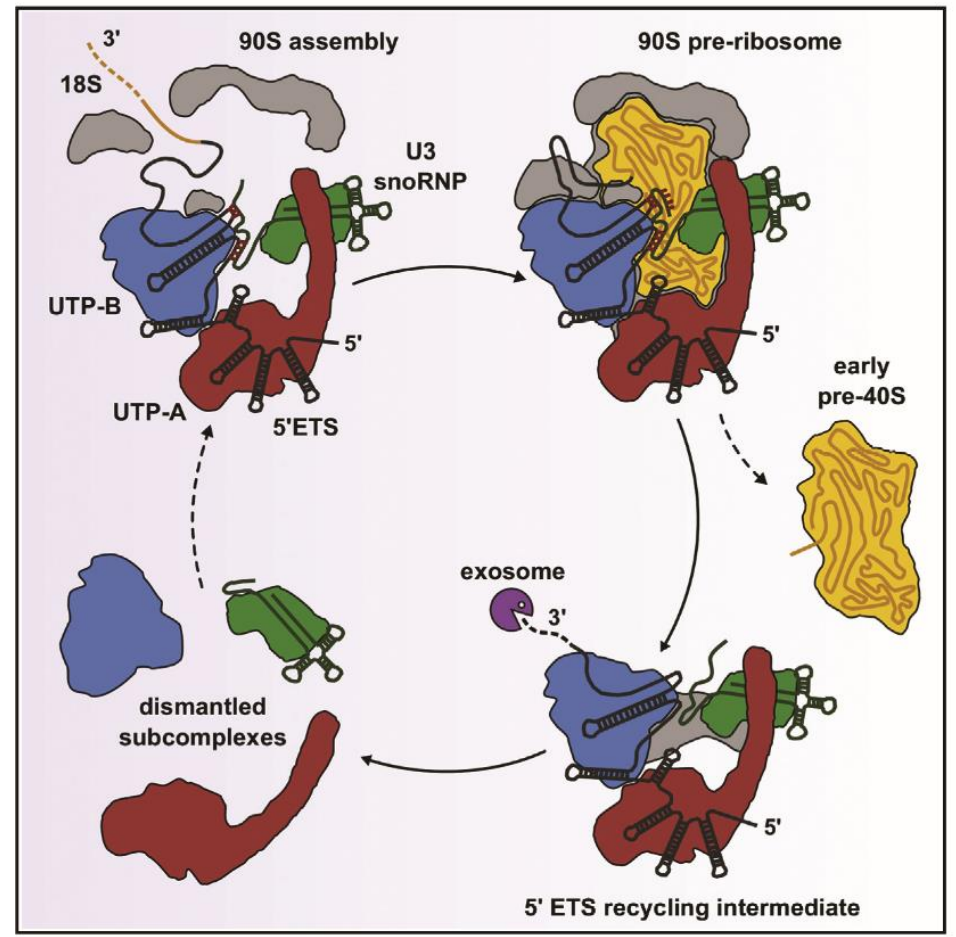

Figure 11: Assembly of the $90 S$ preribosome.

Initially, the UTP-A and UTP-B complex, as well as the U3 snoRNP, assemble co-transcriptionally with the 5'ETS region of the nascent transcript. This results in the $90 \mathrm{~S}$ pre-ribosome, whereby the proper assembly is mediated by the U3 snoRNP. Within the 90S pre-ribosome, the pre-rRNA cleavage events are carried out. After successful cleavage, the early pre-40S subunit is released and subsequently the spliced-out spacer regions are degraded. After that, the complexes are recycled. (Kornprobst et al., 2016)

and $18 \mathrm{~S}$ region. Up to now, the assembly of the subcomplexes as well as their accurate functions are not clearly understood. It is assumed, that the UTP-A complex binds during early transcription independently and is crucial for the association of the other complexes (PérezFernández, Martín-Marcos and Dosil, 2011). The UTP-A complex is furthermore proposed to be important for accurate transcription of the pre-rRNA as well (Dragon et al., 2002) and the UTP-C complex is supposed to regulate multiple components of the SSU processome via phopsporylation by casein kinase II, whereas less is known about the function of UTP-B. Moreover, the Rcl1-Bms1 complex has been shown to be important for the cleavage at the A2 site within the ITS1 region (Dragon et al., 2002; Wojda et al., 2002) .

\subsubsection{Export of pre-ribosomal subunits}

Pre-ribosomal subunits are rapidly exported from the nucleus into the cytoplasm. To enable export, the ribosome with its hydrophilic surface must overcome the hydrophobic meshwork of the inner NPC. For that, several export factors and adaptors are required. Transport of both pre- 
ribosomal subunit is mediated by the general export receptor Xpo1 and the Ran GTPase Gsp1 as well as multiple nucleoporins. For export of the pre-40S subunit, Ltv1 and Dim2 are proposed to function as adaptors by mediating the interaction with Xpo1. In contrast, for nuclear export of pre-60S subunits at least five proteins are known to be required. These are Arx1, Bud20, Ecm1, Mex67 and Nmd3, of which Nmd3 functions as an adaptor for the export receptor Xpo1. Additionally, Npl3 also has been found to facilitate nuclear export of pre-60S subunits (Hackmann et al., 2011; Woolford and Baserga, 2013).

\subsubsection{Nucleolar rRNA quality control}

Generation of mature rRNAs involve a variety of error-prone cleavage and processing events. Therefore, like for other kinds of RNAs, surveillance mechanisms exist that recognize and eliminate aberrant rRNAs. Faulty pre-rRNAs are detected by the TRAMP complex and degraded by the exosome. For that, the TRAMP complex adds a short tail of four or five adenosines to the 3'-end of the aberrant transcript. This oligo (A) tagged RNA is recognized and degraded by the exosome. As mentioned before, the TRAMP complex exists in two different compositions, TRAMP4 and TRAMP5, but the substrate specificities are still unclear (Henras et al., 2015). It was found, that deletion of TRF5 result in a strongly reduced level of oligoadenylated pre-rRNAs in absence of RRP6 indicating that TRAMP5 is important for nucleolar surveillance (Houseley and Tollervey, 2006; Wery et al., 2009). However, it could be shown that deletion of TRF4 leads to similar phenotypes suggesting redundant functions (Dez, Houseley and Tollervey, 2006; Henras et al., 2015). It was proposed, that the nucleolar surveillance machinery also targets pre-rRNAs, which are kinetically delayed in their processing. A delay in the SSU processome assembly and/or inhibition of the first pre-rRNA cleavage events at site $A_{0}, A_{1}$ and $A_{2}$ trigger the cleavage at the site $A_{3}$ by the RNase MRP. Cleavage at site $\mathrm{A}_{3}$ results in the formation of the $23 \mathrm{~S}$ rRNA, which is an aberrant precursor. This aberrant $23 \mathrm{~S}$ is the targeted by the TRAMP/exosome machinery (Lafontaine, 2010) (Figure 12). However, the exact mechanism by which the surveillance machinery is recruited to the aberrant transcripts is still unclear. It was suggested, that the Nrd1-Nab3-Sen1 complex facilitates the recruitment co-transcriptionally (Henras et al., 2015). Moreover, it is assumed, that besides the 3'-5'degradation by the exosome also the 5' to 3 ' degradation by the exonuclease Rat1 is important for the nucleolar surveillance (Fang, Phillips and Butler, 2005). 
(a)
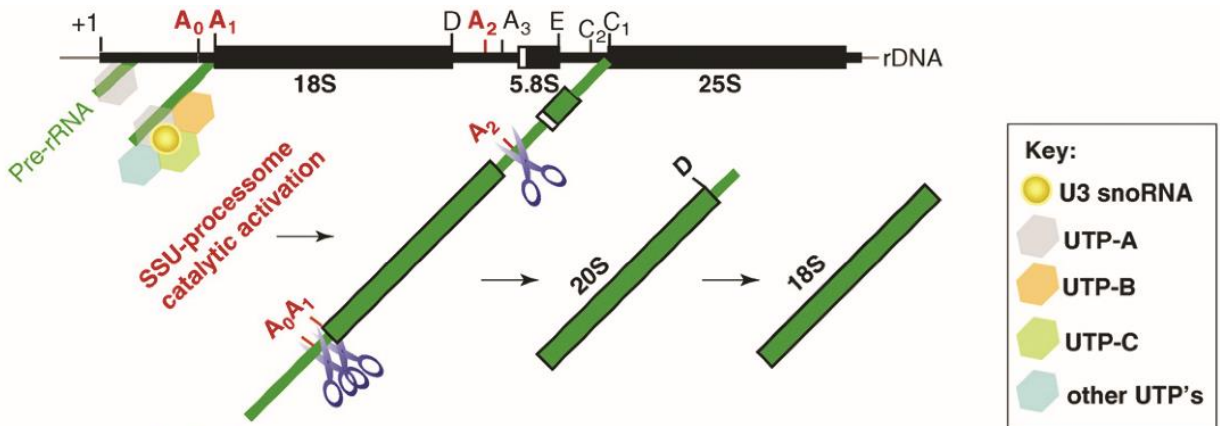

(b)

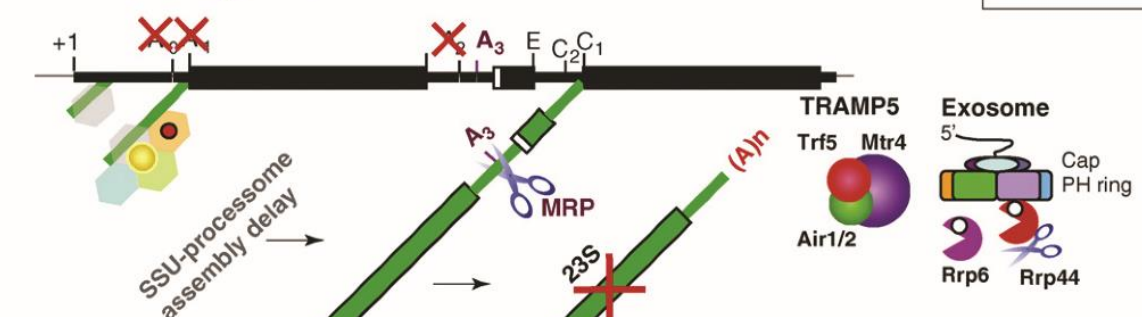

(c)

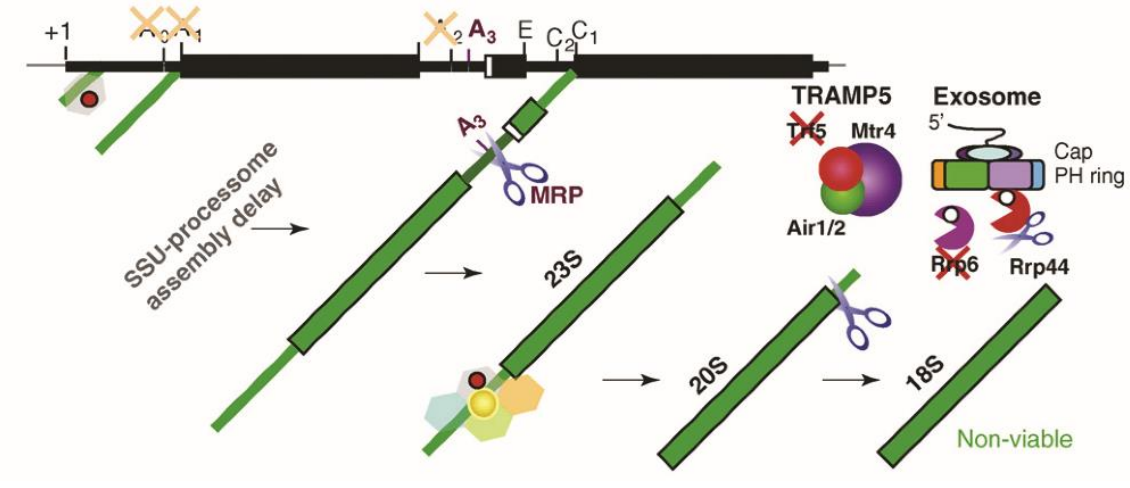

Figure 12: Model of nucleolar surveillance.

(a) In wild type cells, the SSU processome assembles co-transcriptionally on the nascent pre-rRNA in a stepwise manner. Association of the U3 snoRNA lead to the SSU-processome catalytic activation and this trigger the first cleavage events at the sites $\mathrm{A}_{0}, \mathrm{~A}_{1}$ and $\mathrm{A}_{2}$. Cleavage at the $\mathrm{A}_{2}$ site separates the $20 \mathrm{~S}$ rRNA precursor, which is further processed to the mature $18 \mathrm{~S}$ rRNA and part of the SSU, from the LSU.

(b) Mutations in components of the SSU processome that inhibit the SSU assembly or the first cleavage events at the sites $A_{0}, A_{1}$ and $A_{2}$ result in a downstream cleavage at the site $A_{3}$ by the RNase MRP. This cleavage results in an aberrant $23 \mathrm{~S}$ rRNA precursor, which is rapidly degraded by the TRAMP/exosome machinery.

(c) In absence of TRAMP/exosome factors, the aberrant 23S rRNA precursor is not degraded and instead processed to $18 \mathrm{~S}$ rRNA. However, this restored $18 \mathrm{~S}$ rRNA is not functional and the cells are not viable. (Lafontaine, 2010) 


\section{Material and Methods}

\subsection{Equipment and hardware}

Table 1: Equipment and hardware used in this study.

\begin{tabular}{|c|c|c|}
\hline Application & Equipment & Manufacturer \\
\hline Agarose Gelelectrophoresis & Horizontal Chambers & $\begin{array}{l}\text { Workshop Phillips } \\
\text { University, Marburg } \\
\text { (Germany) }\end{array}$ \\
\hline Aspiration & Vacuum pump & $\begin{array}{l}\text { BIORAD, Munich } \\
\text { (Germany) }\end{array}$ \\
\hline Cell Disruption & $\begin{array}{l}\text { Sonifier Cell Disrupter S- } \\
250 \mathrm{~A}\end{array}$ & $\begin{array}{l}\text { Branson Ultrasonics } \\
\text { (Dietzenbach/Germany) }\end{array}$ \\
\hline Centrifugation & $\begin{array}{l}\text { Hereaus Pico21 } \\
\text { Hereaus Fresco21 } \\
\text { Multifuge X3R }\end{array}$ & $\begin{array}{l}\text { Thermo Fisher Scientific } \\
\text { Inc., Waltham (USA) }\end{array}$ \\
\hline $\begin{array}{l}\text { Chemiluminescence } \\
\text { Detection }\end{array}$ & Fusion FX7 & Peqlab, Erlangen (Germany) \\
\hline Counting chamber & $\begin{array}{l}\text { Hemocytometer Neubauer } \\
\text { improved }\end{array}$ & $\begin{array}{l}\text { Carl Roth GmbH } \\
\text { (Karlsruhe/Germany) }\end{array}$ \\
\hline $\begin{array}{l}\text { Drying and Concentration of } \\
\text { samples }\end{array}$ & SpeedVac Concentrator & $\begin{array}{l}\text { Thermo Fisher Scientific } \\
\text { Inc., Waltham (USA) }\end{array}$ \\
\hline Incubators \& Rotators & $\begin{array}{l}\text { Incubator Shaker } \\
\text { Rotator SB2 }\end{array}$ & $\begin{array}{l}\text { INFORS AG, Bottmingen } \\
\text { (Switzerland) } \\
\text { Stuart Keison Products, } \\
\text { Chelmsford (UK) }\end{array}$ \\
\hline Magnetic Stirrer & IKMAG RCT/REO & $\begin{array}{l}\text { Janke \& Kunkel, Staufen i. } \\
\text { Br. (Germany) }\end{array}$ \\
\hline Microscopy & $\begin{array}{l}\text { Light Microscope } \\
\text { Fluorescence Microscope } \\
\text { Leica Microsystems }\end{array}$ & $\begin{array}{l}\text { Nikon, Aphot-2 YS2 } \\
\text { Düsseldorf (Germany) } \\
\text { Leica DMI60008 Wetzlar } \\
\text { (Germany) }\end{array}$ \\
\hline PCR Cycler & MyCycler & $\begin{array}{l}\text { BIORAD, Munich } \\
\text { (Germany) }\end{array}$ \\
\hline
\end{tabular}




\begin{tabular}{|c|c|c|}
\hline pH-Meter & HI221 pH Meter & $\begin{array}{l}\text { HANNA Instruments, Kehl } \\
\text { am Rhein (Germany) }\end{array}$ \\
\hline Photometer & $\begin{array}{l}\text { Biophotometer } \\
\text { UV-1601 } \\
\text { NanoDrop } 2000\end{array}$ & $\begin{array}{l}\text { Eppendorf, Hamburg } \\
\text { (Germany) } \\
\text { Shimadzu, Duisburg } \\
\text { (Germany) } \\
\text { Peqlab, Erlangen (Germany) }\end{array}$ \\
\hline Power Supplies & $\begin{array}{l}\text { EV231 } \\
\text { LNGs 350-06 }\end{array}$ & $\begin{array}{l}\text { Peqlab, Erlangen (Germany) } \\
\text { Heinzinger Electronics, } \\
\text { Rosenheim (Germany) }\end{array}$ \\
\hline Quantitative Real-Time PCR & $\begin{array}{l}\text { Rotor Gene } \\
\text { qPCR Cycler CFX } \\
\text { Connect }\end{array}$ & Qiagen, Hilden (Germany) \\
\hline Scale & $\begin{array}{l}\text { Sartorius Universal } \\
\text { Sartorius Laboratory }\end{array}$ & $\begin{array}{l}\text { Sartorius, Göttingen } \\
\text { (Germany) }\end{array}$ \\
\hline Sonification & Sonorex Super $10 \mathrm{P}$ & $\begin{array}{l}\text { Schütt Labortechnik, } \\
\text { Göttingen (Germany) }\end{array}$ \\
\hline Thermoblock & $\begin{array}{l}\text { Thermomixer comfort } \\
\text { Thermoblocks Workshop }\end{array}$ & $\begin{array}{l}\text { Eppendorf, Hamburg } \\
\text { (Germany) } \\
\text { Georg-August University, } \\
\text { Göttingen (Germany) }\end{array}$ \\
\hline UV Transillumination & UV Transilluminator & $\begin{array}{l}\text { INTAS Science Imaging } \\
\text { Instruments, Göttingen } \\
\text { (Germany) }\end{array}$ \\
\hline UV-Crosslinking & Bio-Link BLX-E365 & $\begin{array}{l}\text { Vilber Lourmat } \\
\text { (Eberhardzell/Germany) }\end{array}$ \\
\hline Vortex & Vortex-Genie 2 & $\begin{array}{l}\text { Scientific Industries Inc., } \\
\text { Bohemia (USA) }\end{array}$ \\
\hline Water Bath & GFL 1083 & Labsource, Manchester (UK) \\
\hline Water Purification & Milli-Q & $\begin{array}{l}\text { Millipore, Schwalbach/Ts. } \\
\text { (Germany) }\end{array}$ \\
\hline Western Blotting & $\begin{array}{l}\text { Blotting Chambers } \\
\text { Rocking Platform }\end{array}$ & $\begin{array}{l}\text { Workshop Phillips } \\
\text { University, Marburg } \\
\text { (Germany) } \\
\text { Süd-Laborbedarf, Gauting } \\
\text { (Germany) }\end{array}$ \\
\hline $\mathrm{X}$-ray film processor & Optimax & $\begin{array}{l}\text { PROTEC } \\
\text { (Oberstenfeld/Germany) }\end{array}$ \\
\hline
\end{tabular}




\subsection{Software}

Table 2: Software used in this study.

\begin{tabular}{l|l} 
Program/software & Supplier/Source \\
\hline Adobe Illustrator CS5; & Adobe Systems (San Jose/USA) \\
\hline Adobe Photoshop CS5 & $\begin{array}{l}\text { M. Wayne Davis } \\
\text { (University of Utah/USA) }\end{array}$ \\
\hline ApE v2.0.37 & Peqlab (Erlangen/Germany) \\
\hline Fiji (1.48s) used for signal quantification & W. Rasband (NIH/USA) \\
\hline Fusion & $\begin{array}{l}\text { Vilber Lourmat } \\
\text { (Eberhardzell, Germany) }\end{array}$ \\
\hline Leica MM AF & Leica Microsystems (Germany) \\
\hline Microsoft Office 2010 & \\
\hline SGD & Microsoft Corporation (Redmond/USA) \\
\hline
\end{tabular}

\subsection{Chemicals, kit systems and consumables}

Table 3: Materials and chemicals used in this study.

\begin{tabular}{l|l} 
Chemicals & Manufacturer \\
\hline 2-Propanol & AppliChem, Darmstadt (Germany) \\
\hline Acetic Acid & Carl Roth, Karlsruhe (Germany) \\
\hline Acetic Anhydride $(100 \%)$ & Sigma-Aldrich, Steinheim (Germany) \\
\hline Agarose NEEO Ultra & Carl Roth, Karlsruhe (Germany) \\
\hline Amersham Hybond N+ Nylon Membrane & GE Healthcare (Freiburg/Germany) \\
\hline $\begin{array}{l}\text { Amersham Protran 0.45 } \mu \mathrm{m} \text { nitrocellulose } \\
\text { membrane }\end{array}$ & GE Healthcare (Freiburg/Germany) \\
\hline Ampicillin & AppliChem, Darmstadt (Germany) \\
\hline Blocking Reagent & Roche (Mannheim/Germany) \\
& 25
\end{tabular}




\begin{tabular}{|c|c|}
\hline Complete EDTA-free protease inhibitor & Roche (Mannheim/Germany) \\
\hline CSPD & Roche (Mannheim/Germany) \\
\hline Coomassie Brilliant Blue & AppliChem, Darmstadt (Germany) \\
\hline DAPI & Merck, Darmstadt (Germany) \\
\hline Deionized Formamide & Applichem (München/Germany) \\
\hline dNTPs & Peqlab, Erlangen (Germany) \\
\hline DTT & GERBU Biotechnik, Gailberg(Germany) \\
\hline EDTA & SERVA, Heidelberg (Germany) \\
\hline Ethanol absolute & VWR, Hannover (Germany) \\
\hline Ethidium Bromide & Carl Roth, Karlsruhe (Germany) \\
\hline $\begin{array}{l}\text { 5-Fluoroortic acid } \\
\text { (FOA) }\end{array}$ & ApolloScientific, Derbyshire (UK) \\
\hline Formaldehyde (37 \%) & Sigma-Aldrich, Steinheim (Germany) \\
\hline Galactose & AppliChem, Darmstadt (Germany) \\
\hline GFP-Trap beads & ChromoTek (Planegg-Martinsried/Germany) \\
\hline Glass Beads & Otto E. Kobe, Marburg (Germany) \\
\hline Glucose & AppliChem, Darmstadt (Germany) \\
\hline Glycerol & SERVA, Heidelberg (Germany) \\
\hline GoTaq ${ }^{\circledR}$ qPCR Master Mix & Promega (Mannheim/Germany) \\
\hline Hydrogen Peroxide (30 \%) & Merck, Darmstadt (Germany) \\
\hline $\mathrm{K}_{2} \mathrm{HPO}_{4}$ & Merck, Darmstadt (Germany) \\
\hline $\mathrm{KCl}$ & Merck, Darmstadt (Germany) \\
\hline $\mathrm{KH}_{2} \mathrm{PO}_{4}$ & Scharlau, Barcelona (Spain) \\
\hline Lithium Acetate & Sigma-Aldrich, Steinheim (Germany) \\
\hline Luminol & Carl Roth, Karlsruhe (Germany) \\
\hline Methanol & VWR, Darmstadt (Germany) \\
\hline $\mathrm{MgCl}_{2}$ & Merck, Darmstadt (Germany) \\
\hline $\mathrm{MgSO}_{4}$ & Carl Roth, Karlsruhe (Germany) \\
\hline $\mathrm{Na}_{2} \mathrm{CO}_{3}$ & Merck, Darmstadt (Germany) \\
\hline $\mathrm{NaCl}$ & AppliChem, Darmstadt (Germany) \\
\hline $\mathrm{NaOH}$ & Carl Roth, Karlsruhe (Germany) \\
\hline Non- Fat Dried Milk Powder & AppliChem, Darmstadt (Germany) \\
\hline PEG 4000 & Sigma-Aldrich, Steinheim (Germany) \\
\hline Phenol/Chloroform & Carl Roth, Karlsruhe (Germany) \\
\hline Poly-L-Lysine & Sigma-Aldrich, Steinheim (Germany) \\
\hline Ponceau S & Sigma-Aldrich, Steinheim (Germany) \\
\hline Potassium Acetate & Carl Roth, Karlsruhe (Germany) \\
\hline Protease Inhibitor Cocktail & Roche, Mannheim (Germany) \\
\hline Protease Inhibitor Cocktail & Sigma-Aldrich, Steinheim (Germany) \\
\hline Protein G-Sepharose Beads & GE Healthcare, München (Germany) \\
\hline qPCRBIO SyGreen Mix Lo-ROX & Nippon Genetics (Düren/Germany) \\
\hline
\end{tabular}




\begin{tabular}{l|l} 
RiboLock RNase Inhibitor & $\begin{array}{l}\text { Thermo Fischer Scientific } \\
\text { (Schwerte/Germany) }\end{array}$ \\
\hline Rotiphorese Acrylamide Mix & Carl Roth, Karlsruhe (Germany) \\
\hline Sodium Dodecyl Sulfate & SERVA, Heidelberg (Germany) \\
\hline Sodiumcitrate & AppliChem, Darmstadt (Germany) \\
\hline Sorbitol & Merck, Darmstadt (Germany) \\
\hline ssDNA & AppliChem, Darmstadt (Germany) \\
\hline TEMED & Carl Roth, Karlsruhe (Germany) \\
\hline Trietholamine & Sigma-Aldrich, Steinheim (Germany) \\
\hline Tris & Carl Roth, Karlsruhe (Germany) \\
\hline Tris-HCl & Carl Roth, Karlsruhe (Germany) \\
\hline Triton X-100 & Sigma-Aldrich, Steinheim (Germany) \\
\hline Trizol® Reagent & Life Technologies (Darmstadt/Germany) \\
\hline Whatman ${ }^{\circledR}$ Blotting Paper $0.8 \mathrm{~mm}$ & Hahnemühle (Dassel/Germany) \\
\hline Yeast tRNA & Extract Invitrogen, Karlsruhe (Germany) \\
\hline$\beta$-Mercaptoethanol & Fluka, Buchs (Switzerland) \\
\hline$\rho$-Coumaric Acid & Sigma-Aldrich, Steinheim (Germany)
\end{tabular}

Table 4: Kit systems used in this study.

\begin{tabular}{l|l} 
Kit System & Manufacturer \\
\hline $\begin{array}{l}\text { Amersham ECL Prime Western Blotting } \\
\text { Detection Kit }\end{array}$ & GE Healthcare (Freiburg/Germany) \\
\hline DIG RNA labeling mix, 10x conc. & Roche (Mannheim/Germany) \\
\hline DNA free $^{\text {TM } \text { Kit }}$ & Ambion/Life technologies, Carlsbad (USA) \\
\hline Maxima Reverse Transcriptase & Thermo Scientific, Waltham (USA) \\
\hline Nucleobond PC 100 & Macherey-Nagel, Düren (Germany) \\
\hline NucleoSpin Gel and PCR Clean-up & Macherey-Nagel, Düren (Germany) \\
\hline qPCR Master Mix & Promega, Madison (USA) \\
\hline RNase free DNase & Qiagen, Hilden (Germany) \\
\hline Total RNA isolation & Macherey-Nagel, Düren (Germany)
\end{tabular}

Table 5: Marker and size standards used in this study.

\author{
Marker / Standard \\ CozyHiTM Prestained Protein Ladder \\ Lambda DNA/EcoRI + HindIII Marker
}

\section{Supplier / Source}

HighQu (Kraichtal/Germany)

Thermo Fischer Scientific

(Schwerte/Germany) 


\begin{tabular}{l|l} 
PageRuler Prestained Protein Ladder & $\begin{array}{l}\text { Thermo Fischer Scientific } \\
\text { (Schwerte/Germany) }\end{array}$ \\
\hline PageRuler Unstained Protein Ladder & $\begin{array}{l}\text { Thermo Fischer Scientific } \\
\text { (Schwerte/Germany) }\end{array}$
\end{tabular}

Chemicals, consumables or other material that are not specifically stated above were purchased from the companies listed below:

AppliChem (München/Germany), BD Biosciences (Heidelberg/Germany), Carl Roth (Karlsruhe/Germany), GE Healthcare (Freiburg/Germany), Life Technologies (Darmstadt/Germany), Merck (Darmstadt/Germany), New England Biolabs (Frankfurt a.M./Germany), OMNILAB GmbH (Bremen/Germany), Peqlab (Erlangen/Germany), Promega (Mannheim/Germany), Roche (Mannheim/Germany), Sarstedt (Nürnbrecht/Germany), Serva (Heidelberg/Germany), Sigma-Aldrich (München/Germany), Thermo Fischer Scientific (Schwerte/Germany), Th.Geyer (Renningen/Germany), VWR (Darmstadt/Germany)

\subsection{Antibodies and Enzymes}

Antibodies that were listed in Table 6 and used for detection in Western blot analyses were diluted in $2 \%(\mathrm{w} / \mathrm{v})$ milk powder in TBS-T.

Table 6: Antibodies used in this study. The dilutions for usage in Western blotting (WB) or Northern blotting (NB) are indicated.

\begin{tabular}{l|l|l} 
Antibody (organism) & Dilution (WB) & Supplier/ Source \\
\hline Anti-Aco1 (rabbit) & $1: 2,000$ & Courtesy of R. Lill (Marburg/Germany) \\
\hline $\begin{array}{l}\text { Anti-Digoxigenin-AP, } \\
\text { Fab fragments (sheep) }\end{array}$ & $1: 10,000$ (NB) & Roche (Mannheim/Germany) \\
\hline Anti-GAPDH (mouse) & $1: 5,000$ & $\begin{array}{l}\text { Thermo Fischer Scientific } \\
\text { (Schwerte/Germany) }\end{array}$ \\
\hline Anti-GFP (mouse) & $1: 5,000$ & $\begin{array}{l}\text { Thermo Fischer Scientific } \\
\text { (Schwerte/Germany) }\end{array}$ \\
\hline Anti-GFP (rabbit) & $1: 500$ & Custom-made, H. Krebber \\
\hline Anti-Hem15 (rabbit) & $1: 10,000$ & \begin{tabular}{l} 
Courtesy of R. Lill (Marburg/Germany) \\
\hline Anti-Mex67 (rabbit)
\end{tabular} \\
\hline Anti-mouse IgG-HRP & $1: 20,000$ & Courtesy of C. Dargemont (Paris, France) \\
\hline
\end{tabular}




\begin{tabular}{l|l|l} 
Anti-Mtr4 (rabbit) & $1: 1,000$ & $\begin{array}{l}\text { Courtesy of P. Lindner (Genf, } \\
\text { Switzerland) }\end{array}$ \\
\hline Anti-Myc (mouse) & $1: 1,000$ & Santa Cruz (Heidelberg/Germany) \\
\hline Anti-Myc (rabbit) & $1: 5,000$ & Santa Cruz (Heidelberg/Germany) \\
\hline Anti-Nop1 (mouse) & $1: 4,000$ & Santa Cruz (Heidelberg/Germany) \\
\hline Anti-Npl3 (rabbit) & $1: 5,000$ & Custom-made, H.Krebber \\
\hline Anti-rabbit IgG-HRP & $1: 20,000$ & Dianova, Hamburg (Germany) \\
\hline Anti-Zwf1 (rabbit) & $1: 4,000$ & Santa Cruz (Heidelberg/Germany)
\end{tabular}

All enzymes listed in Table 7 were used with their appropriate buffer and according to the protocols of the manufacturers.

Table 7: Enzymes used in this study.

\begin{tabular}{l|l} 
Enzymes & Manufacturer \\
\hline DreamTaq DNA Polymerase & Fermentas, St. Leon-Rot (Germany) \\
\hline Maxima Reverse Transcriptase & Thermo Fischer Scientific (Schwerte/Germany \\
\hline RiboLock & Fermentas, St. Leon-Rot (Germany) \\
\hline RNase A & Qiagen (Hilden/Germany) \\
\hline T7-RNA-polymerase & Thermo Scientific (Schwerte/Germany) \\
\hline Xrn1 & \\
\hline Zymolase 20T & New England Biolabs (Frankfurt/Germany) \\
\hline
\end{tabular}

\subsection{Strains, Plasmids and Oligonucleotides}

\subsubsection{Strains}

Table 8: Escherichia coli strains used in this study

\begin{tabular}{|c|c|c|}
\hline Strain & Genotype & Application \\
\hline $\mathrm{DH} 5 \alpha^{\mathrm{TM}}$ & $\begin{array}{l}\mathrm{F}-\text { Ф80lacZ } \Delta \mathrm{M} 15 \Delta(\text { lacZYA-argF) } \mathrm{U} 169 \text { rec } \mathrm{A} 1 \\
\text { endA1 hsd } \mathrm{R} 17(\mathrm{rK}-, \mathrm{mK}+) \text { phoA sup } 44 \lambda-\text { thi-1 } \\
\text { gyrA96 relA1 }\end{array}$ & Plasmid amplification \\
\hline
\end{tabular}


Table 9: Saccharomyces cerevisiae strains used in this study.

\begin{tabular}{|c|c|c|}
\hline Strain & Genotype & Reference \\
\hline HKY36 & 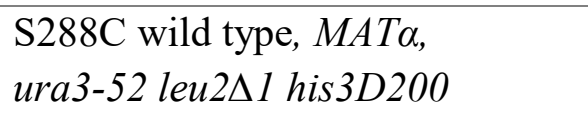 & (Winston et al, 1995) \\
\hline HKY319 & MATa his $3 \Delta 1$ leu $2 \Delta 0$ ura $3 \Delta 0$ & $\begin{array}{l}\text { Laboratory of Heike } \\
\text { Krebber }\end{array}$ \\
\hline HKY380 & 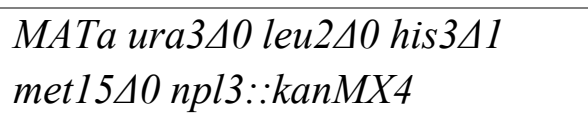 & Euroscarf \\
\hline HKY381 & $\begin{array}{l}\text { BY } 4742 \text { wild type } M A T \alpha, \text { his } 3 \Delta l \\
\text { leu } 2 \Delta 0 \text { ura } 3 \Delta 0 \text { lys } 2 \Delta 0\end{array}$ & $\begin{array}{l}\text { Laboratory of Heike } \\
\text { Krebber }\end{array}$ \\
\hline HKY500 & $\begin{array}{l}\text { MATa his } 3 \Delta 1 \text { leu2 } 20 \text { met } 15 \Delta 0 \\
\text { ura3 } \Delta 0 \text { RCL1-GFP:HIS3MX6 }\end{array}$ & Invitrogen \\
\hline HKY682 & $\begin{array}{l}M A T \alpha \text { his } 3 \Delta 1 \text { leu } 2 \Delta 0 \text { met } 15 \Delta 0 \\
\text { ura3 } \Delta 0 \text { npl3::kanMX4 }\end{array}$ & $\begin{array}{l}\text { Laboratory of Heike } \\
\text { Krebber }\end{array}$ \\
\hline HKY694 & $\begin{array}{l}\text { MATa ura } 3 \Delta 0 \text { leu } 2 \Delta 0 \text { his } 3 \Delta 1 \\
\text { met15 } 50 \text { rpal4::kanMX4 }\end{array}$ & Euroscarf \\
\hline HKY1027 & 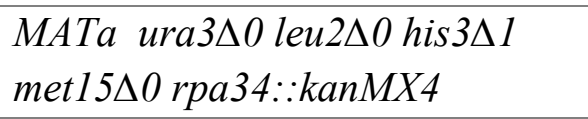 & Euroscarf \\
\hline HKY1028 & 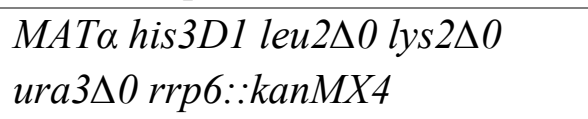 & Euroscarf \\
\hline HKY1066 & 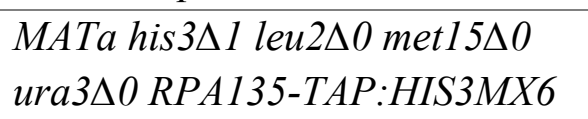 & Open Biosystems \\
\hline HKY1112 & $\begin{array}{l}\text { MATa ura } 3 D 0 \text { leu } \Delta 0 \text { his } 3 \Delta l \\
\text { met } 15 \Delta 0 \text { trf4: }: k a n M X 4\end{array}$ & Euroscarf \\
\hline HKY1136 & 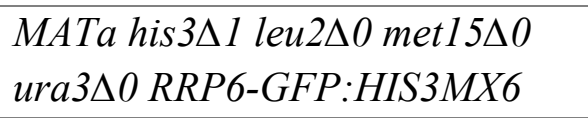 & Invitrogen \\
\hline HKY1171 & 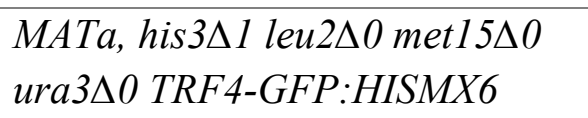 & Invitrogen \\
\hline HKY1196 & 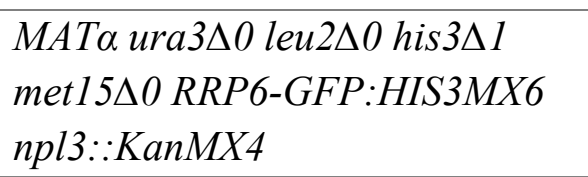 & $\begin{array}{l}\text { Laboratory of Heike } \\
\text { Krebber }\end{array}$ \\
\hline HKY1224 & $\begin{array}{l}\text { MATa ade5 his7-2 leu2-112 trp1- } \\
289 \text { ura3-52 rrn3-8 }\end{array}$ & (Blattner et al., 2011) \\
\hline HKY1237 & $\begin{array}{l}\text { MATa ura } 3 \Delta 0 \text { leu } 2 \Delta 0 \text { his } 3 \Delta 1 \\
\text { met } 15 \Delta 0 \text { air } 1: \text { kanMX } 4\end{array}$ & Euroscarf \\
\hline HKY1238 & $\begin{array}{l}\text { MATa ura } 3 \Delta 0 \text { leu } 2 \Delta 0 \text { his } 3 \Delta 1 \\
\text { met } 15 \Delta 0 \text { air } 2: \text { kanMX } 4\end{array}$ & Euroscarf \\
\hline HKY1304 & $\begin{array}{l}\text { MATa his } 3 \Delta 1 \text { leu } 2 \Delta 0 \text { met } 15 \Delta 0 \\
\text { ura3 } \Delta 0 \text { TRF5-GFP: HISMX6 }\end{array}$ & Invitrogen \\
\hline HKY1309 & $\begin{array}{l}\text { MAT } \alpha \text { ura } 3 \Delta 0 \text { leu } 2 \Delta 0 \text { his } 3 \Delta 1 \\
\text { met } 15 \Delta 0 \text { rrp6::kanMX4 } \\
\text { npl3::kanMX4 }\end{array}$ & $\begin{array}{l}\text { Laboratory of Heike } \\
\text { Krebber }\end{array}$ \\
\hline
\end{tabular}




\begin{tabular}{|c|c|c|}
\hline HKY1373 & 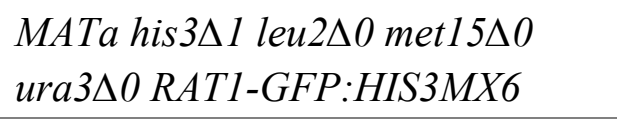 & Invitrogen \\
\hline HKY1460 & $\begin{array}{l}\text { MATa his } 3 \Delta 1 \text { leu } 2 \Delta 0 \text { met } 15 \Delta 0 \\
\text { ura3 } \Delta 0 \text { SUP45-GFP:HIS3MX6 }\end{array}$ & Invitrogen \\
\hline HKY1485 & 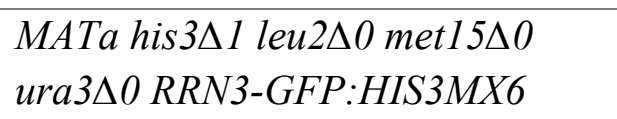 & Invitrogen \\
\hline HKY1489 & 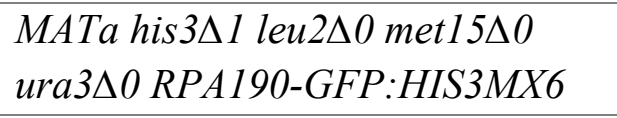 & Invitrogen \\
\hline HKY1507 & $\begin{array}{l}\text { MATa ura } 3 \Delta 0 \text { leu } 2 \Delta 0 \text { his } 3 \Delta 1 \\
\text { met } 15 \Delta 0 \text { rat1-1::kanR }\end{array}$ & $\begin{array}{l}\text { Laboratory of Heike } \\
\text { Krebber }\end{array}$ \\
\hline HKY1509 & $\begin{array}{l}\text { MATa ura } 3 \Delta 0 \text { leu } 2 \Delta 0 \text { his } 3 \Delta 1 \\
\text { met } 15 \Delta 0 \text { cet } 1-2:: \text { kanR }\end{array}$ & $\begin{array}{l}\text { Laboratory of Heike } \\
\text { Krebber }\end{array}$ \\
\hline HKY1586 & $\begin{array}{l}\text { MATa his } 3 \Delta 1 \text { leu } 2 \Delta 0 \text { met } 15 \Delta 0 \\
\text { ura3 } \Delta 0 \text { AIRl-GFP:HIS3MX6 }\end{array}$ & Invitrogen \\
\hline HKY1587 & $\begin{array}{l}\text { MATa his } 3 \Delta 1 \text { leu2 } \Delta 0 \text { met } 15 \Delta 0 \\
\text { ura3 } \Delta 0 \text { AIR2-GFP:HIS3MX6 }\end{array}$ & Invitrogen \\
\hline HKY1654 & 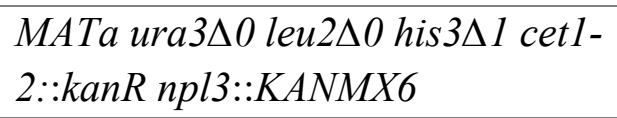 & $\begin{array}{l}\text { Laboratory of Heike } \\
\text { Krebber }\end{array}$ \\
\hline HKY1655 & 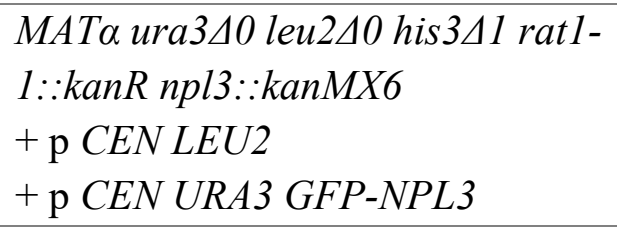 & $\begin{array}{l}\text { Laboratory of Heike } \\
\text { Krebber }\end{array}$ \\
\hline HKY1659 & $\begin{array}{l}\text { MAT } \alpha \text { ura } 3 \Delta 0 \text { leu } 2 \Delta 0 \text { his } 3 \Delta 1 \\
\text { met } 15 \Delta 0 \text { air } 2:: k a n M X 4 \\
\text { npl3::kanMX4 }\end{array}$ & $\begin{array}{l}\text { Laboratory of Heike } \\
\text { Krebber }\end{array}$ \\
\hline HKY1661 & $\begin{array}{l}\text { MATa ura } 3 \Delta 0 \text { leu } 2 \Delta 0 \text { his } 3 \Delta l \\
\text { met } 15 \Delta 0 \text { trf4::kanMX4 } \\
\text { npl3::kanMX4 }\end{array}$ & $\begin{array}{l}\text { Laboratory of Heike } \\
\text { Krebber }\end{array}$ \\
\hline HKY1665 & 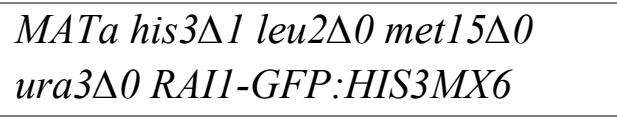 & Invitrogen \\
\hline HKY1668 & 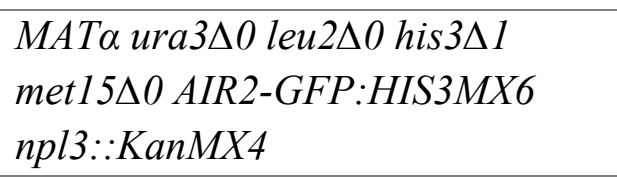 & This study \\
\hline HKY1673 & 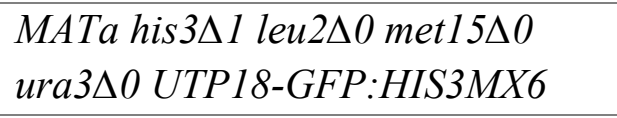 & Invitrogen \\
\hline HKY1683 & $\begin{array}{l}\text { MATa ura3 } \Delta 0 \text { leu } 2 \Delta 0 \text { his } 3 \Delta 1 \\
\text { met } 15 \Delta 0 \text { nop } 1-3:: k a n M X 4\end{array}$ & $\begin{array}{l}\text { Laboratory of Heike } \\
\text { Krebber }\end{array}$ \\
\hline HKY1687 & $\begin{array}{l}\text { MAT } \alpha \text { ura } 3 \Delta 0 \text { leu } 2 \Delta 0 \text { his } 3 \Delta 1 \\
\text { met } 15 \Delta 0 \text { air } 1:: \text { kanMX4 } \\
\text { air } 2:: k a n M X 4\end{array}$ & $\begin{array}{l}\text { Laboratory of Heike } \\
\text { Krebber }\end{array}$ \\
\hline HKY1721 & $\begin{array}{l}\text { MATa ura } 3 \Delta 0 \text { leu } 2 \Delta 0 \text { his } 3 \Delta 1 \\
\text { met } 15 \Delta 0 \text { imp } 4-2: \text { kanMX4 }\end{array}$ & $\begin{array}{l}\text { Laboratory of Heike } \\
\text { Krebber }\end{array}$ \\
\hline HKY1723 & 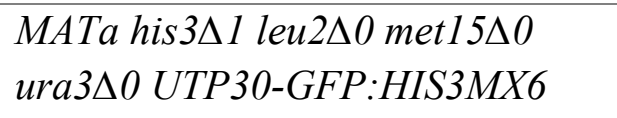 & Invitrogen \\
\hline
\end{tabular}




\begin{tabular}{|c|c|c|}
\hline HKY1764 & 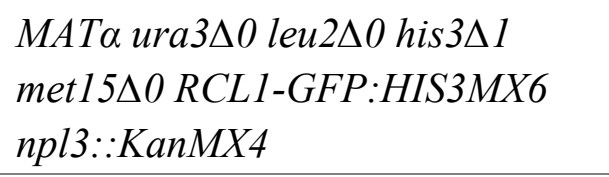 & This study \\
\hline HKY1766 & 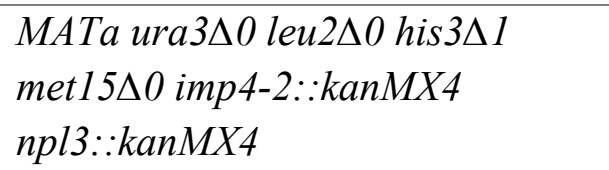 & This study \\
\hline HKY1767 & 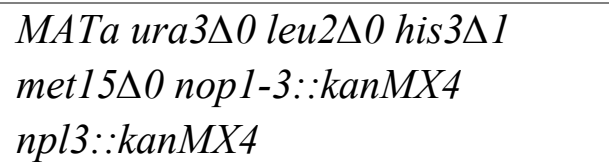 & This study \\
\hline HKY1821 & 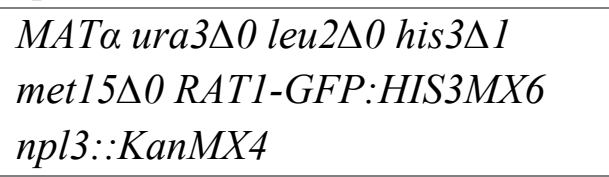 & This study \\
\hline HKY1826 & $\begin{array}{l}\text { MATa ura } 3 \Delta 0 \text { leu } 2 \Delta 0 \text { his } 3 \Delta 1 \\
\text { met } 15 \Delta 0 \text { rail }: \because \text { kanMX4 }\end{array}$ & Euroscarf \\
\hline HKY1827 & $\begin{array}{l}\text { MATa ade2-1 ura3-1 his 3-11 rp1- } \\
1 \text { leu 2-3 can1-100cet1 } 2:: L E U 2 \\
+ \text { pRS313-CET1-GFP (CEN HIS3 } \\
\text { CET-GFP) }\end{array}$ & (Takizawa et al., 2013) \\
\hline HKY1828 & $\begin{array}{l}\text { MATa ade2-1 ura3-1 his 3-11 rpl- } \\
1 \text { leu 2-3 can1-100ceg1 } 2:: L E U 2 \\
+ \text { pRS313-CEG1-GFP (CEN HIS3 } \\
\text { CET-GFP) }\end{array}$ & (Takizawa et al., 2013) \\
\hline HKY1830 & 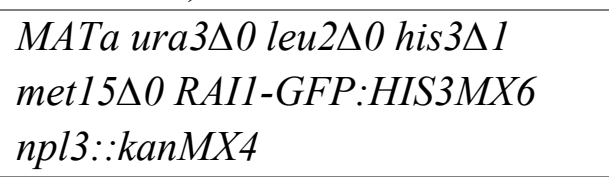 & This study \\
\hline HKY1838 & $\begin{array}{l}\text { MATa ura } 3 \Delta 0 \text { leu2 } \Delta 0 \text { his } 3 \Delta 1 \\
\text { met } 15 \Delta 0 \text { rail }:: k a n M X 4 \\
\text { npl3::kan } M X 4\end{array}$ & This study \\
\hline
\end{tabular}

\subsubsection{Plasmids}

All plasmids used in this work are depicted in the following table (Table:10).

Table 10: Plasmids used in this study.

\begin{tabular}{l|l|l} 
Plasmid & Features & Source \\
\hline pHK87 & CEN LEU2 & $\begin{array}{l}\text { (Sikorski and Hieter, } \\
1989)\end{array}$ \\
\hline pHK88 & CEN URA3 & $\begin{array}{l}\text { (Sikorski and Hieter, } \\
1989)\end{array}$ \\
\hline pHK765 & CEN URA3 GFP-NPL3 & (Hackmann et al., 2014) \\
\hline pHK779 & CEN URA3 9xmyc-NPL3 & (Hackmann et al., 2014)
\end{tabular}




\begin{tabular}{l|l|l} 
& & \\
\hline pHK778 & CEN LEU2 9xmyc-NPL3 & (Hackmann et al., 2014) \\
\hline pHK893 & CEN ARS URA3 GFP NPL3 RA8 & (Hackmann et al., 2014)
\end{tabular}

\subsubsection{Oligonucleotides}

All oligonucleotides listed in table 11 were purchased from Sigma-Aldrich and stored as 100 $\mu \mathrm{M}$ solutions at $-20{ }^{\circ} \mathrm{C}$.

Table 11: Oligonucleotides used in this study.

\begin{tabular}{|c|c|c|}
\hline Name & Sequence & Description \\
\hline HK976 & $\begin{array}{l}\text { 5'-taatacgactcactataggg } \\
\text { CTTTAATGATCCTTCCGCAGGTTC-3' }\end{array}$ & $\begin{array}{l}18 S \text { reverse with } \mathrm{T} 7- \\
\text { promoter }\end{array}$ \\
\hline HK2439 & 5'-CCATCTGCATATTTTGAGTAAATATTCGG-3 & ERB1 reverse \\
\hline HK2434 & 5'-GGTTCTGATGGTTATTGGTCTTGC-3' & NOP2 reverse \\
\hline HK2433 & 5'-GGAGCAGGAAGAAATGATGGC-3' & NOP2 forward \\
\hline HK2429 & 5'-GGACAAGCTTTTATCCGTTGACG-3' & $E R B 1$ forward \\
\hline HK2155 & 5'-GCAATTGTCTTCTGATACTTAGCAC-3' & HEM15 reverse \\
\hline HK2154 & 5'-CCAGAACAATCCGTACACAAGG-3' & HEM15 forward \\
\hline HK2063 & $\begin{array}{l}\text { 5'-taatacgactcactataggg } \\
\text { CAAGACTCTGTAACCCATAGCC -3' }\end{array}$ & $\begin{array}{l}\text { ADH1 reverse with } \\
\text { T7-promoter }\end{array}$ \\
\hline HK2052 & $\begin{array}{l}\text { 5'-taataggactcactataggg } \\
\text { GGCTATTCAACAAGGCATTCCC-3' }\end{array}$ & $\begin{array}{l}\text { ETS1 reverse with } \\
\text { T7-promoter }\end{array}$ \\
\hline HK2042 & 5'-CGAGTAGGCTTGTCGTTCGTTATG-3' & ETS1 forward \\
\hline HK1886 & $\begin{array}{l}\text { 5'-taatacgactcactataggg } \\
\text { TTGAGCTTTTGCCGCTTCAC-3' }\end{array}$ & $\begin{array}{l}\text { ITS2 reverse with } \\
\text { T7-promoter }\end{array}$ \\
\hline HK1885 & $\begin{array}{l}\text { 5'-taatacgactcactataggg } \\
\text { GCCCCGATTGCTCGAATG-3' }\end{array}$ & $\begin{array}{l}\text { ITS1 reverse with } \\
\text { T7-promoter }\end{array}$ \\
\hline HK 1880 & 5'-CTAGGCAGATCTGACGATCACC-3' & ETS1 reverse \\
\hline HK1879 & 5'-ATGCGAAAGCAGTTGAAGACAAG-3' & ETS1 forward \\
\hline HK 1869 & 5'-AGAGAGCGTCTAGGCGAACAATG-3' & ITS2 forward \\
\hline HK1868 & 5'-GCCCCGATTGCTCGAATG-3 & ITS1 rRNA reverse \\
\hline HK1867 & 5'-CAAACGGTGAGAGATTTCTGTGC-3' & ITS1 rRNA forward \\
\hline HK1867 & 5'-CAAACGGTGAGAGATTTCTGTGC-3' & ITS1 forward \\
\hline HK1599 & 5'-GAAGGTTTCGGCAGCGGTG-3' & $R P L 8 A$ reverse \\
\hline HK1598 & 5'-GGCCCCAGGTAAGAAAGTCG-3' & $R P L 8 A$ forward \\
\hline HK1452 & 5'-CGAGCTTCTGCTATCCTGAGGG-3' & 25S rRNA reverse \\
\hline HK1451 & 5'-AGGCTCGTAGCGGTTCTGAC-3' & 25S rRNA forward \\
\hline HK1397 & 5'-ATTGCCTCAAACTTCCATCGGC-3 & 18S rRNA reverse \\
\hline HK1396 & 5'-CATGGCCGTTCTTAGTTGGTGG-3' & 18S rRNA forward \\
\hline HK1143 & $\begin{array}{l}\text { 5'-taatacgactcactataggg } \\
\text { AAATGACGCTCAAACAGGCATG-3' }\end{array}$ & $\begin{array}{l}\text { 5.8S rRNA reverse } \\
\text { with T7-promoter }\end{array}$ \\
\hline HK1142 & 5'-AAACTTTCAACAACGGATCTCTTGG-3' & 5.8S rRNA forward \\
\hline
\end{tabular}




\begin{tabular}{l|l|l} 
HK1139 & $\begin{array}{l}\text { 5'-taatacgactcactataggg } \\
\text { ATGGAATTTACCACCCACTTAGAGC-3' }\end{array}$ & $\begin{array}{l}\text { 25S rRNA reverse } \\
\text { with T7-promoter }\end{array}$ \\
\hline HK1138 & 5'-AGGTAGGAGTACCCGCTGAA-3' & 25S rRNA forward \\
\hline HK1067 & 5'-CCAAAGAACCTAGACCACCAGC-3' & ADH1 reverse \\
\hline HK1066 & 5'-GGTTGAACGGTTCTTGTATGGC-3' & ADH1 forward \\
\hline HK1003 & 5'-TCAGAGGAGACAACGGCATC-3' & TDH1 reverse \\
\hline HK1002 & 5'-TGCTAAGGCTGTCGGTAAGG-3' & TDH1 forward
\end{tabular}




\subsection{Cell biological methods}

\subsubsection{Cultivation of cells}

All media for cultivation of Escherichia coli (E. coli) or Saccharomyces cerevisiae ( $S$. cerevisiae) strains were autoclaved prior to usage. Heat-sensitive compounds like antibiotics or galactose were sterile-filtered and added after autoclaving. Solid plates were generated by adding $1.5 \%$ (for $E$. coli) or $1.8 \%$ (for S. cerevisiae) agar to the corresponding liquid medium.

\subsubsection{Cultivation of Escherichia coli}

In general, E. coli strains were cultivated in liquid LB medium or on LB plates at $37{ }^{\circ} \mathrm{C}$ according to standard protocols Sambrook, Fritsch, \& Maniatis (1989).

\section{LB medium $(\mathrm{pH} 7,5): \quad 0.5 \%$ Yeast Extract \\ $1 \%$ Peptone \\ $0.5 \% \mathrm{NaCl}$}

For the selection of plasmids with respective resistance genes, the media contained the appropriate antibiotic $(100 \mu \mathrm{g} / \mathrm{ml}$ ampicillin or $20 \mu \mathrm{g} / \mathrm{ml}$ of kanamycin). Liquid cultures were incubated in culture tubes in a rotator or in flasks on a shaker at $160 \mathrm{rpm}$.

\subsection{Transformation of $E$. coli}

Chemically ultra-competent E.coli were produced and transformation of E. coli was performed according to Inoue, Nojima, \& Okayama (1990). For transformation, $100 \mu 1$ of competent $E$. coli cells were thawed on ice and $100 \mathrm{ng}$ plasmid DNA were added. The mixture was incubated for 30 minutes on ice and subsequently heat shocked at $42^{\circ} \mathrm{C}$ for two minutes. After that, 800 $\mu 1 \mathrm{LB}$ medium was added immediately and the cells were incubated at $37^{\circ} \mathrm{C}$ for 45 minutes. After incubation, the mixture was centrifuged at $2500 \mathrm{rpm}$ for five minutes. The supernatant was discarded, the pellet was resuspended in a drop left behind and the cells were plated on LB medium plates containing the appropriate antibiotic for selection. The plates were incubated at $37^{\circ} \mathrm{C}$ overnight. 


\subsubsection{Cultivation of Saccharomyces cerevisiae}

S. cerevisiae strains were cultivated according to standard protocols from Rose, Winston, \& Hieter, (1991) and Sherman (1991). Yeast strains were either grown in YPD rich medium or selective media. Selective medium was used for selection of a plasmid- or genome-encoded marker gene that complements a metabolic auxotrophy of the respective yeast strain. Consequently, the selective medium contains every amino acid and nucleobase except for the metabolic product resulting from the marker gene. The dropout mixes for selective media was composed according to the formula of Sherman (1991).

Selective Medium: $\quad 0.2 \%$ Drop Out

$0.17 \%$ Nitrogen Base

$0.51 \%(\mathrm{NH} 4) 2 \mathrm{SO} 4$

YPD: $\quad 1 \%$ Yeast Extract

$2 \%$ Peptone

$2 \%$ Glucose

Yeast cells were grown on appropriate agar plates at $25^{\circ} \mathrm{C}$ except stated otherwise and stored at $4{ }^{\circ} \mathrm{C}$. Liquid cultures were inoculated using a single colony from the plate or a liquid preculture. Cells were grown at $25^{\circ} \mathrm{C}$ until logarithmic phase $(1-3 \times 107$ cells/ml $)$ in culture tubes or Erlenmeyer flasks in a rotator (tubes) or a shaker (flasks, $160 \mathrm{rpm}$ ). If necessary, the activation of a temperature sensitive allele was achieved by shifting the cells to $37^{\circ} \mathrm{C}$ for an appropriate time.

\subsection{Loss of $U R A 3$ gene selection}

FOA plates were used to select for the loss of an URA3 gene-containing plasmid. Cells expressing $U R A 3$ produce on FOA plates the toxic compound 5-Fluorouracil which is lethal to the cells.

FOA plates: $\quad 0.17 \%$ Nitrogen Base

$0.51 \%(\mathrm{NH} 4) 2 \mathrm{SO} 4$

$0.2 \%$ Drop Out,

$2 \%$ Glucose

$0.005 \%$ Uracil

$0.1 \% 5$-FOA 
The liquid medium was sterile-filtered and added to the autoclaved agar.

\subsubsection{Determination of cell growth}

The number of cells in liquid cultures was determined using a hemocytometer. For that, $10 \mu 1$ of an appropriate diluted sample were applied to the chamber and the cells were counted in $5 \mathrm{x}$ 5 squares of the hemocytometer. The number of cells in the original mixture was calculated with the following formula:

cells $/ \mathrm{ml}=$ number of cells counted $* 10^{4} *$ sample dilution.

Alternatively, the growth was quantified with an UV/Vis Spectrometer, whereby the optical density was measured at a wave length of $600 \mathrm{~nm}$. The respective sterile culture medium was used as a reference.

\subsubsection{Growth Test}

Yeast cells were resuspended in sterile water and the cell density was determined using a hemocytometer. The number of cells were adjusted to a serial dilution $\left(1 \times 10^{5}\right.$ cells $/ \mathrm{ml}, 1 \times 10^{4}$ cells $/ \mathrm{ml}, 1 \times 10^{3}$ cells $/ \mathrm{ml}, 1 \times 10^{2}$ cells $/ \mathrm{ml}$ and $1 \times 10^{1}$ cells $\left./ \mathrm{ml}\right) .10 \mu \mathrm{l}$ of each was spotted onto YPD or selective plates. For FOA plates $30 \mu 1$ were used. The plates were then incubated for two to three days at the respective temperatures.

\subsubsection{Sporulation and tetrad dissection of S.cerevisiae}

Mating, sporulation and tetrad dissection were performed as generally described in Sherman (1991) and Sherman \& Hicks (1991). Yeast strains were combined by mating two haploid strains of the opposite mating types (MAT a or MAT $\alpha)$. For that, the respective strains were mixed on YPD plates. After incubation for 1 day, the combined strains were brought onto appropriate agar plates that select for diploids. After 2 days of incubation, $2 \mathrm{ml}$ of Super-SPO medium were inoculated with the selected diploid cells and were incubated for three to seven days. 


\section{Super-SPO medium: $\quad$ Solution 1: $\quad 0.5 \%(\mathrm{w} / \mathrm{v})$ Yeast extract}

$306 \mathrm{mM}$ Potassium acetate

$$
\begin{array}{ll}
\text { Solution 2: } & 5 \mathrm{mM} \text { Glucose } \\
& 0.4 \mathrm{mM} \text { Adenine } \\
& 0.7 \mathrm{mM} \text { Uracil } \\
& 0.4 \mathrm{mM} \text { Tyrosine } \\
& 0.2 \mathrm{mM} \text { Histidine } \\
& 0.3 \mathrm{mM} \text { Leucine } \\
& 0.2 \mathrm{mM} \text { Lysine } \\
& 0.2 \mathrm{mM} \text { Tryptophan } \\
& 0.3 \mathrm{mM} \text { Methionine } \\
& 0.2 \mathrm{mM} \text { Arginine } \\
& 1.2 \mathrm{mM} \text { Phenylalanine } \\
& 5.9 \mathrm{mM} \text { Threonine }
\end{array}
$$

Solution 1 was autoclaved and solution 2 was sterile-filtered and then both solutions were mixed $1: 1$.

Due to the low amount of nutrients, the diploid cells undergo meiosis and form tetrads composed of four haploid cells. To dissect these tetrads, first $100 \mu 1$ of the culture were spun down, washed once with sterile water, resuspended in $50 \mu \mathrm{l}$ P-solution and incubated with $1 \mu \mathrm{g} / \mu \mathrm{l}$ zymolyase for about 5 to $10 \mathrm{~min}$ until the digestion of the ascus wall was visible with the light microscope. Then, the cells were washed with in P-solution, diluted in sterile water and transferred on YPD-plates. The four spores of a tetrad were separated on the YPD-plate using a tetrad microscope. After separation, the plates were incubated at $25^{\circ} \mathrm{C}$ until the isolated spores became visible. The genotype of the spores was investigated using different selective agar plates and different incubation temperatures. Furthermore, isolation of genomic DNA (gDNA) and subsequent PCR analysis was used to verify specific genotypes. Determination of the mating type was performed according to Sprague (1991).

$$
\begin{array}{ll}
\text { B-plates: } & 0.17 \%(\mathrm{w} / \mathrm{v}) \text { Yeast nitrogen base } \\
& 0.51 \%(\mathrm{w} / \mathrm{v}) \text { Ammonium sulfate } \\
& 2 \%(\mathrm{w} / \mathrm{v}) \text { Glucose } \\
& 3 \%(\mathrm{w} / \mathrm{v}) \text { Agar }
\end{array}
$$

To identify the mating type of the spores, the cells were transferred on MATa or MATa tester strains and after two to three days of incubation they were brought onto B-plates, whose select for diploid cells that have mated before. 


\subsubsection{Permanent storage}

For permanent storage of yeast strains, cells from the desired strain were collected from an agarplate and resuspended in $1 \mathrm{ml}$ sterile $50 \%(\mathrm{v} / \mathrm{v})$ glycerol. Glycerol stocks were then stored at $80^{\circ} \mathrm{C}$.

\subsubsection{High-Efficient Lithium Acetat Transformation of S. cerevisiae}

Transformation of S.cerevisiae was in general performed according to Gietz, St Jean, Woods, \& Schiestl (1992).

TE /Lithium acetate (pH 7.5):

$\underline{\text { TE /Lithium acetate/PEG ( } \mathrm{pH} 7.5):}$
$100 \mathrm{mM}$ Lithium acetate

$10 \mathrm{mM}$ Tris- $\mathrm{HCl}$

1 mM EDTA

$40 \%$ (v/v) PEG 4000

$100 \mathrm{mM}$ Lithium acetate

$10 \mathrm{mM}$ Tris- $\mathrm{HCl}$

1 mM EDTA

For that, S. cerevisiae overnight cultures were diluted to $5 \times 10^{6}$ cells $/ \mathrm{ml}$ in fresh YPD medium and grown for about four hours to $1-2 \times 10^{7}$ cells $/ \mathrm{ml}$. After that, cells were centrifuged at 2000 rpm for five minutes and resuspended in $1 \mathrm{ml}$ sterile $\mathrm{ddH}_{2} \mathrm{O}$. Subsequently, the cells were spun down at $13000 \mathrm{rpm}$ for one minute and washed in $1 \mathrm{ml} \mathrm{TE} / \mathrm{Lithium}$ acetate. Then, the cells were resuspended in TE/Lithium acetate to $1 \times 10^{9}$ cells $/ \mathrm{ml}$. $50 \mu \mathrm{l}$ of the cell suspension were mixed with $1 \mu \mathrm{g}$ plasmid DNA and $50 \mu \mathrm{g}$ ssDNA. The ssDNA needs to be boiled at $95^{\circ} \mathrm{C}$ for five minutes and cooled for two minutes on ice before use. $300 \mu 1$ PEG 4000/Lithium acetate/TE were added and the mixture was vortexed thoroughly. The mixture was incubated with agitation at $25{ }^{\circ} \mathrm{C}$ for 30 minutes and after incubation heat shocked at $42^{\circ} \mathrm{C}$ for 15 minutes. Afterwards, the suspension was centrifuged at $13000 \mathrm{rpm}$ for one minute. The supernatant was removed, and the cells were resuspended in $1 \mathrm{ml}$ sterile water. The cells were centrifuged again, resuspended in $100 \mu 1$ sterile water and plated on selective plates with a Drigalski spatula. The plates were incubated at $25^{\circ} \mathrm{C}$ for about 2-4 days until the single colonies became visible. 


\subsubsection{Nucleo-cytoplasmic fractionation}

Cytoplasm extract was prepared according to Sklenar \& Parthun (2004) with modifications. For the nucleo-cytoplasmic fractionation, cells were grown either in full- or selective medium to log-phase. Then, the cells were spun down $\left(1000 \mathrm{~g}, 10 \mathrm{~min}, 4^{\circ} \mathrm{C}\right)$ and were resuspended in $5 \mathrm{ml}$ $\mathrm{H}_{2} \mathrm{O} .1 \mathrm{ml}$ were taken as control of total RNA and $500 \mu \mathrm{l}$ as protein control. Then, the remaining cells were spun down again and resuspended in 1ml YPD/ 1 M Sorbitol/ 2 mM DTT. After that, cells were resuspended in YPD/ $1 \mathrm{M}$ Sorbitol/ $1 \mathrm{mM}$ DTT and spheroblasted by addition of $1 \mathrm{mg}$ Zymolyase. Cells were observed under the light microscope and incubated 30-60 min at RT until at least $70 \%$ were spheroblasted. Next, $50 \mathrm{ml}$ YPD/ $1 \mathrm{M}$ Sorbitol was added, the spheroblasts were first recovered for $30 \mathrm{~min}$ at $25^{\circ} \mathrm{C}$ and subsequently shifted to $37^{\circ} \mathrm{C}$ for an appropriate time if applicable. After that, the spheroblasts were chilled on ice, centrifuged at $1000 \mathrm{~g}$ for $5 \mathrm{~min}$ and resuspended in $500 \mu \mathrm{l}$ Ficoll buffer.

Ficoll buffer (pH 6.0): $\quad 18 \%(w / v)$ Ficoll 400

$10 \mathrm{mM}$ HEPES

Buffer A (pH6.0): $\quad 50 \mathrm{mM} \mathrm{NaCl}$

$1 \mathrm{mM} \mathrm{MgCl} 2$

$10 \mathrm{mM}$ HEPES

Subsequently, $1 \mathrm{ml}$ of buffer A was added to the lysate. After mixing thoroughly, it was centrifuged at 1,500 $\mathrm{g}$ for $15 \mathrm{~min}$. The supernatant represents the cytoplasmic fraction and was used for further analyses. The proper fractionation was confirmed by western blot analyses. Therefore, the total lysate and the cytoplasmic fraction were analyzed for the presence of the nucleolar protein Nop1 and the cytoplasmic protein Zwf1, respectively. RNA was purified from the total lysate and the cytoplasmic fraction using the NucleoSpin RNA Kit (Macherey Nagel) according to the instructions of the manufacturer.

\subsection{Molecular biological methods}

\subsubsection{DNA and RNA isolation}

\subsubsection{Isolation of plasmid DNA from $E$. coli}

Plasmid DNA was isolated from E. coli using the Nucleobond PC 100 Kit. The isolation was carried out according to the manufacturer's instructions for high-copy plasmid purification. 


\subsubsection{2 gDNA isolation from S. cerevisiae}

Genomic DNA (gDNA) from yeast cells was isolated as described in Rose, Winston, \& Hieter (1991).

Detergent lysis buffer ( $\mathrm{pH} 8.0)$ : $\quad 2 \%(\mathrm{v} / \mathrm{v})$ Triton X-100

$1 \%(\mathrm{w} / \mathrm{v})$ SDS

$100 \mathrm{mM} \mathrm{NaCl}$

$10 \mathrm{mM}$ Tris-HCl

$1 \mathrm{mM}$ EDTA

$\underline{\text { TE-buffer ( } \mathrm{pH} 8.0) \text { : }}$

$10 \mathrm{mM}$ Tris-HCl

$1 \mathrm{mM}$ EDTA

To isolate chromosomal/ gDNA from yeast, cells were grown in $10 \mathrm{ml}$ liquid culture to saturation. This saturated culture was then harvested by centrifugation at $4000 \mathrm{~g}$ for $5 \mathrm{~min}$. After washing of the cells with $1 \mathrm{ml}$ of $\mathrm{H}_{2} \mathrm{O}$, the pellet was resuspended in $300 \mu \mathrm{l}$ of detergent lysis buffer and $200 \mu \mathrm{l}$ of phenol/chloroform/isoamyl alcohol (25:24:1) (P/C/I). One pellet volume of glass beads was added and the cells were disrupted using the FastPrep- 24 machine at $4.5 \mathrm{~m} / \mathrm{s}$ for $30 \mathrm{sec}$. After disruption, $200 \mu \mathrm{l}$ of TE-buffer was added, the sample was mixed and subsequently was centrifuged at $21000 \mathrm{~g}$ for $5 \mathrm{~min}$ at RT to separate the phases. The upper phase was transferred carefully into a fresh tube. Next, the same amount of P/C/I was added, it was mixed thoroughly and centrifuged at $21000 \mathrm{~g}$ for $5 \mathrm{~min}$ at RT. These steps were repeated until the interlayer appeared clear. Then, the gDNA was precipitated from the upper phase by adding $6 \mu \mathrm{l}$ of $7.5 \mathrm{M}$ ammonium acetate, $1 \mathrm{ml}$ of $100 \%$ ethanol and subsequent centrifugation for $10 \mathrm{~min}$ at $21000 \mathrm{~g}$ at $4^{\circ} \mathrm{C}$. Finally, the precipitated gDNA was washed once with $70 \%$ ethanol, air dried and resuspended in 50-100 $\mu$ l of deionized $\mathrm{H}_{2} \mathrm{O}$.

\subsubsection{Isolation of RNA using Trizol®}

RNA derived from RNA- Co-IP experiments was purified using Trizol®. For that, $1 \mathrm{ml}$ Trizol® was added to the cell lysates and to the beads with the bound protein-RNA complexes and incubated at $65{ }^{\circ} \mathrm{C}$ for $10 \mathrm{~min}$ with agitation. Next, $200 \mu \mathrm{l}$ chloroform was added and the samples were mixed thoroughly. After centrifugation at 20,000g for $10 \mathrm{~min}$, the resulting upper phase was carefully transferred into a fresh tube. For RNA precipitation, $1 \mu 1$ glycogen and 500 $\mu 1$ isopropanol were added and mixed. After incubation for at least $30 \mathrm{~min}$ at $-20^{\circ} \mathrm{C}$, the sample 
was centrifuged at $20,000 \mathrm{~g}$ at $4^{\circ} \mathrm{C}$ for $30 \mathrm{~min}$. The resulting RNA pellet was then washed twice with $70 \%$ ice-cold ethanol made with DEPC-treated deionized water. RNA was resuspended in 20-100 $\mu$ l DEPC-treated deionized water and dissolved at $65^{\circ} \mathrm{C}$ for $10 \mathrm{~min}$. RNA was stored at $-80^{\circ} \mathrm{C}$.

\subsubsection{Isolation of RNA using the NucleoSpin RNA Kit system}

Isolation of RNA from yeast cells, cell extracts and cytoplasmic fractions were performed using the NucleoSpin RNA Kit according to the manufacturer's instructions.

\subsubsection{Determination of DNA/RNA concentration}

The concentration of DNA/RNA was determined with the spectrophotometer NanoDrop 2000 at a wavelength of $260 \mathrm{~nm}$. $1 \mu \mathrm{l}$ of the sample was used for determination. $\mathrm{ddH}_{2} \mathrm{O}$ or the respective buffer served as blank control.

\subsubsection{Polymerase chain reaction $(\mathrm{PCR})$}

Specific DNA-fragments were amplified from gDNA or plasmids with appropriate oligonucleotide (primer) pairs and a thermostable DNA polymerase via polymerase chain reaction (PCR). For generation of templates for DIG-labeling (section 3.7.3.1) and analytic PCRs "DreamTaq"-DNA-polymerase (Thermo Scientific) was used. A reaction was set up as indicated in the following table:

\begin{tabular}{c|c} 
Component & $\begin{array}{c}\text { Concentration } \\
\sum \mathbf{2 5} \boldsymbol{\mu l}\end{array}$ \\
\hline 10x DreamTaq buffer & $1 \mathrm{x}$ \\
\hline $2 \mathrm{mM}$ dNTP-mix & $0.2 \mathrm{mM}$ \\
\hline $10 \mu \mathrm{M}$ primer forward & $1 \mu \mathrm{M}$ \\
\hline $10 \mu \mathrm{M}$ primer reverse & $1 \mu \mathrm{M}$ \\
\hline DreamTaq DNA-polymerase & $1.25 \mathrm{U}$ \\
\hline Template & $1 \mu \mathrm{gDNA}$ or $50 \mathrm{ng}$ plasmid
\end{tabular}

The PCR was run in general with the program depicted below. Annealing time was chosen according to the melting temperatures of the primers and the number of cycles was chosen 
depended on the type of experiment, usually 30-35 cycles.

\section{PCR program:}

$\left.\begin{array}{lll}95^{\circ} \mathrm{C} & 3 \mathrm{~min} & \text { Initial denaturation } \\ 95^{\circ} \mathrm{C} & 30 \mathrm{~s} & \text { Denaturation } \\ \mathrm{x} & 30 \mathrm{~s} & \text { Annealing } \\ 72^{\circ} \mathrm{C} & 1 \mathrm{~min} / \mathrm{kb} & \text { Elongation } \\ 72^{\circ} \mathrm{C} & 10 \mathrm{~min} & \text { Final extension }\end{array}\right] \times$ cycles

To verify the PCR reaction, the samples were applied to Agarose gel electrophoresis. For that, either the whole sample were loaded on the gel and if necessary the fragments were purified from the gel or an aliquot of the sample was loaded on the gel and the fragments were purified from the remaining reaction mixture. Purification of the fragments was carried out using the NucleoSpin Gel and PCR Clean-up Kit (Macherey-Nagel).

\subsubsection{Agarose Gel Electrophoresis}

DNA fragments deriving from PCR reactions were separated via agarose gel electrophoresis. For that, $1 \%$ agarose $(\mathrm{w} / \mathrm{v})$ was dissolved in $1 \mathrm{x}$ TAE buffer by boiling it in a microwave.

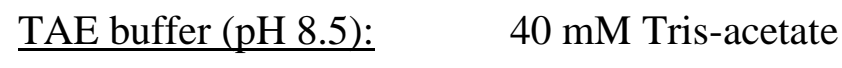
$1 \mathrm{mM}$ EDTA

6x DNA loading dye: $\quad 10 \mathrm{mM}$ Tris $\mathrm{pH} 7.6$

$60 \%(\mathrm{v} / \mathrm{v})$ Glycerol

$60 \mathrm{mM}$ EDTA

$0.03 \%(\mathrm{w} / \mathrm{v})$ Bromophenol blue

$0.03 \%(w / v)$ Xylene cyanol

After the dissolved agarose cooled down to $50-60^{\circ} \mathrm{C}, 0.5 \mu \mathrm{g} / \mathrm{ml}$ ethidium bromide was added. Subsequently, the agarose was poured into a gel chamber and a comb was placed in the gel. After the gel has solidified, it was covered with 1x TAE buffer. Then, the samples were mixed with 1x Loading Dye and loaded into the gel pockets. Additionally, a DNA size standard was loaded. The gel was run with $120 \mathrm{~V}$ for approximately 40 minutes. The fragments were analyzed under UV light with the gel documentation system and compared to a DNA ladder to determine their size. If required, the DNA fragments were cut from the gel with a clean scalpel and purified using the NucleoSpin Gel and PCR Clean-up Kit (Macherey-Nagel). 


\subsubsection{Quantitative RT-PCR (qRT-PCR) and cDNA synthesis}

Quantitative RT-PCR was used to determine the relative amount of different RNAs in a whole cell lysate or a cytoplasmic fraction, to detect and quantitate protein-bound RNAs and furthermore to detect protein-bound DNA from ChIP experiments. This method relies on fluorescent labeling with molecules like SYBR® Green, that become fluorescent upon binding to double stranded DNA. The fluorescence is measured after each PCR cycle and the increase of fluorescence is proportional to the amount of the amplified DNA. The PCR cycle/ quantitation cycle $(\mathrm{Cq})$ in which the fluorescent signal is initially detected is used for the calculation of the starting DNA amount. To detect total or protein-bound RNA using qRT-PCR, these purified RNAs had to be transcribed into coding DNA (cDNA), which was generated using Maxima Reverse Transcriptase according to the instructions of the manufacturer. In general, equal amounts of RNA were transcribed into cDNA and a random hexamer primer was used. Samples that were treated equally but without reverse transcriptase (-RT) were used as negative control. The cDNA was diluted 1:20-1:50 depending on the amount of applied RNA. $8 \mu \mathrm{qPCR}$ master mix were added to $2 \mu 1$ of the diluted cDNA and applied to a two-step qPCR, using the qPCR cycler CFX Connect (BioRad).

\section{qPCR master mix:}

$5,0 \mu \mathrm{l} \quad$ qPCR mix

$0,08 \mu \mathrm{l}$ primer forward

$0,08 \mu \mathrm{l}$ primer reverse

$2,8 \mu \mathrm{l} \quad$ nuclease free $\mathrm{H}_{2} \mathrm{O}$

\section{PCR program:}

$95^{\circ} \mathrm{C} \quad 5 \mathrm{~min}$ Initial denaturation

$\left.\begin{array}{ccc}95{ }^{\circ} \mathrm{C} & 5 \mathrm{~s} & \text { Denaturation } \\ 60{ }^{\circ} \mathrm{C} & 30 \mathrm{~s} & \text { Extension }\end{array}\right]-45$ cycles

At the end of the PCR a melting curve was recorded starting from $65{ }^{\circ} \mathrm{C}$ to $95{ }^{\circ} \mathrm{C}$ to verify that only one specific product was amplified with the respective primers. Resulting $\mathrm{Cq}$ - values were normalized where applicable and/or fold changes were set in relation to total RNA, a wildtype isolate or a specific gene according to requirements of the experiment. For that, the relations were calculated using the $2^{-\Delta \Delta \mathrm{Cq}}$ method (Livak and Schmittgen, 2001). 


\subsubsection{Non-radioactive Northern blot}

Nothern blot experiments were performed to investigate the steady state level of ribosomal RNAs among different yeast strains. RNA was isolated as described in section 3.7.1.4, separated by size on a denaturing RNA-formaldehyde agarose gel and analyzed via Nothern blotting as generally described previously (Sambrook, Fritsch and Maniatis, 1989; Wu, Becker and Krebber, 2014). Non-radioactive Northern blotting with DIG-labeled RNA probes was performed according to the manufacturer's instructions (Roche Diagnostics, DIG Application Manual for Filter Hybridization, 2008).

\subsubsection{Generation of digoxigenin (DIG)-labeled RNA-probes}

Digoxigenin (DIG)-labeled RNA-probes were used for the detection of specific RNAs in and in non-radioactive Northern blot experiments. These probes were generated according to the instructions by the manufacturer of the DIG-labeling mix (Roche Diagnostics, DIG Application Manual for Filter Hybridization, 2008). Templates for these RNA specific probes were produced by PCR using primer pairs that generate a 200-500 bp sized fragment carrying a T7 promoter. After purification, these templates were in vitro transcribed using the $\mathrm{T}_{7}$-RNApolymerase and the "DIG RNA labeling mix" (Roche). This labeling mix is composed of all four natural NTPs occurring in RNAs and additionally DIG-11-UTP, which results in an incorporation of DIG-UTP every $20^{\text {th }}-25$ th nucleotide. The reaction was set up according to the manufacturer's instructions.

DIG-labeling reaction $(20 \mu \mathrm{l}): \quad 200-250 \mathrm{ng}$ DNA template

1x Transcription buffer

1x DIG RNA labeling mix

20 U RiboLock RNase Inhibitor

40 U T7 RNA polymerase

The reaction mixture was incubated for $2 \mathrm{~h}$ at $37^{\circ} \mathrm{C}$. After incubation, the template DNA was digested with $2 \mu \mathrm{DN}$ Dase I for $15 \mathrm{~min}$ at $37^{\circ} \mathrm{C}$. Then, the sample were filled up to $50 \mu \mathrm{l}$ volume with DEPC-treated $\mathrm{H}_{2} \mathrm{O}$ and subsequently the RNA probe was precipitated with 0.25 volumes $4 \mathrm{M} \mathrm{LiCl}, 1 \mu \mathrm{l}$ glycogen and 3 volumes $100 \%$ ethanol overnight at $-20{ }^{\circ} \mathrm{C}$. The next day, the RNA was pelleted by centrifugation for $30 \mathrm{~min}$ at $21,100 \mathrm{~g}$ and $4{ }^{\circ} \mathrm{C}$, washed with $70 \%$ ethanol and dried on ice. Then, the probe was resuspended in $25 \mu \mathrm{l}$ of $1 \mathrm{M} \mathrm{TE} \mathrm{pH} 7.5+1 \mathrm{mg} / \mathrm{ml} \mathrm{heparin}$, $25 \mu \mathrm{l}$ of deionized formamide and $50 \mu \mathrm{l}$ of $\mathrm{Hyb}-\mathrm{Mix}$. RNA-probes were stored at $-20^{\circ} \mathrm{C}$. 
Hybridization mix (HybMix): $\quad 50 \%(\mathrm{v} / \mathrm{v})$ deionized formamide

$5 \mathrm{x}$ SSC

1x Denharts solution

$0.1 \mathrm{mg} / \mathrm{ml}$ Heparin

50x Denharts solution:

$1 \%(\mathrm{w} / \mathrm{v})$ Ficoll

$1 \%(\mathrm{w} / \mathrm{v})$ Polyvinylpyrrolidone

$1 \%(\mathrm{w} / \mathrm{v}) \mathrm{BSA}$

\subsubsection{Denaturing RNA-formaldehyde agarose gel electrophoresis}

Before running the gel, the gel chamber and corresponding equipment were incubated in $0.1 \mathrm{M}$ $\mathrm{NaOH}$ for 30 min and after that rinsed with deionized $\mathrm{H}_{2} \mathrm{O}$. After cleaning the equipment, a 1 $\%$ agarose gel containing $2 \%$ formaldehyde was prepared. For that, $1.5 \mathrm{~g}$ agarose was dissolved in $127 \mathrm{ml}$ of DEPC treated water, cooled down to $55^{\circ} \mathrm{C}$ and mixed with $15 \mathrm{ml}$ of $10 \mathrm{x}$ MOPS and $8.1 \mathrm{ml}$ of $37 \%$ formaldehyde.

10x MOPS (pH 7.0):

$$
\begin{aligned}
& 200 \mathrm{mM} \text { MOPS } \\
& 50 \mathrm{mM} \text { Sodium acetate } \\
& 10 \mathrm{mM} \text { EDTA }
\end{aligned}
$$

RNA Loading Dye: $\quad 50 \%(\mathrm{v} / \mathrm{v})$ deionized formamide

$6 \%(\mathrm{v} / \mathrm{v})$ Formaldehyde

1x MOPS

$25 \mathrm{ng} / \mathrm{ml}$ Ethidium bromide

$10 \%$ Glycerol (RNase-free)

Bromophenol blue and Xylene cyanol

20x SSC (pH 7.0): $\quad 3 \mathrm{M} \mathrm{NaCl}$

$300 \mathrm{mM}$ Sodium citrate

Generally, $1 \mu \mathrm{g}$ RNA of each sample was diluted in $5 \mu \mathrm{l}$ DEPC treated $\mathrm{H}_{2} \mathrm{O}$ and mixed with the double volume $(10 \mu 1)$ of freshly prepared RNA loading dye. These samples were incubated at $65^{\circ} \mathrm{C}$ for $10 \mathrm{~min}$ and subsequently chilled on ice for $2 \mathrm{~min}$. After this denaturation step, the samples were loaded completely into the wells of the polymerized formaldehyde agarose gel. Next, the gel was run in 1x MOPS buffer at $120 \mathrm{~V}$ for $1,5-2$ hours. After that, the integrity of RNA was checked using a UV transilluminator. Subsequently, the gel was washed two times with DEPC-treated $\mathrm{H}_{2} \mathrm{O}$ and two times with 20x SSC for $15 \mathrm{~min}$ to remove the formaldehyde before blotting. 


\subsubsection{Dry Nothern blotting, hybridization and detection}

To perform a Dry Nothern Blot overnight, a blot sandwich was set-up as the following:

- the gel facing down on a glass plate and wrapped around with parafilm

- a dry, positively charged nylon membrane with the same size as the membrane

- three Whatman paper in the same size

- a stack of paper towels

- 200-500 g weight

After overnight blotting, the RNA was cross-linked by exposing it to UV light for $7 \mathrm{~min}$ at 5000 $\mathrm{J} / \mathrm{cm}^{2}$ and additionally by baking the membrane for $2 \mathrm{~h}$ at $80^{\circ} \mathrm{C}$. After that, the membrane was either stored dry at RT or directly used for hybridization. For that, the membrane was transferred in a glass tube and pre-hybridized with hybridization buffer for 1 hour at $68^{\circ} \mathrm{C}$ in a hybridization oven. After pre-hybridization, 1-5 $\mu$ l of the respective DIG-labeled probe (preparation of DIGlabeled probes see section 3.7.3.1) was added to the hybridizing buffer. Before that, the DIG labeled probe was denatured for $5 \mathrm{~min}$ at $55^{\circ} \mathrm{C}$.

$\underline{\text { Hybridization buffer }} \quad 0.5 \mathrm{M}$ Na-phosphate $\mathrm{pH} 7.2$

(pH 7.2): $\quad 7 \%(\mathrm{w} / \mathrm{v})$ SDS

$1 \mathrm{mM}$ EDTA

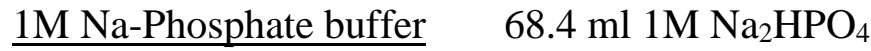

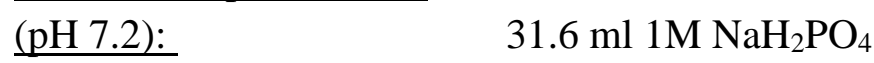

After overnight hybridization at $68^{\circ} \mathrm{C}$, the membrane was washed for $15 \mathrm{~min}$ four times in $2 \mathrm{x}$ $\mathrm{SSC} / 0.1 \% \mathrm{SDS}$ at RT, in $1 \mathrm{x} \mathrm{SSC/} 0.1 \% \mathrm{SDS}$ at RT and twice in 0.5x SSC/ $0.1 \% \mathrm{SDS}$ at $68^{\circ} \mathrm{C}$. For detection, the membrane was first washed in washing buffer for 5 min and after that blocked in 1x blocking buffer for $30 \mathrm{~min}$ at RT.

$\underline{5 x \text { Maleic acid buffer }} \quad 0.5 \mathrm{M}$ Maleic acid

(pH 7.5): $\quad 0.75 \mathrm{M} \mathrm{NaCl}$

1x Blocking reagent: $\quad 1 x$ Blocking reagent (Roche)

1x Maleic acid buffer

Washing buffer: $\quad 1 x$ Maleic acid buffer

$0.3 \%(\mathrm{v} / \mathrm{v})$ Tween 20 
Detection buffer:

$0.1 \mathrm{M}$ Tris $\mathrm{pH} 9.5$

$\mathrm{M} \mathrm{NaCl}$

Then, the membrane was incubated with anti-Digoxigenin-alkaline phosphatase $(1: 10000$ in blocking buffer) for 30-60min at RT. After washing twice for 15 min with washing buffer, the membrane was equilibrated for 2-5 min in detection buffer and finally incubated with the chemiluminescent substrate CSPD (diluted 1:100 in detection buffer) for $5 \mathrm{~min}$. Next, the membrane was sealed in an autoclave bag and incubated for $10 \mathrm{~min}$ at $37^{\circ} \mathrm{C}$ to reduce background signals. To detect the signals of emitted light, either the Fusion camera was used or the membrane was exposed to an X-ray sensitive film. For a second hybridization with another DIG-labeled probe, the procedure was repeated starting at the hybridization step.

\subsection{Protein and RNA biochemical methods}

\subsubsection{Preparation of yeast cell lysate}

In general, yeast cells were grown in 400-800 ml cultures to logarithmic phase $\left(\mathrm{OD}_{600}=1,2-1,4\right)$ and harvested by spinning them at $4^{\circ} \mathrm{C}$ and $4000 \mathrm{rpm}$ for 5 minutes. The pellet was washed in $20 \mathrm{ml}$ water, centrifuged again, resuspended in $2 \mathrm{ml}$ water and transferred in a $15 \mathrm{ml}$ falcon tube or $2 \mathrm{ml}$ screw top tubes. Then, the cells were pelleted at $4^{\circ} \mathrm{C}$ and maximum speed for one minute. The pellets were either frozen in liquid nitrogen until usage or directly used. For lysis, $5 \mu 1$ per $100 \mu 1$ cell pellet of Protease Inhibitor (Roche), the same amount of glass beads and of the assay-specific lysis buffer were added to the cell pellet. Subsequently, cells were disrupted using the FastPrep machine with $4,5 \mathrm{~m} / \mathrm{s}$ for 30 seconds three times. The lysate was cleared by centrifugation at $4{ }^{\circ} \mathrm{C}$ and $21,000 \mathrm{~g}$ for ten minutes. The cleared lysates were then applied for the further experiments. All steps were performed on ice to avoid degradation of proteins or nucleic acids.

\subsubsection{Co-Immunoprecipitation (Co-IP)}

Physical interactions of proteins in vivo were analyzed via co-Immunoprecipitation (Co-IP). For this, an antibody against the fused tag of one protein of interest was added to the cell lysate and the resulting antibody-protein complex was then coupled with beads and pulled down. All possible interaction partners are co-precipitated and can be detected in subsequent Western Blot 
analysis via their respective tags or via a protein specific antibody. Here, coimmunoprecipitation analysis were performed with cells expressing GFP-, myc- or TAP-tagged proteins as basically described earlier (Gross et al., 2007). For immunoprecipitation with GFPtagged proteins, GFP-Trap beads (Chromotek) that have covalently bound anti-GFP antibodies were used. Precipitation of myc-tagged proteins was performed by coupling $20 \mu \mathrm{g}$ of the specific antibody (anti-myc) with $20 \mu$ slurry of IgG-sepharose beads. TAP (tandem affinity purification) tags exhibit besides a calmodulin-binding peptide and a TEV cleavage site two IgG-binding units of protein A of Staphylococcus aureus (ProtA) (Rigaut et al., 1999) and are therefore precipitated using IgG-Sepharose beads. To perform the Co-immunoprecipitation, first the appropriate beads were prepared. For that, $20 \mu \mathrm{l}$ IgG-sepharose beads or $10 \mu \mathrm{l} \mathrm{GFP-}$ Trap beads were used per IP. $1 \mathrm{ml}$ PBSKMT buffer was added to each aliquot and the beads were centrifuged at $400 \mathrm{~g}$ for one minute. This washing step was repeated two times. After the final washing, $20 \mu 1$ PBSKMT Buffer were left over the bead fraction and kept on ice until usage.

PBSKMT buffer $\mathrm{pH} 7.5: \quad$ 1x PBS pH 7.5

$3 \mathrm{mM} \mathrm{KCl}$

$2.5 \mathrm{mM} \mathrm{MgCl} 2$

$0.5 \%(\mathrm{v} / \mathrm{v})$ Triton-X-100

$\underline{\text { 2x SDS-loading buffer }} \quad 125 \mathrm{mM}$ Tris/HCl $\mathrm{pH} 6.8$

$25 \%(\mathrm{v} / \mathrm{v})$ Glycerol

$2 \%(\mathrm{w} / \mathrm{v})$ SDS

$5 \%(\mathrm{v} / \mathrm{v}) \beta$-Mercaptoethanol

Bromophenol blue

For co- immunoprecipitation, first $15 \mu 1$ of the prepared cell lysates were taken and mixed with $15 \mu 12 \mathrm{x}$ Sample Buffer as control. Then, $20 \mu \mathrm{g}$ myc-mouse antibody were added to the remaining lysate and the samples were incubated in a rotator at $4^{\circ} \mathrm{C}$ for $30 \mathrm{~min}$. For GFP-IP, GFP Trap $^{\circledR}$ beads were directly used without previous antibody incubation. After this incubation, the lysate was added to the beads and the mixture was again incubated in a rotator at $4^{\circ} \mathrm{C}$ for one to three hours to precipitate the antibody binding protein complex. For RNase A treatment, the lysate was splitted and one part was treated with $200 \mu \mathrm{g} / \mathrm{ml}$ RNase A. The beads were washed at least five times with $1 \mathrm{ml}$ PBSKMT buffer. After the last washing step, the supernatant was removed completely, and the beads were resuspended in $30 \mu 12 x$ Sample buffer. 


\subsubsection{SDS-acrylamide gel-electrophoresis (SDS-PAGE)}

SDS-acrylamide gel-electrophoresis (SDS-PAGE) were performed to separate proteins deriving from total cell lysates or precipitations according to their size as basically described in Garfin (2009). For that, a Tris-glycine buffer and denaturing system (LAEMMLI, 1970) were used together with an SDS-gel composed of $5 \%$ stacking gel and 6\% to $10 \%$ resolving gel. SDSPolyacrylamid gels were run in self-made vertical chambers with a gel size of $12 \times 18 \mathrm{~cm}$.

Stacking gel (5\%): $\quad 16.7 \%(\mathrm{v} / \mathrm{v})$ Rotiphorese Gel 30

$125 \mathrm{mM}$ Tris-HCl pH 6.8

$0.1 \%(\mathrm{w} / \mathrm{v}) \mathrm{SDS}$

$0.1 \%(\mathrm{w} / \mathrm{v})$ APS

$0.1 \%(\mathrm{v} / \mathrm{v})$ TEMED

Resolving gel (10\%): $\quad 33.3 \%(\mathrm{v} / \mathrm{v})$ Rotiphorese Gel 30

$375 \mathrm{mM}$ Tris/HCl $\mathrm{pH} 8.8$

$0.1 \%(\mathrm{w} / \mathrm{v}) \mathrm{SDS}$

$0.1 \%(\mathrm{w} / \mathrm{v})$ APS

$0.1 \%(\mathrm{v} / \mathrm{v})$ TEMED

Resolving gel (8\%): $\quad 26,7 \%$ (v/v) Rotiphorese Gel 30

$375 \mathrm{mM}$ Tris/HCl pH 8.8

$0.1 \%(\mathrm{w} / \mathrm{v})$ SDS

$0.1 \%(\mathrm{w} / \mathrm{v})$ APS

$0.1 \%(\mathrm{v} / \mathrm{v})$ TEMED

Resolving gel (6\%): $\quad 20 \%$ (v/v) Rotiphorese Gel 30

$375 \mathrm{mM}$ Tris/HCl $\mathrm{pH} 8.8$

$0.1 \%(\mathrm{w} / \mathrm{v}) \mathrm{SDS}$

$0.1 \%(\mathrm{w} / \mathrm{v})$ APS

$0.1 \%(\mathrm{v} / \mathrm{v})$ TEMED

The appropriate resolving gel was prepared according to the protein sizes, poured in the chamber and overlaid with $100 \%$ isopropanol. After polymerization of the resolving gel, the isopropanol was discarded, and the gel was rinsed with $\mathrm{H}_{2} \mathrm{O}$. A $5 \%$ stacking gel was prepared, poured on top of the resolving gel and a comb was placed into the gel. The solidified gel was placed vertically into the chamber, which was filled up with 1x SDS Running buffer. 
Running buffer: $\quad 25 \mathrm{mM}$ Tris

$192 \mathrm{mM}$ Glycine

$0.1 \%(w / v)$ SDS

The samples, containing 1 x Sample buffer, were boiled at $95^{\circ} \mathrm{C}$ for five minutes and centrifuged shortly prior to loading. A sample volume of $30 \mu \mathrm{l}$ was loaded into the pockets of the stacking gel. Additionally, a standard size either $5 \mu 1$ prestained or unstained protein ladder was loaded on the gel. The stacking gel was run with $25 \mathrm{~mA}$ for about $30 \mathrm{~min}$ and the separating gel with $35 \mathrm{~mA}$ for about 3 hours. Alternatively, the gel was run at $5 \mathrm{~mA}$ overnight.

\subsubsection{Western Blotting}

After protein separation via SDS-PAGE, the proteins were transferred to a nitrocellulose membrane to enable detection by specific antibodies and chemiluminescent substrates. This method was initially described in Towbin, Staehelin, \& Gordon (1979) and performed with modifications as indicated as follows. For Semi-Dry Western Blotting, Whatman paper, a nitrocellulose membrane, and the SDS gel were soaked in Blotting buffer.

Blotting buffer: $\quad 25 \mathrm{mM}$ Tris-Base $\mathrm{pH} 8.3$

$192 \mathrm{mM}$ Glycine

$20 \%$ (v/v) Methanol (freshly added)

Ponceau solution: $\quad 0.2 \%(\mathrm{w} / \mathrm{v})$ Ponceau S

$5 \%(\mathrm{v} / \mathrm{v})$ Glacial acetic acid

TBS-T (pH 7.4): $\quad 50 \mathrm{mM}$ Tris-Base $\mathrm{pH} 7.4$

$150 \mathrm{mM} \mathrm{NaCl}$

$0.1 \%(\mathrm{v} / \mathrm{v})$ Tween-20

The soaked Whatman paper was placed on the anode of the electro-blotter. First the nitrocellulose membrane and then the SDS gel were placed on the Whatman paper in this order. Then, another layer of Whatman Paper was added on the top. After that, air bubbles were removed from this blot sandwich and the cathode was installed. The blot was run with $1.5 \mathrm{~h}$ at $1.5 \mathrm{~mA} / \mathrm{cm}^{2}$. Afterwards, the membrane was incubated 2 min Ponceau solution, which stains rapidly aromatic amino acid, to control the efficiency of the transfer and to visualize the unstained protein marker if applicable. The Ponceau stain was washed away with TBS-T and the membrane was blocked in Blocking Buffer (5\% non-fat dried milk powder in TBS-T) for one hour. 


\subsection{Detection}

The primary antibody was diluted in TBS-T containing $2 \%$ non-fat dried milk powder. The membrane was incubated with the antibody at least 1 hour at RT or overnight at $4^{\circ} \mathrm{C}$. After incubation, the membrane was washed in TBS-T three times for five minutes. The secondary antibody, diluted in TBS-T containing $2 \%$ non-fat dried milk powder, was added to the membrane and incubated at room temperature for at least 1 hour. After incubation, the membrane was washed with TBS-T two times for five minutes and once with TBS. The detection was triggered by ECL solutions either selfmade or Amersham ${ }^{\mathrm{TM}}$ ECL $^{\mathrm{TM}}$ Prime Western Blotting Detection (GE Healthcare, Buckinghamshire (USA)). The signal was detected the Fusion FX7, an image acquisition device that captures chemiluminescence.

\subsubsection{RNA Co-immunoprecipitation (RIP)}

RNA co-Immunoprecipitation (RIP) was performed to analyze protein-RNA interaction/binding in vivo. For that, cell lysis was performed as generally described in section 3.8.1. Indeed, RNA-IP buffer was used for cell lysis and the cells were disrupted in the FastPrep machine at $6 \mathrm{~m} / \mathrm{s}$ for $20 \mathrm{sec}$.

$\begin{array}{ll}\text { RNA-IP buffer } \mathrm{pH} 7.5: & 25 \mathrm{mM} \text { Tris/HCl } \mathrm{pH} 7.5 \\ & 100 \mathrm{mM} \mathrm{KCl} \\ & 0.2 \%(\mathrm{v} / \mathrm{v}) \text { Triton-X-100 } \\ & 0.2 \mathrm{mM} \text { PMSF } \\ & 5 \mathrm{mM} \text { DTT } \\ & \text { Ribo Lock } \\ & \text { Protease Inhibitor }\end{array}$

$100 \mu \mathrm{l}$ from the cleared lysate were mixed with $1 \mathrm{ml}$ TRIZOL $^{\circledR}$ as RNA input control and $15 \mu 1$ from the cleared lysate were mixed with $15 \mu 12 x$ Sample buffer as protein input control. Both samples were frozen in liquid nitrogen and stored at $-20^{\circ} \mathrm{C}$ until usage. Precipitation of the protein of interest was carried out as described in section 3.8.2, except that RNA-IP was used and the beads were equally divided in fresh tubes during the last washing step. Half of the beads were mixed with $1 \mathrm{ml}$ TRIZOL $^{\circledR}$ for following isolation of the co-precipitated RNA and the other half of the beads were mixed with $30 \mu 12 x$ Sampler buffer for subsequent western blotting. Western blotting was performed to control the precipitation of the protein of interest 
and was carried out as described in section 3.8.3. RNA was purified as described in section 3.7.1.3.

\subsubsection{Chromatin immunoprecipitation (ChIP)}

Chromatin immunoprecipitation (ChIP) studies were performed to analyze whether proteins are co-transcriptionally loaded to emerging transcripts or even are associated to DNA. For that, 50 $\mathrm{ml}$ yeast cultures were grown to $\log$-phase $\left(\sim \mathrm{OD}_{600}=1,2\right)$ and cross-linked by the addition of $1,39 \mathrm{ml}$ formaldehyde ( $1 \%$ final). The cells were incubated for $10 \mathrm{~min}$ at RT and were mixed by gently swirling every two minutes. After this incubation, the cross-linking reaction was stopped by adding 2,75 $\mathrm{ml}$ of 2,5 $\mathrm{M}$ glycine (125 mM final) and incubating for $5 \mathrm{~min}$ at RT with swirling. Then, the cells were pelleted by centrifugation at $4000 \mathrm{~g}$ for $10 \mathrm{~min}$ at $4{ }^{\circ} \mathrm{C}$, washed once with $20 \mathrm{ml}$ cold TBS $+125 \mathrm{mM}$ glycine, washed once in $20 \mathrm{ml}$ cold TBS and finally resuspended in $1 \mathrm{ml}$ TBS. The suspension was transferred in a 2-ml screw top tube and pelleted at $21000 \mathrm{~g}$ and $4^{\circ} \mathrm{C}$ for $30 \mathrm{sec}$. The pellets were either frozen in liquid nitrogen and stored at $-80^{\circ} \mathrm{C}$ until usage or directly used for cell lysis. For lysis, the cell pellets were resuspended in $400 \mu \mathrm{l}$ and $20 \mu \mathrm{l}$ protease inhibitor and furthermore an equal amount $(\sim 500 \mu \mathrm{l})$ of glass beads were added.

ChIP lysis buffer:

ChIP lysis buffer: $\underline{\text { (High Salt) }}$

ChIP wash buffer:
50mM HEPES pH 7,5

$140 \mathrm{mM} \mathrm{NaCl}$

$1 \%$ Triton

$0,1 \%$ Sodium deoxycholate

1 mM EDTA

50mM HEPES $\mathrm{pH} 7,5$

$500 \mathrm{mM} \mathrm{NaCl}$

$1 \%$ Triton

$0,1 \%$ Sodium deoxycholate

1 mM EDTA

$10 \mathrm{mM}$ TRIS $\mathrm{pH} 8,0$

$250 \mathrm{mM} \mathrm{LiCl}$

$0,5 \%$ NP-40

$0,5 \%$ Sodium deoxycholate

$1 \mathrm{mM}$ EDTA 


\section{ChIP elution buffer: $\quad 50 \mathrm{mM}$ TRIS $\mathrm{pH} 8,0$ \\ $1 \%$ SDS \\ $10 \mathrm{mM}$ EDTA}

The cells were disrupted using the Fast Prep machine at $4,5 \mathrm{~m} / \mathrm{s}$ for $40 \mathrm{sec}$ three times. After that, the lids of the screw top tubes were removed, and the bottom was pierced with a hot $20 \mathrm{G}$ needle. The pierced tubes were put into $15 \mathrm{ml}$ falcon tubes and these were centrifuged at 4000 $\mathrm{g}$ and $4{ }^{\circ} \mathrm{C}$ for five minutes. After that, the cell extract was transferred completely into the 15 $\mathrm{ml}$ falcon tubes, but the glass beads were still in the screw top tubes and were easily discarded. The insoluble pellet of the cell extract was emulsified, and everything was transferred into a 2$\mathrm{ml}$ round bottom tube. The cell extracts were sonicated using a water bath sonicator at level 5 and $100 \%$ duty for 2,5 min. After clarification of the extracts by centrifugation at top speed for $10 \mathrm{~min}$, the supernatants were transferred into fresh $1,5 \mathrm{ml}$ tubes and the protein amount was determined using the NanoDrop. 1mg of total protein was diluted in $200 \mu \mathrm{l} \mathrm{ChIP} \mathrm{lysis} \mathrm{buffer}$ and used for immunoprecipitation. From this, $2 \mu 1$ were transferred into a fresh tube, mixed with $150 \mu \mathrm{l} \mathrm{ChIP}$ elution buffer and put aside as input samples. For immunoprecipitation, the GFP-tagged proteins were pulled down using the GFP-trap beads. $10 \mu \mathrm{l}$ of the beads were washed three times with $250 \mu \mathrm{l} \mathrm{ChIP} \mathrm{lysis} \mathrm{buffer}$ and after that the washed beads were added to the $200 \mu 1$ samples. The samples were then incubated for one hour in the cold room with end over end rotation. After that, the beads were spun down at $400 \mathrm{~g}$ and $4{ }^{\circ} \mathrm{C}$ for $1 \mathrm{~min}$ and washed two times with $1 \mathrm{ml}$ ChIP lysis buffer, two times with $1 \mathrm{ml}$ ChIP lysis buffer high salt, two times with $1 \mathrm{ml}$ ChIP wash buffer and two times with 1x TE $(\mathrm{pH} \mathrm{8,0).} \mathrm{The} \mathrm{beads} \mathrm{were}$ resuspended in $85 \mu \mathrm{l}$ of $\mathrm{ChIP}$ elution buffer and incubated at $65{ }^{\circ} \mathrm{C}$ and $950 \mathrm{rpm}$ in a thermomixer for $10 \mathrm{~min}$. Afterwards, the beads were spun down and the supernatant was transferred into a fresh tube. Again $75 \mu \mathrm{l} \mathrm{ChIP} \mathrm{elution} \mathrm{buffer} \mathrm{was} \mathrm{added} \mathrm{to} \mathrm{the} \mathrm{beads} \mathrm{and} \mathrm{the}$ elution step was repeated. Both, the $150 \mu \mathrm{l}$ IP sample and the $150 \mu \mathrm{l}$ input sample were incubated at $65^{\circ} \mathrm{C}$ overnight to reverse crosslinks. The DNA was purified using the NucleoSpin Gel and PCR Clean-up Kit (Macherey Nagel) and eluted in $50 \mu 1$ of nuclease-free $\mathrm{H}_{2} \mathrm{O}$. The purified DNA was directly used for qPCR analyses. 


\subsection{Microscopic studies}

\subsubsection{GFP microscopy}

GFP microscopy was used to determine the subcellular localization of a specific protein tagged with GFP in formaldehyde-fixed cells as described previously in Windgassen \& Krebber (2003). For this method, $10 \mathrm{ml}$ culture was grown to $2-3 \times 10^{7}$ cells $/ \mathrm{ml}$ at $25^{\circ} \mathrm{C} .5 \mathrm{ml}$ of the culture was shifted to $37^{\circ} \mathrm{C}$ for an appropriate time generally between 30 min and 3 hours. Subsequently after the shift, the cells were fixed by adding $350 \mu 137 \%$ formaldehyde and were immediately spun down at $2000 \mathrm{~g}$ and $4^{\circ} \mathrm{C}$ for 5 minutes.

\section{$0.1 \mathrm{M}$ phosphate-buffer ( $\mathrm{pH} 6.5): 33 \mathrm{mM} \mathrm{K} 2 \mathrm{HPO} 4$} $67 \mathrm{mM}$ KH2PO4

P-solution ( $\mathrm{pH} 6.5): \quad 0.1 \mathrm{M}$ phosphate-buffer $\mathrm{pH} 6.5$

1.2 M sorbitol

Aby Wash 2:

$0.1 \mathrm{M}$ Tris $\mathrm{pH} 9.5$

$0.1 \mathrm{M} \mathrm{NaCl}$

Mounting media ( $\mathrm{pH} 8.0)$ :

$2 \%(\mathrm{w} / \mathrm{v})$ n-Propyl gallate

$80 \%$ (v/v) Glycerol

in PBS (pH 8.0)

The cells were washed once in $1 \mathrm{ml} \mathrm{0,1} \mathrm{M}$ phosphate buffer and once in $1 \mathrm{ml}$ P-solution and finally resuspended in $100 \mu \mathrm{l}-1 \mathrm{ml}$ P-solution depending on the amount of the cells. For microscopy, a polylysine- treated slide was prepared. For that, $20 \mu 10,3 \%$ polylysine was applied to each well and incubated for $5 \mathrm{~min}$ at RT. The wells were once rinsed with water and dried at RT. Then, $20 \mu 1$ of the cells were brought on the polylysine coated slide and incubated for $15 \mathrm{~min}$ at RT. Excess of cell suspension was aspirated off and $20 \mu 1$ 0,5\% Triton-X100 diluted in P-solution was added to permeabilize the cells. The cells were once washed with Psolution and once washed with Aby wash 2. The nuclei were stained with DAPI (diluted 1:10000 in Aby wash 2) for 3min and afterwards washed three times with Aby wash 2. The slides were dried at $37^{\circ} \mathrm{C}$ and kept in the dark to prevent bleaching of the GFP and DAPI signal. Finally, the slides were mounted with mounting media, decorated with a coverslip, sealed with clear nail polish and observed under the fluorescence microscope with the respective filter and channel setting using the $63 \mathrm{x}$ magnification. 


\subsection{Quantification and statistical analysis}

Intensities of chemiluminescent signals obtained from Western blot analyses were measured and quantified using the Bio1D Software (Peqlab). For Co-immunoprecipitation analyses, the band of the pull-down was related to the band of the interaction partner. Then, the ratio of the wild type was set to $100 \%$ and the ratios of mutant/deletion strains were related to the wild type. Northern blot signals intensities were measured using the Fiji software. After subtraction of the background signal, the relative intensities were calculated. For statistical analyses an unpaired, two-sided students t-test was used. P-values were calculated by applying equal or unequal variance depending on the type of experiment and are indicated as follows: ***: $\mathrm{p}<0.001, * *: \mathrm{p}<0.01, *: \mathrm{p}<0.5$. 


\section{Results}

\subsection{The role of $\mathrm{Npl3}$ in mRNA surveillance}

The general RNA-binding protein $\mathrm{Npl3}$ accompanies mRNAs during their entire maturation and shuttles with export competent mRNPs into the cytoplasm. It is co-transcriptionally loaded to the 5'-end of an emerging mRNA via the CTD of RNAP II and interacts with the CBC (Shen et al., 2000; Lei, Krebber and Silver, 2001; Baejen et al., 2014). Once loaded onto an mRNA, $\mathrm{Npl3}$ is involved in the recruitment of the spliceosome and furthermore it functions as an adapter for the export receptor heterodimer Mex67-Mtr2 and thereby promotes the nuclear export of mRNPs (Hurt et al., 2000; Huang and Steitz, 2005; Kress, Krogan and Guthrie, 2008). Because it was shown that the two other SR-proteins Gbp2 and Hrb1 are key surveillance factors for intron-containing mRNAs (Hackmann et al., 2014), the question arose whether Npl3 has also a function in quality control of mRNAs. Due to the fact, that Np13 in contrast to Gbp2 and Hrb1 is early loaded to the 5'-end of an emerging mRNA it could be possible, that Npl3 monitors capping as first mRNA processing event. This idea is supported by the finding that Npl3 interacts genetically with Cet1 (Dr. Gesa Zander, Phd thesis), which together with Ceg1 form the capping enzyme. Cet1 and Ceg1 are both essential factors that carrying out the conversion of the free 5' end into a capped mRNA whereby Cet1 acts as the 5'-triphosphatase. The $t s$ mutant strain cet $1-2$ alone exhibited a mild growth defect at $30^{\circ} \mathrm{C}$ in comparison to wild type, whereas the combination with the $n p l 3 \Delta$ deletion strain, cet1-2 $n p l 3 \Delta$, showed a severe growth defect (Dr. Gesa Zander, Phd thesis). Moreover, it was shown that Npl3 accumulates in the nucleus of cet1-2 and the ts mutant of Ceg1, cegl-3, upon a temperature shift to nonpermissive temperature (Heike Krebber, unpublished results). This indicates, that Npl3 might bind to aberrant transcripts which are produced in cet1-2 and ceg1-3 and may retain these transcripts in the nucleus for degradation.

\subsubsection{Npl3 is loaded to pre-mRNA after capping is completed}

As it was previously supposed that $\mathrm{Npl} 3$ only binds emerging mRNA if the $\mathrm{m}^{7}-\mathrm{G}$ cap is properly processed (Shen et al., 2000), the question arose at which time point Npl3 is loaded to emerging transcripts. It would be possible, that Npl3 is either loaded at the same time as the capping enzyme and monitors the capping reaction or that $\mathrm{Npl3}$ is loaded after capping is completed and check the presence of a proper cap structure. To test this, physical interaction studies between the factors of the capping enzyme, Cet1 and Ceg1, and Npl3 were performed in vivo. 
For that, co-immunoprecipitation studies were conducted using a cet $1 \Delta 2$ strain expressing plasmid derived Cet1-GFP or a cegl $1 \Delta$ strain expressing plasmid derived Ceg1-GFP. The GFPtagged proteins were precipitated and co-precipitated Npl3 was detected using its direct antibody. Hem15 served as a negative control. As seen in figure 13, Npl3 did not co-purify either with Cet1 or Ceg1, not even in an RNA-mediated manner. This result strongly suggests, that Npl3 is loaded to emerging mRNAs when the capping reaction is completed, and the capping enzyme is already released.

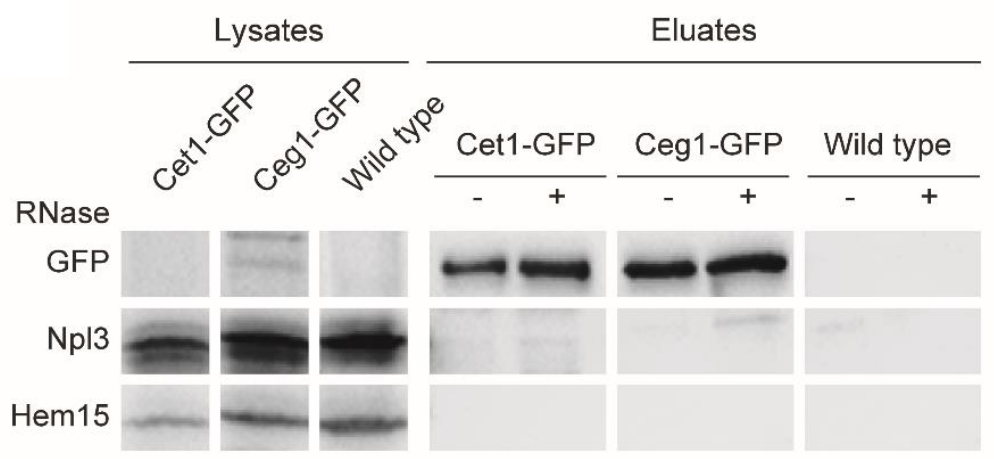

Figure 13: Npl3 does not physically interact with the capping enzyme in vivo.

Cells were grown to late logarithmic growth phase and subjected to a co-immunoprecipitation. GFP-tagged proteins were precipitated and detected in western blot analysis with GFP-specific antibodies. Co-precipitated $\mathrm{Npl3}$ was detected with antibodies directed againts the protein. One sample of each was treated with RNase (+/-). Antibodies against Hem15 and precipitation from a lysate without any tagged protein served as negative controls.

\subsubsection{Npl3 prevents leakage of uncapped pre-mRNAs into the cytoplasm}

As mentioned before, unpublished data suggest that Npl3 accumulates in the nucleus of cet 1-2 and ceg1-3 upon temperature shift (Heike Krebber, unpublished results), suggesting that Npl3 is important to retain aberrantly or uncapped pre-mRNAs in the nucleus. To further investigate this hypothesis, the amount of uncapped mRNAs in the cytoplasm was compared among the cet 1-2 single mutant and the cet 1-2npl3 $\Delta$ double mutant. To analyze whether Npl3 is required to retain uncapped or aberrantly capped transcripts in the nucleus for subsequent degradation, a deletion strain of NPL3 combined with the cet1-2 mutation strain was used. This strain probably produces uncapped or improper processed pre-mRNAs that might not be retained in the nucleus in the absence of $\mathrm{Npl} 3$ and thus would result in a leakage of these pre-mRNAs into the cytoplasm. 
For this experiment, it was first analyzed whether the $t s$ mutation cet1-2 produces uncapped or improper processed pre-mRNAs, which are usually substrates for the degradation machinery. To test this, total RNA was isolated from wild type and cet1-2 mutant cells after 2 hours temperature shift to $37^{\circ} \mathrm{C}$. The isolated RNA was incubated with the 5'-3' exonuclease Xrn1, which degrades uncapped RNAs. After Xrn1 digestion, the amount of specific mRNAs was compared between wild type and cet 1-2 using qRT-PCR. In cet 1-2 cells, the number of mRNAs was reduced to less than $50 \%$ upon Xrn1 digestion in relation to wild type (Figure 14a). This

$\mathbf{a}$

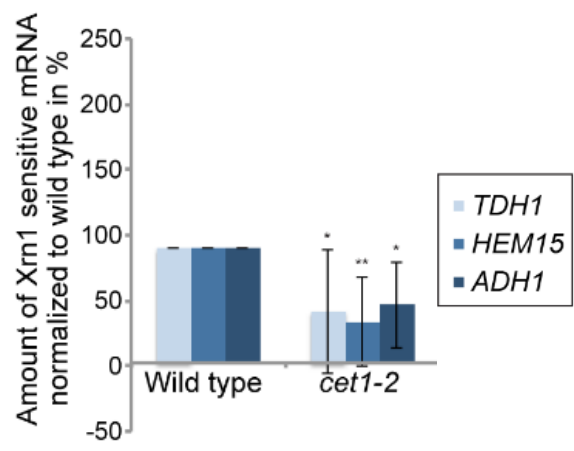

b

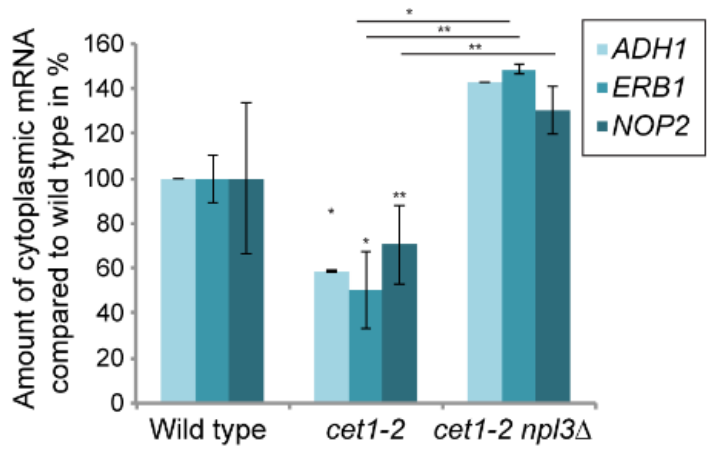

c

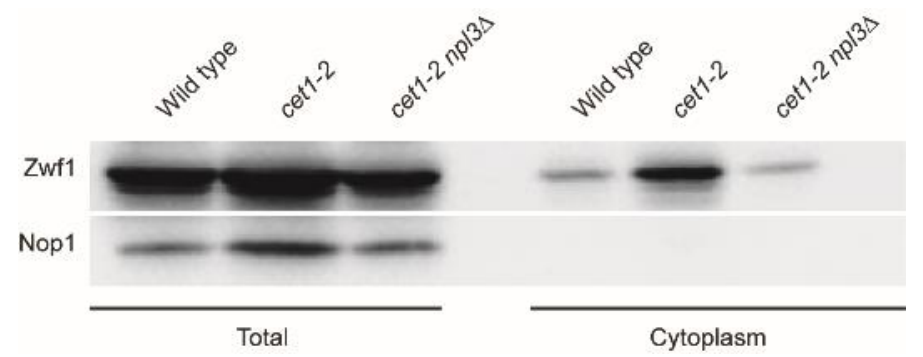

Figure 14: Deletion of NPL3 leads to a leakage of uncapped mRNAs into the cytoplasm.

a) Log phase cells of the indicated strains were shifted for 2 hours to $37^{\circ} \mathrm{C}$ and total RNA was isolated. Uncapped RNAs were degraded by Xrn1 digestion for 2 hours. Xrn1 digested samples were applied for cDNA synthesis and subsequent qRT-PCR analysis using primer pairs for the indicated specific mRNAs. Cq-values of the eluates were first normalized to the total RNA samples prior to digestion and then the values deriving from cetl-2 were related to wild type. Average and standard deviation were calculated and an unpaired two-sample t-test was performed. $(* * *: \mathrm{p} \leq 0.001, * *: \mathrm{p} \leq 0.01, *: \mathrm{p} \leq 0.05)$

b) Cytoplasmic fractionation including a two-hour temperature shift and subsequent RNA isolation was performed in the indicated strains. Cytoplasmic RNA was subjected to cDNA synthesis and qRT-PCR using primer pairs for the indicated specific mRNAs. Cq-values of the eluates were first normalized to the total RNA and then the values were related to wild type. Average and standard deviation were calculated and an unpaired two-sample t-test was performed. $(* * *: p \leq 0.001, * *: p \leq 0.01, *: p \leq 0.05)$

c) Cytoplasmic fractionation was controlled by detection of the cytoplasmic protein Zwf1 and nucleolar protein Nop1 with specific antibodies by western blotting. 
indicates, that after two hours of shift in cetl-2 aberrantly or uncapped pre-mRNAs are produced, which are substrates of the degradation machineries. To further address the question whether Npl3 is important to retain aberrant or uncapped transcripts in the nucleus for nuclear degradation, cytoplasmic fractionation and subsequent qRT-PCR analyses were performed. The amount of specific mRNAs in the cytoplasm were compared between the cet1-2 single mutant and the combination cet 1-2 npl3A. In the cytoplasm of the cet 1-2 single mutant, the number of mRNAs was significantly reduced (Figure 14b). This could be due to the fact, that aberrantly or uncapped pre-mRNAs, which were produced in cet1-2, are rapidly degraded in the nucleus and therefore the number of mRNAs reaching the cytoplasm is reduced in comparison to wild type. Interestingly, the number of mRNAs in the cytoplasm is significantly enriched upon deletion of NPL3 in comparison to the single mutant cet1-2 (Figure 14b). This finding shows, that deletion of NPL3 results in a leakage of aberrantly or uncapped pre-mRNAs, which are produced at the non-permissive temperatures in cet1-2. These results suggest, that Npl3 is important to retain premature capped transcripts into the nucleus.

\subsubsection{Npl3 cooperates with the 5' to 3'-end degradation machinery}

As the previous experiments revealed that Npl3 is important to surveil the capping reaction, the question arose whether Npl3 interacts with the RNA degradation machinery that attacks aberrant capped transcripts. It has been reported previously, that the capping event occurs already upon synthesis of a $\sim 20 \mathrm{nt}$ long transcript (Coppola, Field and Luse, 1983), thus it is likely that the degradation of aberrant capped transcripts occur primarily from 5 'to 3 'direction. Furthermore, it has been shown, that the exonuclease Rat1 together with its co-factor Rai1 is responsible for the 5'- 3' degradation of uncapped mRNA. Rail was reported to exhibit a decapping endonuclease activity and furthermore to be involved in recognition of uncapped or unmethylated mRNAs, however the precise mechanisms are still unclear (Xiang et al., 2009; Jiao et al., 2010; Jimeno-González et al., 2010).

\subsubsection{Npl3 genetically interacts with the 5' to 3'-end degradation machinery}

To get a first hint, whether Npl3 works together with the 5' to 3'-end degradation machinery a drop dilution assay was performed with an NPL3 deletion strain in combination with either a mutant of $R A T 1$, rat1-1, or a deletion of RAI1, rail 1 . For that, the strain combination of $n p l 3 \Delta$

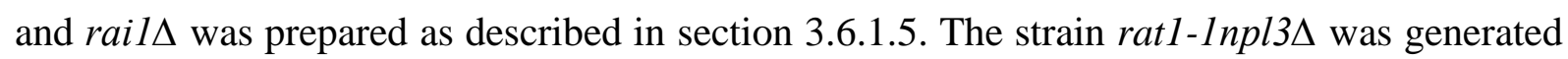
previously (Dr. Gesa Zander, Phd Thesis). If Npl3 is involved in recognizing aberrant or 


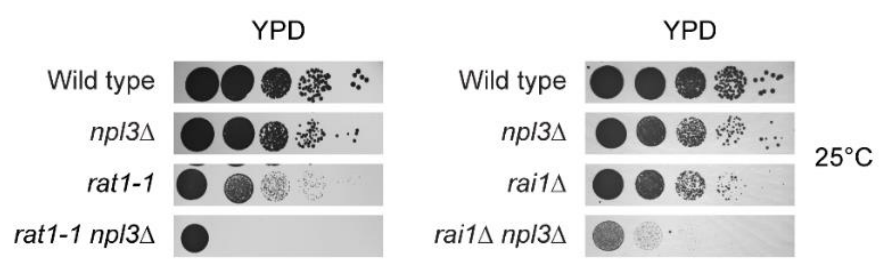

Figure 15: Deletion of NPL3 combined with a mutant of the nuclear 5 ' exonuclease RAT1 or a deletion of its co-factor $R A I I$ lead to severe growth defects.

Serial dilutions of the indicated strains were spotted onto full media containing plates and incubated at $25^{\circ} \mathrm{C}$ for 3 days.

uncapped pre-mRNAs or in recruiting the degradation machinery to these transcripts, it is likely that the absence of both, $\mathrm{Npl3}$ and a factor of the degradation machinery, would lead to an increased number of faulty transcripts that might overwhelm the nuclear compartment and thus leak uncontrolled into the cytoplasm. This in turn will intervene with growth and proliferation of the cell. Here, it was shown that both, the deletion of RAII rail $\triangle$ and the mutant of RATI rat1-1, in combination with the deletion of $N P L 3 \mathrm{npl} 3 \Delta$ result in a severe growth defect even at $25^{\circ} \mathrm{C}$ (Figure 15). This suggests, that $\mathrm{Npl3}$ cooperates with the Rat1-Rai1 mediated 5' to 3' degradation.

\subsubsection{Npl3 physically interacts with the 5' to 3' exonuclease Rat1 and its cofactor Rai1 in vivo}

The next step to investigate the interplay between Npl3 and the Rat1-Rai1 degradation system was to analyze if they would physical interact in vivo. If $\mathrm{Npl} 3$ is indeed a quality control factor for aberrant or uncapped transcripts, it is likely that it interacts with its degradation machinery. To test this, endogenously tagged Rai1-GFP and Rat1-GFP were immunoprecipitated and copurified Np13 was detected with an anti-Npl3 antibody. Hem15 served as a negative control. As shown in figure 16, Npl3 co-purified RNA independent with Rail and RNA mediated with Rat1. This result show, that $\mathrm{Npl3}$ indeed interacts with the 5' to 3' degradation machinery.

\subsubsection{Npl3 is required to recruit the 5'-3'-end degradation machinery}

Because the previous experiment showed that $\mathrm{Npl3}$ is important to control the capping event and physically and genetically interacts with the 5' to 3 ' degradation machinery Rat1 and Rai1, the question arose whether $\mathrm{Npl3}$ is required for its recruitment. If $\mathrm{Npl} 3$ controls whether premRNAs exhibit proper cap structures, it is possible that $\mathrm{Npl} 3$ recruits the degradation machinery 

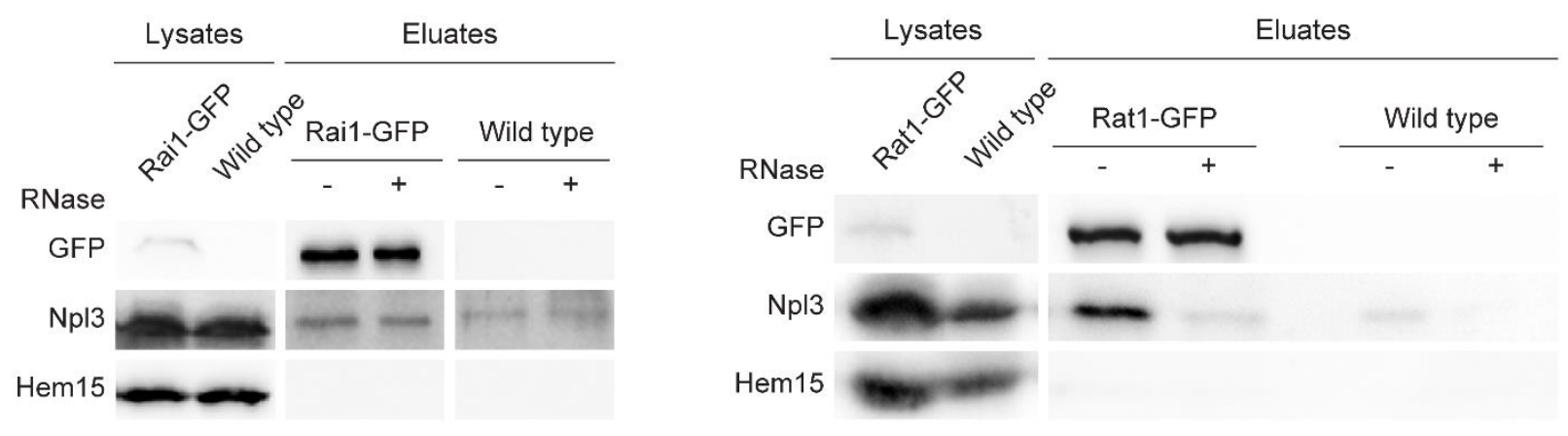

Figure 16: Npl3 physically interacts with the 5'-3' degradation machinery Rat1-Rai1 in vivo.

Cells were grown to late logarithmic growth phase and subjected to a co-immunoprecipitation. GFP-tagged proteins were precepitated and detected in western blot analysis with the GFP-specific antibody. Co-precipitated Npl3 was detected with antibodies against the protein. One sample of each was treated with RNase (+/-). Antibodies against Hem15 and precipitation from a lysate without any tagged protein served as negative control

to aberrant capped pre-mRNAs or that Npl3 servers as a signal for its recruitment. To investigate this, RIP experiments were performed. For that, the endogenously tagged strains Rat1-GFP and Rai1-GFP were combined with the deletion of NPL3 npl3A as described in section 3.6.1.5. These NPL3 deleted strains, the wild type strains expressing either Rai1-GFP or Rat1-GFP and moreover non-tagged wild type controls were used for the following RIP experiments. The GFPtagged proteins were immunoprecipitated and the co-precipitated RNA was analyzed and quantified using qRT-PCR. These experiments revealed, that both, Rail and Rail, bound significantly less mRNA in $n p l 3 \Delta$ than in a wild type background (Figure 17), suggesting, that Npl3 is required to recruit the 5' to 3' mRNA degradation machinery. Together with the previous data, this indicates that $\mathrm{Npl3}$ is necessary to control whether pre-mRNAs exhibit a proper cap structure and if not, it is important to recruit the 5' to 3' degradation machinery to these aberrant transcripts. Furthermore, our data suggest that Npl3 interacts with the Rat1-Rail degradation system via Rai1, as it interacts RNA independent with Rai1, but RNA dependent with Rat1.

\subsubsection{Binding between the export receptor Mex67 and Npl3 is impaired upon disturbed capping}

Our results indicate, that $\mathrm{Npl3}$ is loaded to emerging pre-mRNA after the capping reaction is completed and control proper 5' capping. Furthermore, we show that Npl3 retains aberrantly capped pre-mRNAs in the nucleus and is moreover required to recruit the 5' to 3' degradation machinery for degradation of such aberrant pre-mRNAs. However, how export of aberrant transcripts is prevented is unclear. It was shown previously, that the export of spliced transcripts is controlled by an exclusive binding of either the exosome co-factor Mtr4 to the SR-protein 

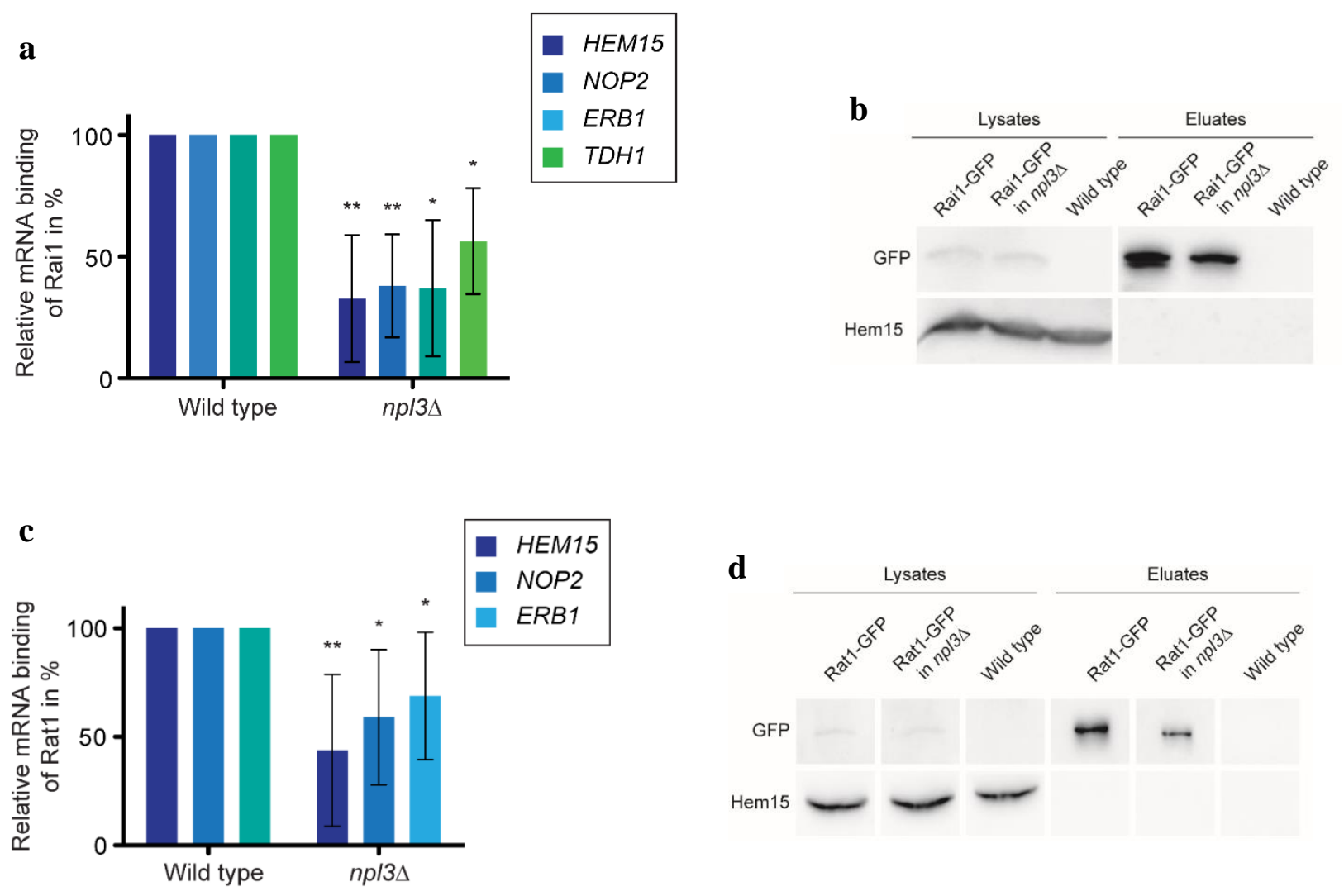

Figure 17: Npl3 is required to recruit the 5' -3 ' mRNA degradation machinery.

Rai1-GFP or Rat1-GFP was pulled with GFP-trap beads in the Rai1-/Rat1 wildtype and $n p l 3 \Delta$ strains. As negative control a wildtype strain without any tagged protein was used and treated equally.

a,c) RNA was isolated from eluate samples and lysate controls. 200ng of isolated RNA were transcribed into cDNA using random hexamer primers. A two-step qPCR was performed and the resulting $\mathrm{Cq}$ values of lysate controls were subtracted from the corresponding eluate $\mathrm{Cq}$ value, which were then normalized to the no tag control. Furthermore, the binding of Rai1/Rat1 in npl3 $\Delta$ samples was related to the wild type samples. Average and standard deviation were calculated from at least three independent samples and an unpaired two-sample t-test was performed (***: $\mathrm{p} \leq 0.001, * *: \mathrm{p} \leq 0.01, *: \mathrm{p} \leq 0.05)$.

b,d) Proper Rai1-/Rat1-GFP pulldown was confirmed by western blot analysis. Rai1-/Rat1-GFP was detected with a GFP-specific antibody. Hem15 was detected with its direct antibody.

Gbp2 or the export receptor Mex67 (Hackmann et al., 2014). Therefore, it seems possible that a similar mechanism exists for the Npl3 mediated quality control at the 5' cap. If Npl3 is indeed required to retain aberrant capped transcripts, it is likely that its binding to the export receptor Mex67 is reduced in cet $1-2$ and rat1-1 cells. This could additionally be a first hint that there is a similar exclusive binding of the degradation machinery or Mex67 to Npl3. To investigate this, co-immunoprecipitation analysis was performed. For this, cet $1-2$ and rat $1-1$ as well as a wild type strain were transformed with a plasmid containing Myc-tagged Npl3. These strains as well as a non-tagged wild type control were shifted for 2 hours to $37^{\circ} \mathrm{C}$ before the Myc-tagged Npl3 was precipitated from cell lysates. Co-purified Mex67 and Hem15 were detected with 
$\mathbf{a}$

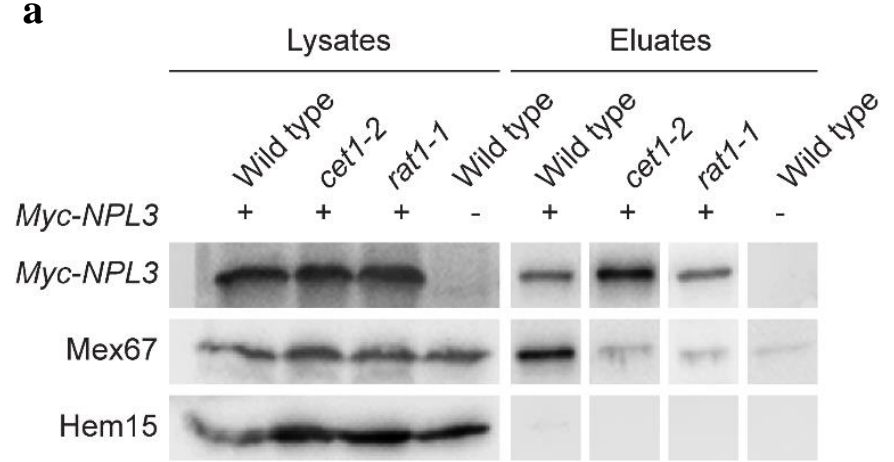

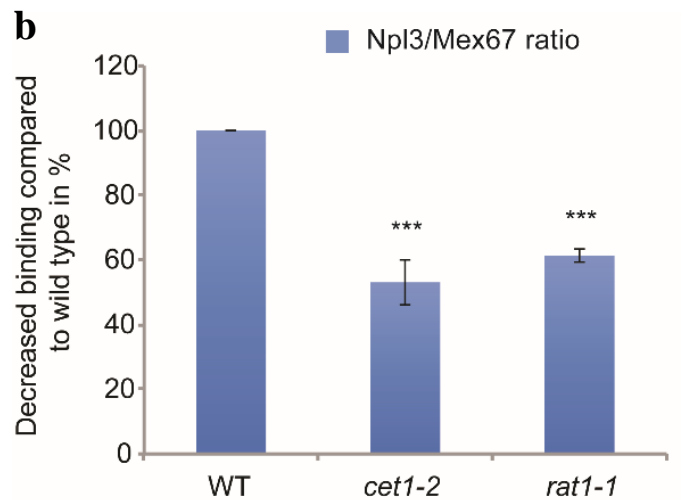

Figure 18: Reduced binding between $\mathrm{Npl3}$ and Mex67 upon generation of aberrant capped transcripts.

a) Cells were grown to logarithmic growth phase, shifted for 2 hours at $37^{\circ} \mathrm{C}$ and subjected to a Coimmunoprecipitation. MYC-tagged proteins were precepitated and detected in western blot analysis with the MYCspecific antibody. Co-precipitated Mex67 was detected with its direct antibody. Antibodies against Hem15 and precipitation from a lysate without any tagged protein served as negative control.

b) Signal intensities were measured and set in relation to wild type. Average and standard deviation was calculated and a two-tailed, two sample, unequal variance t-test was performed $\left({ }^{* *}: \mathrm{p} \leq 0.001,{ }^{* *}: \mathrm{p} \leq 0.01,{ }^{*}: \mathrm{p} \leq 0.05\right)$.

antibodies against the proteins. As shown in figure 18, binding of Mex67 to Npl3 is clearly reduced in cet 1-2 and rat1-1 compared to wild type. This supports the idea, that Npl3 retains aberrant capped transcripts in the nucleus and furthermore this could be a first hint that there is an exclusive binding of the export receptor Mex67 and possibly factors of the degradation machinery.

\subsubsection{Npl3 cooperates with the TRAMP-complex mediated degradation machinery of false mRNAs}

As the previous data indicated that Npl3 is important for the 5' to 3' degradation of pre-mRNAs it might be possible that $\mathrm{Npl} 3$ is also involved in the 3' to 5' degradation. It is currently unclear, whether the degradation of aberrant or uncapped pre-mRNAs is only facilitated by the exonuclease Rat1 together with Rai1 in 5' to 3' direction or whether these transcripts are also degraded by the nuclear exosome in 3 ' to 5' direction. Npl3 does not only bind to the 5 ' end of mRNAs, it is also supposed to promote transcription elongation and prevent premature termination by competing with cleavage and polyadenylation factors. It was speculated, that phosphorylation of Npl3 by CKII reduces its binding to mRNA and thereby enables the binding of termination factors (Bucheli and Buratowski, 2005; Dermody et al., 2008). Additionally, it 
was suggested that the Glc7-mediated dephosphorylation of Npl3 supports the nuclear export of the export-competent mRNP (Gilbert and Guthrie, 2004).

Additionally, it was shown previously that deletion of NPL3 in combination with a deletion of either AIR1 or AIR2 resulted in a mild growth defect. Deletion of NPL3 combined with the deletion of TRF5 also led to a mild growth defect, while the double deletion of NPL3 and TRF4 led to a severe growth defect. Double deletion of NPL3 and the nuclear exosome component $R R P 6$ as well as the combination of a thermosensitive mutant of MTR4, $m$ tr $4 G 677 D$, with $n p l 3 \Delta$ led to a growth defect (Heike Krebber, unpublished results). This leads to the idea, that Npl3 might be also important to control further maturation steps together with the nuclear exosome and the TRAMP complex, which are required to recognize and degrade faulty mRNAs from their 3 '-ends.

\subsubsection{Npl3 physically interacts with factors of the TRAMP complex, but not with the exosome factor Rrp6}

To investigate whether Npl3 cooperates with the TRAMP-complex mediated quality control, physical interaction studies were performed. For that, co-immunoprecipitation was carried out with each TRAMP component and the nuclear exosome component Rrp6. To test the interaction between Npl3 and the two RNA-binding proteins Air1-GFP and Air2-GFP as well as the two TRAMP polymerases Trf4-GFP and Trf5-GFP, endogenously GFP-tagged strains were used. GFP-tagged proteins were precipitated and co-precipitated Npl3 was detected. As shown in figure 19a, Npl3 co-purifies with both Air proteins Air1 and Air2 independently of the presence of RNA. Furthermore, Npl3 also interacts with both, Trf4 and Trf5, but this interaction is dependent of the presence of RNA (Figure19b). To investigate a potential physical interaction between Npl3 and the TRAMP complex component Mtr4, a wild type strain was transformed with either a plasmid containing myc-tagged Npl3 or an empty plasmid as control. Myc-tagged Npl3 was precipitated and co-precipitated Mtr4 was detected with Mtr4-specific antibodies. As shown in figure 19c, Npl3 does not physically interact with Mtr4. Physical interaction between the nuclear exosome component Rrp6 and Npl3 was analyzed using a strain that endogenously expresses GFP-tagged Rrp6. GFP-tagged Rrp6 was precipitated and co-purified Npl3 was detected with protein specific antibodies. It was shown, that Npl3 does not co-purify with Rrp6 (Figure 19d). These data implicate, that Npl3 potentially cooperates with the TRAMP-exosome 

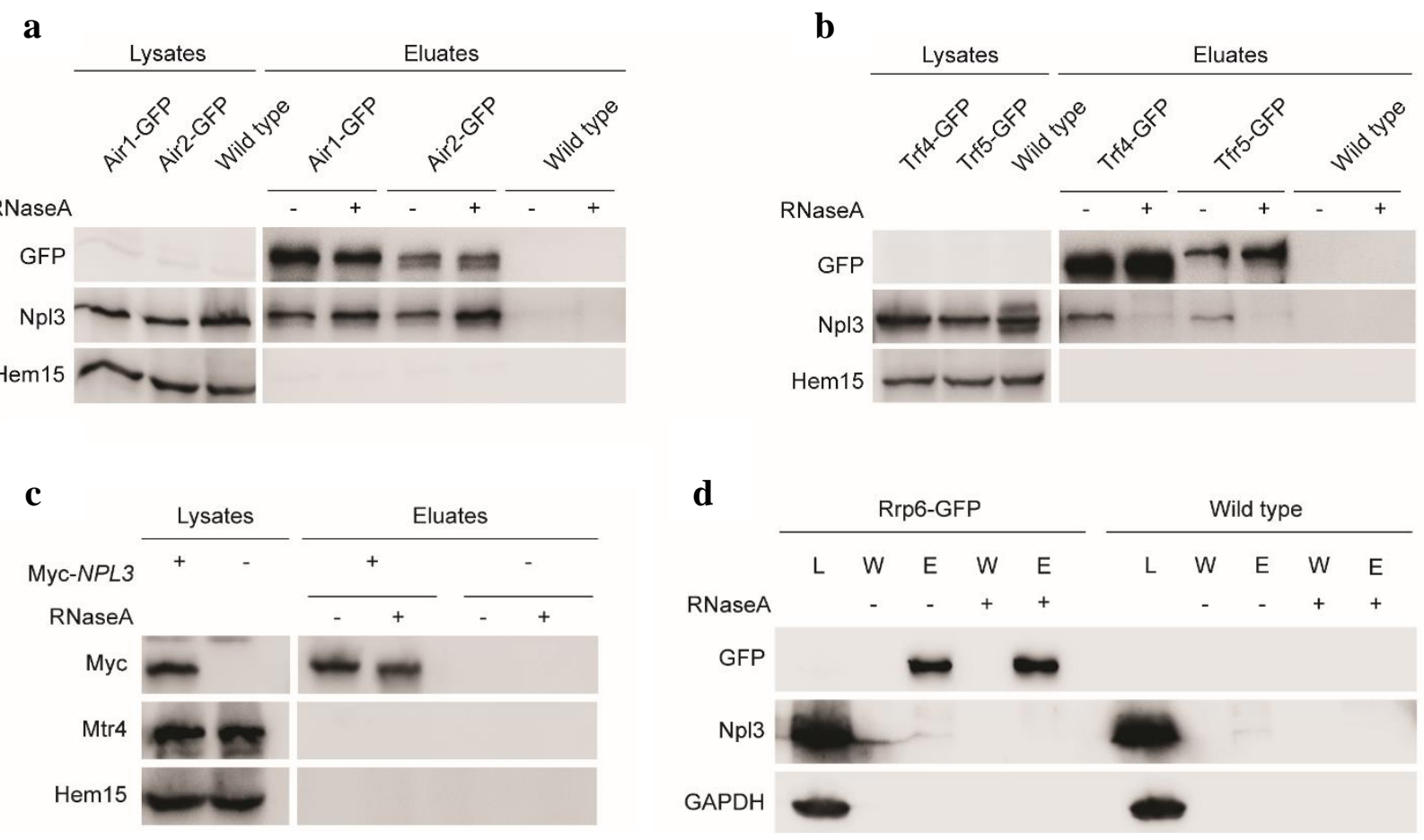

Figure 19: Npl3 physically interacts with Air1 and Air2 RNA-independently and in dependence of RNA with Trf4 and Trf5, but not with Mtr4 and Rrp6.

Cells were grown to late logarithmic growth phase and subjected to a co-immunoprecipitation.

a,b) GFP-tagged proteins were precipitated and detected in western blot analysis with GFP-specific antibodies. Coprecipitated $\mathrm{Npl} 3$ was detected with antibodies against the protein.

c) Npl3-myc was precipitated and detected in western blot analysis with myc-specific antibodies. Co-precipitated Mtr4 was detected with antibodies against the protein.

d) GFP-tagged Rrp6 was precipitated and detected in western blot analysis with GFP-specific antibodies. Coprecipitated Npl3 was detected with antibodies against the protein. A sample of the last washing step (W) controls proper washing. Antibodies against GAPDH and precipitation from a lysate without any tagged protein served as negative control.

a-c) Antibodies against Hem15 and precipitation from a lysate without any tagged protein served as negative control. a-d) One sample of each lysate was treated with RNase (+/-).

mediated surveillance system, but physical interactions seem to be restricted to the RNA binding proteins Air1 or Air2.

\subsubsection{Npl3 is required to recruit the 3' to 5' end degradation machinery}

The previous experiments revealed that Npl3 cooperates with the TRAMP complex and the nuclear exosome. The nuclear exosome together with the TRAMP complex is required to process and degrade several kinds of RNAs including mRNAs, rRNAs, snoRNAs, snRNAs and tRNAs. Aberrant mRNAs are degraded by the exosome in 3' to 5' direction and by Rat1 in 5' to 3' direction, whereby the majority is degraded via the exosome (Bernstein and Toth, 2012). 

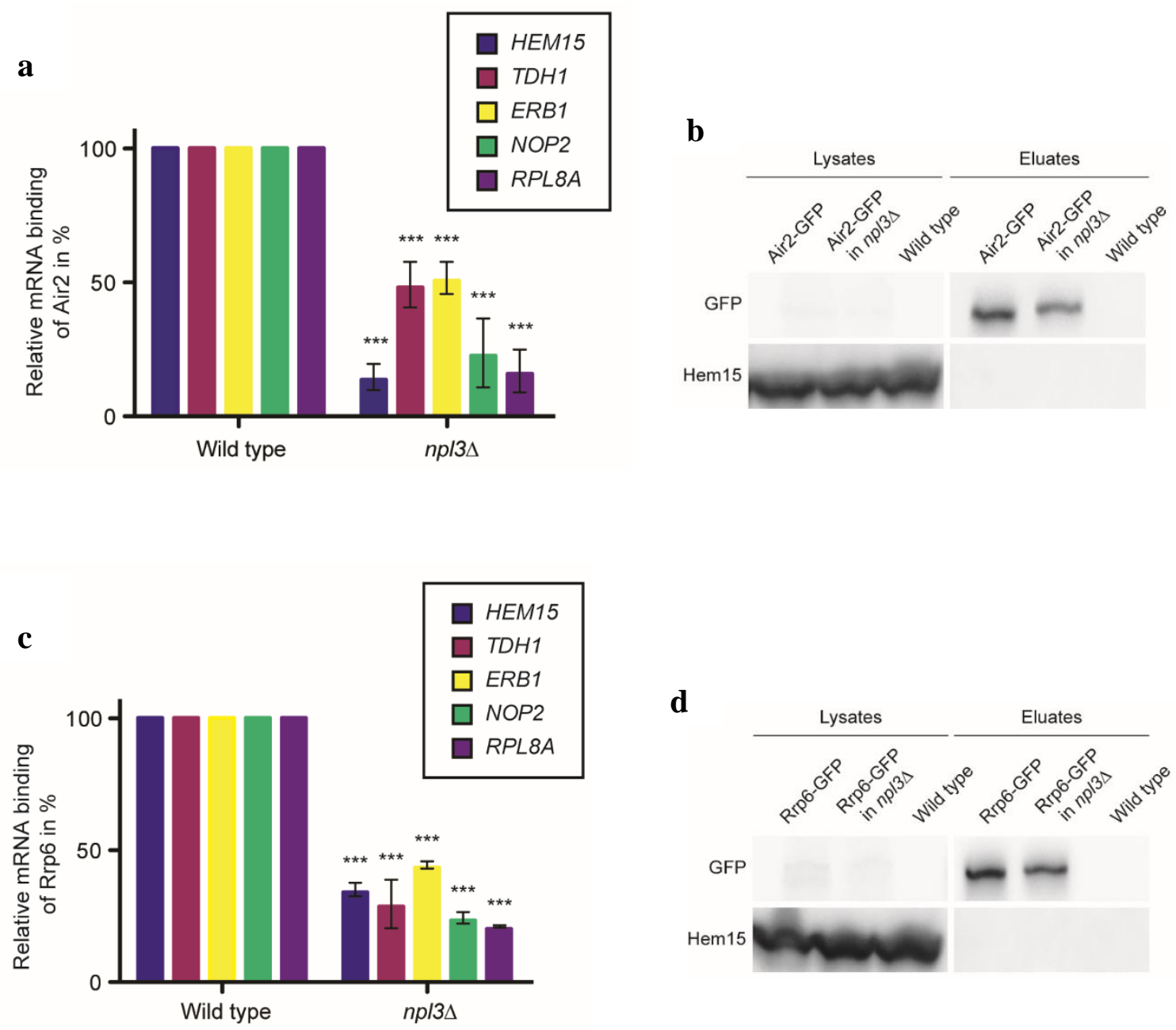

d

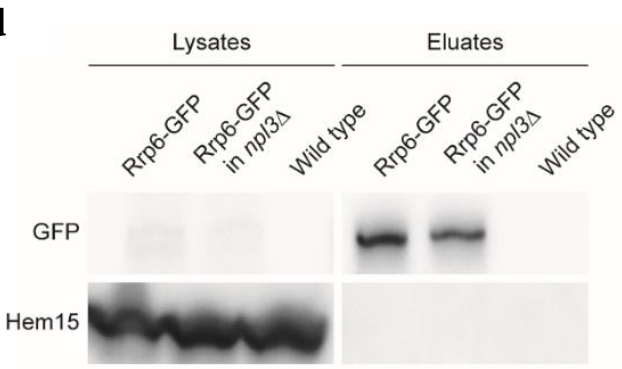

Figure 20: Npl3 is required to recruit the TRAMP-exosome degradation machinery to mRNAs.

Air2-GFP or Rrp6-GFP were precipitated with GFP-trap beads in wild type and $n p l 3 \Delta$ strains. As negative control a wild type strain without any tagged protein was used and treated equally.

a,c) RNA was isolated from eluate samples and lysate controls. 200ng of isolated RNA were transcribed into cDNA using random hexamer primers. A two-step qPCR was performed and the resulting Cq values of lysate controls were subtracted from the corresponding eluate $\mathrm{Cq}$ value, which were then normalized to the no tag control. Furthermore, the binding of Air2/Rrp6 in $n p l 3 \Delta$ samples was related to the wild type samples. Average and standard deviation were calculated from at least three independent samples and an unpaired two-sample t-test was performed (***: $\mathrm{p} \leq 0.001, * *: \mathrm{p} \leq 0.01, *: \mathrm{p} \leq 0.05)$.

b,d) Proper Air2-GFP and Rrp6-GFP pulldown was confirmed by western blot analysis. GFP-tagged Air2 and Rrp6 were detected with GFP-specific antibodies. Hem15 was detected with antibodies against the protein and served as a negative control.

Therefore, the question arose whether Npl3 is also important to recruit this 3' to 5' degradation machinery to mRNAs. In this case, a deletion of NPL3 would result in a decreased binding of the TRAMP complex and the nuclear exosome components to mRNAs. To test this hypothesis, RIP experiments with either Air2 or Rrp6 in wild type and $n p l 3 \Delta$ strains were performed. First strains that express Air2-GFP or Rrp6-GFP in the background of the NPL3 deletion were constructed. The GFP-tagged proteins were precipitated, and co-precipitated RNA was 
analyzed using qRT-PCR. These experiments showed, that both, Air2 and Rrp6, bound significantly less mRNA in $n p l 3 \Delta$ than in a wild type background (Figure 20). These results suggest, that $\mathrm{Npl} 3$ is important for the recruitment of the $3^{\prime}$ to $5^{\prime}$ degradation machinery to mRNAs. 


\subsection{Npl3 functions in ribosome biogenesis}

As reported in the previous part, the general RNA binding protein Npl3 accompanies mRNA from its transcription in the nucleus until its translation in the cytoplasm. Npl3 is loaded cotranscriptionally to the emerging 5'-end (Lei, Krebber and Silver, 2001; Baejen et al., 2014), helps to recruit the splicing machinery (Kress, Krogan and Guthrie, 2008) and functions as adapter for the export receptor heterodimer Mex67-Mtr2 (Hurt et al., 2000; Huang and Steitz, 2005). Furthermore, Npl3 is important to surveil the quality of the cap structure by cooperating with both, the 3' to 5' and 5' to 3' degradation machinery (This work). Interestingly, early studies revealed, that Npl3 is also involved in rRNA processing (Russell and Tollervey, 1992). Moreover, it was shown, that large ribosomal subunits require $\mathrm{Npl3}$ as an adapter for nuclear export (Hackmann et al., 2011a). Therefore, the question arose whether Npl3 is not only involved in mRNA biogenesis, but participates also in the generation of the rRNA and thus the ribosome.

\subsubsection{Npl3 physically interacts with the rRNA transcription machinery}

To investigate, whether Npl3 is loaded to rRNAs during their biogenesis, the localization of Npl3 was analyzed in deletions strains of RNAP I subunits as well as in a thermosensitive mutant of Rrn3, which acts in recruiting RNAP I to the site of transcription. Due to impaired transcription of rRNA in these strains, which leads to a delay in transcription and processing, it is expected that Npl3 accumulates in the nucleus of the mutants if it binds to rRNA. To investigate this, the strains were transformed with an at steady state cytoplasmic version of GFP tagged Npl3 (GFP-Npl3 ). This mutant has a decreased nuclear import rate (Häcker and Krebber, 2004). Expectedly, the thermosensitive mutation in RNAP II largest subunit Rpb1, rpb1-1, lead to a strong nuclear accumulation of GFP-Npl3 c due to defects in mRNA production. Strikingly, GFP-Npl3 $\mathrm{c}$ also accumulates in the nucleus of the RNAP I subunit

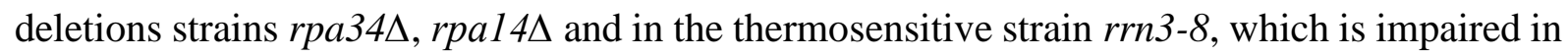
recruitment of RNAP I (Figure 21). These results suggest, that Npl3 is also loaded to rRNAs during their biogenies. Additionally, the combination of the $n p l 3 \Delta$ strain together with deletion

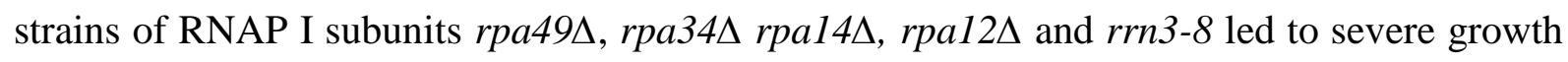
defects (Heike Krebber, unpublished results). This strongly supports the idea that Npl3 is involved in early steps of rRNA transcription and processing. To further analyze whether Npl3 is loaded early to rRNA, physical interaction studies between. subunits of RNAP I and Npl3 as well as Rrn3 and Npl3 were performed in vivo. For this, co-immunoprecipitation studies were 


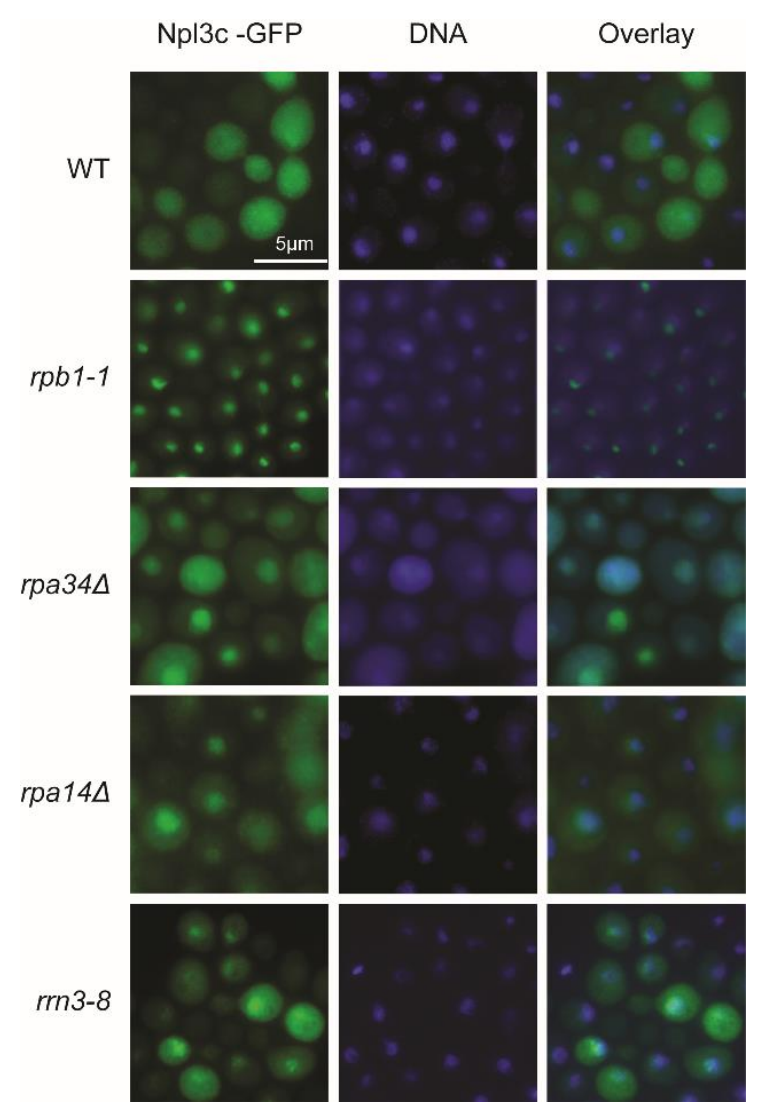

\section{Figure 21: Npl3 interacts with the rRNA transcription machinery.}

Log phase cells of the indicated strains containing Npl3c-GFP were shifted for $2 \mathrm{~h}$ to $37^{\circ} \mathrm{C}$. DNA was stained with Hoechst. Fluorescence signals were detected under the fluorescence microscope in the respective filter and channel settings.

conducted using strains expressing endogenously tagged Rpa190-GFP, Rpa135-TAP or Rrn3GFP. Either GFP- or TAP-tagged proteins were pulled down and co-purified. Npl3 was detected. As shown in figure 22, Npl3 co-purified with Rpa190 and Rpa135, the largest and second largest subunit of RNAP I. The interaction between Rpa190 and Npl3 was slightly reduced upon RNase A treatment, while the interaction between Rpa135 was not influenced. Moreover, Np13 co-purified with Rrn3, but this interaction was dependent of the presence of RNA. These data reveal, that Npl3 physically interacts with RNAP I and with its recruiting factor Rrn3, indicating an early loading of Npl3 to an emerging rRNA.

\subsubsection{Npl3 is loaded co-transcriptionally to nascent rRNA}

The co-transcriptional loading of $\mathrm{Npl3}$ onto rRNA was further supported by Chromatin immunoprecipitation (CHIP) experiments. Endogenously GFP-tagged Rpa190 and Sup45 as 


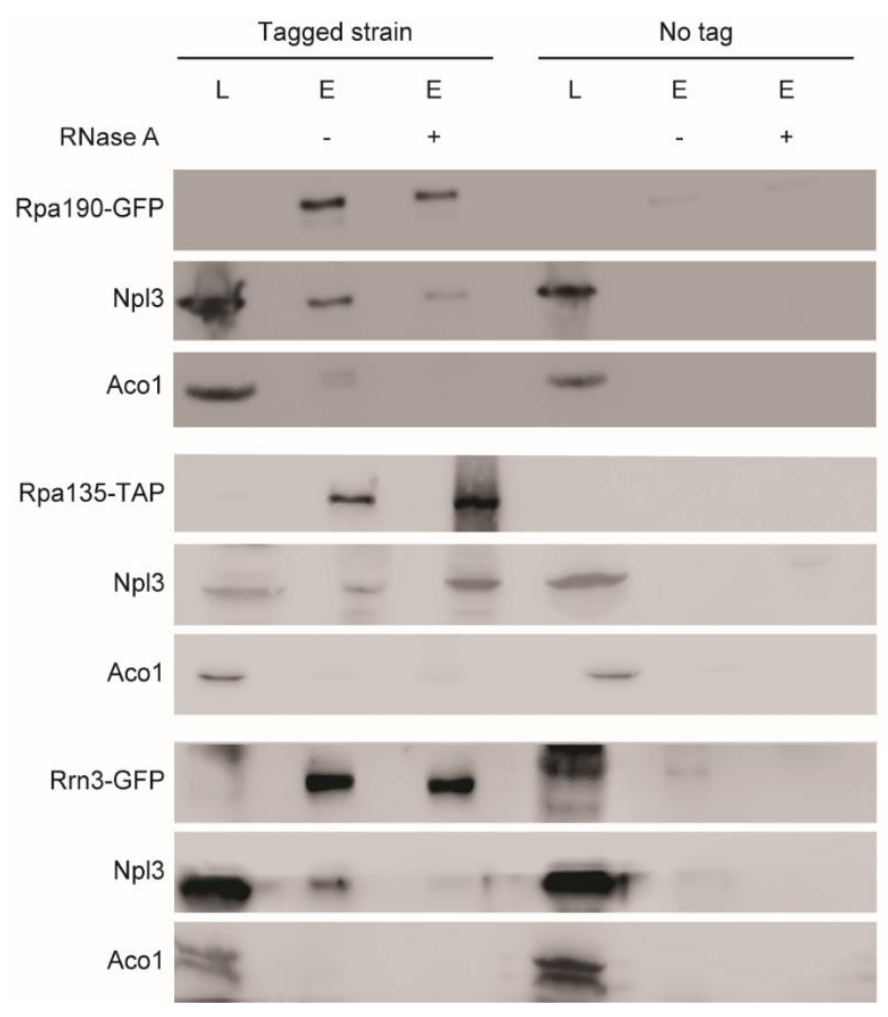

\section{Figure 22: Npl3 interacts with the rRNA transcription machinery.}

Cells were grown to late logarithmic growth phase and subjected to a Co-immunoprecipitation. Either GFP- or TAP-tagged proteins were precepitated and detected in western blot analysis with the appropriate antibody. Coprecipitated Npl3 was detected with its direct antibody. One sample of each was treated with RNase (+/-). Antibodies against Aco1 and precipitation from a lysate without any tagged protein served as negative control.

well as a $n p l 3 \Delta$ strain expressing plasmid derived GFP-Npl3 were grown to log phase and fixed with formaldehyde. After cell lysis, the chromatin was fragmented resulting in fragments of about $200-500 \mathrm{bp}$. Then, the GFP-tagged proteins were precipitated and co-precipitated DNA as well as a lysate control was analyzed using qRT-PCR. For that, a primer pair amplifying an about $200 \mathrm{bp}$ fragment in the 5'-ETS region of the pre-rRNA was used. Cq-values of the eluates were first normalized to a non-transcribed region (NTR) of the DNA and then related to a no tag control. It was shown, that the 5'-ETS region co-purifies with Npl3 and the occupancy is about 30-fold higher relative to no tag. For Rpa190, which served as a positive control, the occupancy of the 5'-ETS region was about 150 -fold higher in than no tag. In contrast, the occupancy of the 5'-ETS region that co-purified with Sup45, which is a translation initiation factor and therefore serves as a negative control, was below a 10-fold enrichment relative to no 
tag (Figure 23). The ChIP experiments clearly confirmed that Npl3 is co-transcriptionally loaded onto the nascent pre-rRNA transcript at its very 5 '-end.

\subsubsection{Npl3 is involved in pre-rRNA processing}

To gather more insight into the function of Npl3 in ribosome biogenesis, a potential role of Npl3 in pre-rRNA processing was investigated. Previous studies indicate, that the depletion of Npl3 after 12 hours resulted in an accumulation of the 35S rRNA precursor and in addition the accumulation of both, the $27 \mathrm{~S}$ and $20 \mathrm{~S}$ rRNA precursor. Moreover, it was shown that after 36 hours of Npl3 depletion, the aberrant 23S rRNA precursor accumulated in these cells (Russell and Tollervey, 1992). To investigate the situation $n p l 3 \Delta$ deletion strain, northern blot analyses were performed. For that, the total RNA of an $n p l 3 \Delta$ and a wild type strain was isolated, separated on an agarose gel, transferred to a nylon membrane and finally detected with probes complementary to sequences of mature rRNAs or rRNA precursors, respectively. Clearly, the

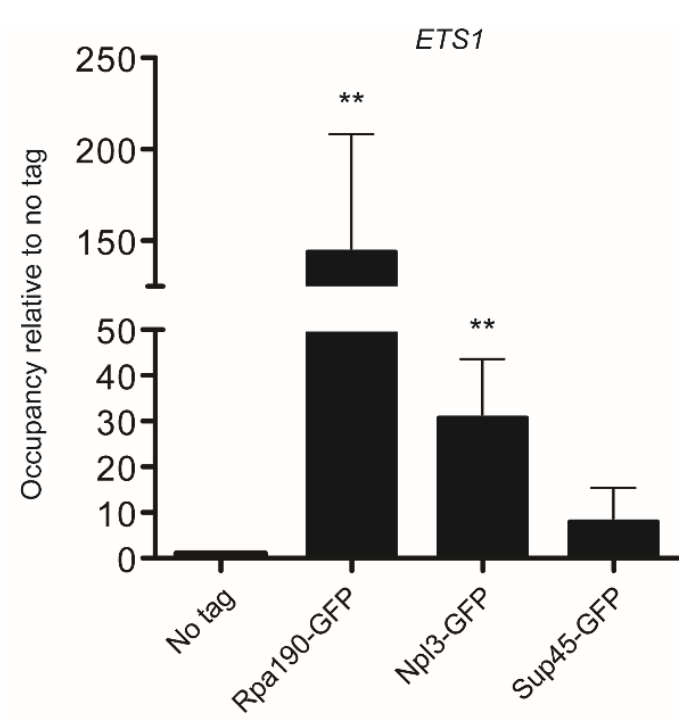

Figure 23: Npl3 is co-transcriptionally loaded to pre-rRNA.

CHIP analyses were performed with GFP-tagged Rpa190, Npl3 and Sup45. GFP tagged proteins were precipitated and associated DNA was analyzed using qRT-PCR with primers specific for the 5'-ETS region. Cq-values of the eluates were first normalized to a non -transcribed region (NTR) and then related to the no tag control. Average and standard deviation were calculated and an unpaired two-sample t-test was performed. (***: $\mathrm{p} \leq 0.001, * *$ : $\mathrm{p} \leq 0.01, *: \mathrm{p} \leq 0.05)$.

absence of Npl3 result in an 1,5-fold accumulation of the primary 35S rRNA precursor and a 
reduction of the mature 18S rRNA (Figure24). This again indicates, that Npl3 is required for proper pre-rRNA processing particularly in the first steps.

\subsubsection{Npl3 cooperates with the exosome and the TRAMP complex in pre-rRNA processing and surveillance}

As reported before, Npl3 cooperates with the TRAMP complex and the nuclear exosome. The $\operatorname{trf} 4 \Delta n p l 3 \Delta$ deletion strain and the triple deletion strain air $1 \Delta$ air $2 n p l 3 \Delta$ exhibits a severe

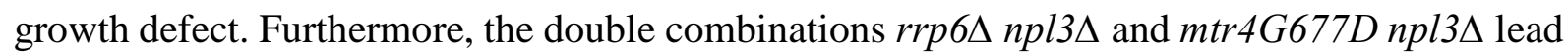
to a growth defect (Heike Krebber, unpublished results). Npl3 interacts also physically with

a

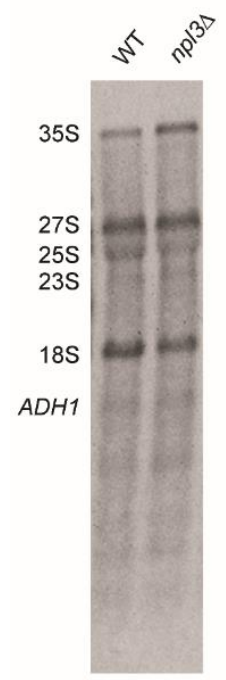

b

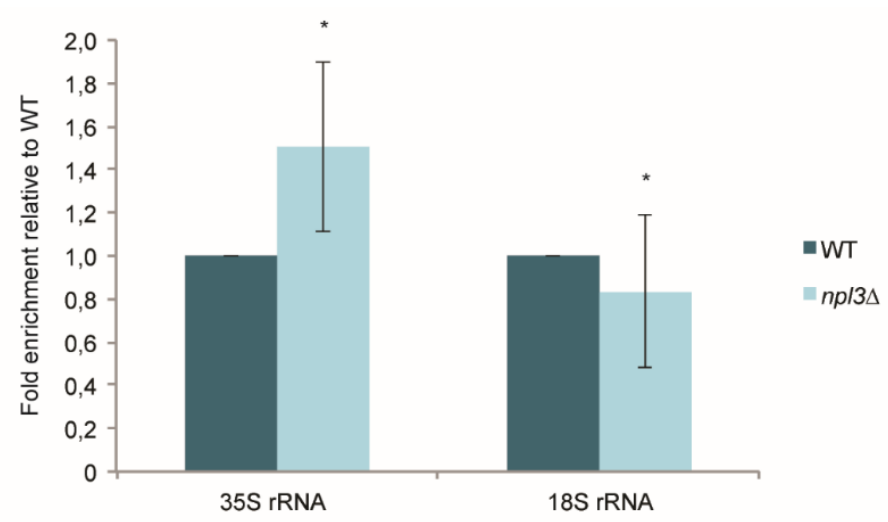

Figure 24: Npl3 is involved in pre-rRNA processing.

a) Gel electrophoresis ( $1 \%$ agarose/MOPS/formaldehyde gel) of $1 \mu \mathrm{g}$ total RNA extracted from the different strains and subsequent Nothern blotting was performed. Non-radioactive detection was carried out with DIGlabeled RNA probes against 27S, 25S, $23 \mathrm{~S}$ and $18 \mathrm{~S}$ rRNAs, which also recognize their precursor molecules. The detection of the $A D H 1$ mRNA served as loading control.

b) Signal intensities were measured, normalized to the loading control and set in relation to wild type. Average and standard deviation was calculated and a two-tailed, two sample, unequal variance $\mathrm{t}$-test was performed $(* * *$ : $\mathrm{p} \leq 0.001, * *: \mathrm{p} \leq 0.01, *: \mathrm{p} \leq 0.05)$.

both Air proteins and RNA- dependent with Trf4 and Trf5, but not with Mtr4 and Rrp6 (Figure 19). In fact, Npl3 is important to recruit the TRAMP complex and the exosome to mRNAs. Because the exosome together with either the TRAMP complex or the RNA helicase Mtr4 is furthermore required for processing and surveillance of rRNAs (Bernstein and Toth, 2012). Thus, it could be possible that Npl3 has similar functions in rRNA surveillance as in mRNA 
surveillance. The exosome is required to degrade the external and internal transcribed spacer regions from the $35 \mathrm{~S}$ rRNA precursor in 3' to 5' direction that are cleaved out during ribosome biogenesis. Additionally, the exosome together with TRAMP complex also degrades aberrant rRNA fragments. Impaired processing of the first cleavage events at site $A_{0}, A_{1}$ and $A_{2}$ lead to a premature cleavage at site $\mathrm{A}_{3}$ and this in turn generates an aberrant precursor called the $23 \mathrm{~S}$ rRNA that is also targeted and degraded by the TRAMP complex and the exosome. To investigate whether Npl3 cooperates with the exosome and the TRAMP complex in rRNA processing and surveillance, nothern blot analysis was performed. The single deletions or mutants of the TRAMP complex or exosome components were compared with the double deletions of these strains with $n p l 3 \Delta$. For that, the total RNA of the respective strains was isolated upon a 2-hour shift to $37^{\circ} \mathrm{C}$, separated on an agarose gel, transferred to a nylon membrane and finally detected with probes complementary to sequences of mature rRNAs or rRNA precursors, respectively. It could be shown again, that the 35S rRNA accumulates in $n p l 3 \Delta$ (Figure 25a,c). Moreover, it was shown that the aberrant 23S precursor accumulates in the $\operatorname{rrp} 6 \Delta$ deletion strain and this accumulation is increased in combination with deletion of $N P L 3$ (Figure 25a,b). In the single deletion strains $\operatorname{trf} 4 \Delta$ and air $2 \Delta$, the $35 \mathrm{~S}$ rRNA precursor and the aberrant $23 \mathrm{~S}$ rRNA, were slightly increased. In combination with a deletion of NPL3, the overall amount of rRNA seems to be reduced (Figure 25). These results indicate, that the degradation of the aberrant $23 \mathrm{~S}$ precursor via the exosome requires $\mathrm{Npl3}$, because the double deletion $\operatorname{rrp} 6 \Delta$ npl3 $\Delta$ lead to its increased accumulation.

\subsubsection{Npl3 is important to recruit the TRAMP/exosome machinery to the processing sites in ETSI}

As the previous northern blot results indicate that $\mathrm{Npl} 3$ cooperates with $\mathrm{Mtr} 4$ and the exosome component Rrp6 in either rRNA processing or surveillance or even both, the question arose whether Npl3 is also important to recruit the TRAMP complex and the exosome to rRNA. To 


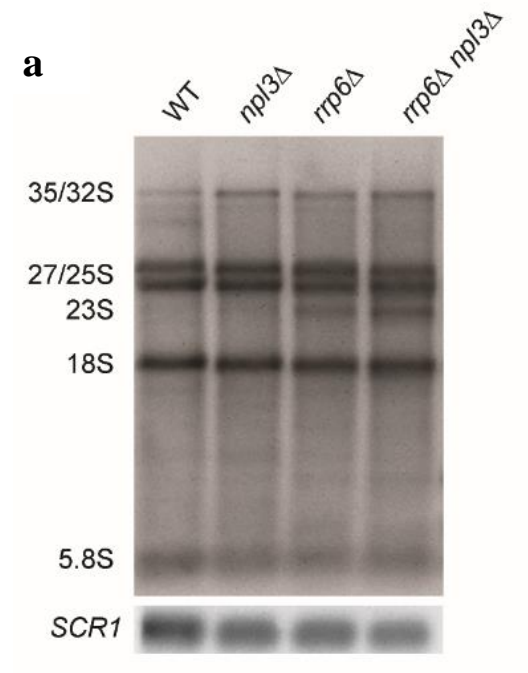

b
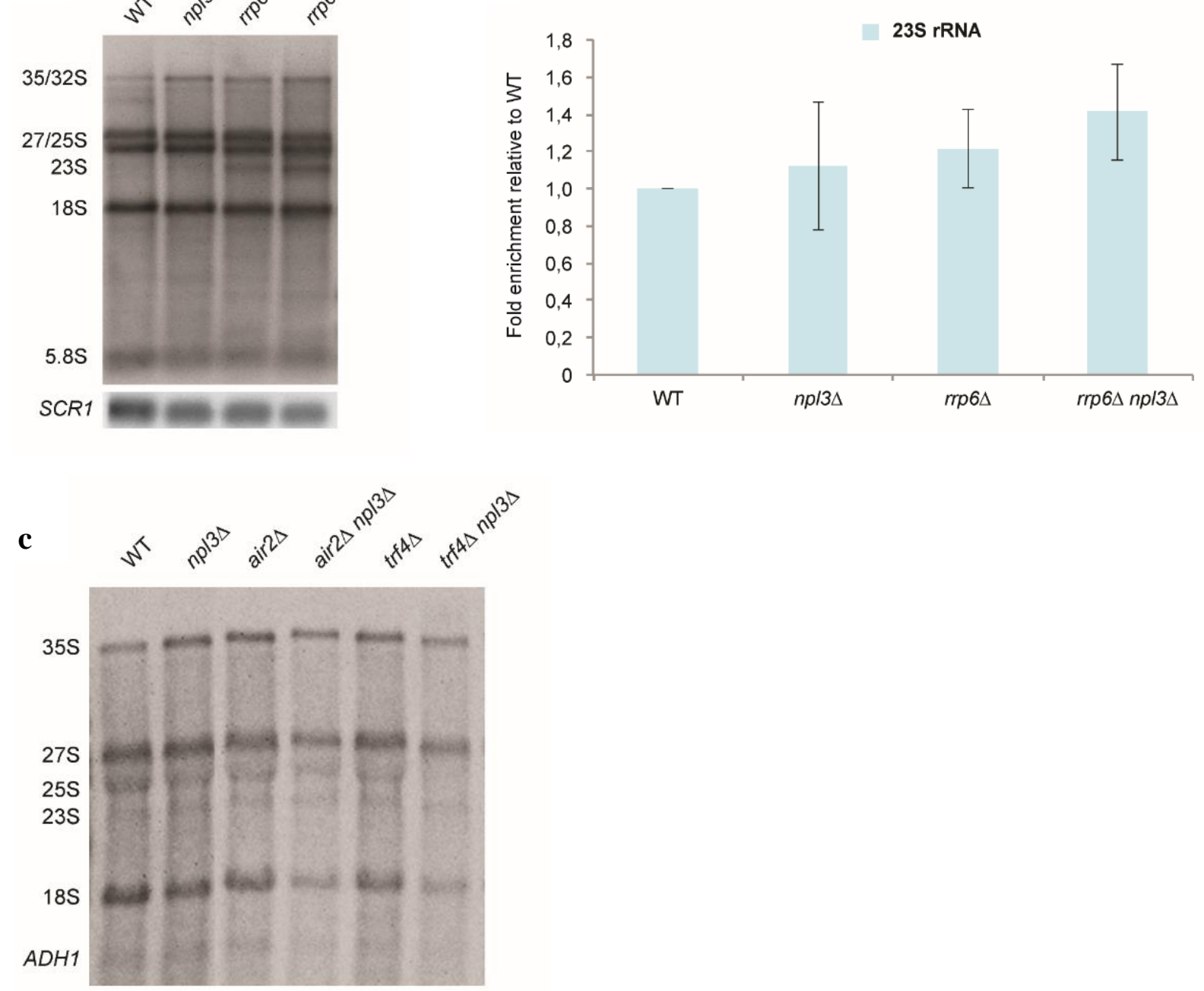

Figure 25: Npl3 is required for proper rRNA processing and surveillance.

a,c) Gel electrophoresis (1\% agarose/MOPS/formaldehyde gel) of $1 \mu \mathrm{g}$ total RNA extracted from the different strains upon $2 \mathrm{~h}$ shift to $37^{\circ} \mathrm{C}$ and subsequent Nothern blotting was performed. Non-radioactive detection was carried out with DIG-labeled RNA probes targeting 27S, 25S, 23S, 5.8S, and 18S rRNAs, which also recognize their precursor molecules. As loading controls either the non-coding RNA SCRI or the mRNA ADHI was detected b) Signal intensities were measured, normalized to the loading control and set in relation to wild type. Average and standard deviation was calculated.

test this, RIP experiments with either Air2 or Rrp6 in wild type and $n p l 3 \Delta$ strains were performed. The GFP-tagged proteins were precipitated, and co-precipitated RNA was analyzed and quantified using qRT-PCR, in which the binding of Air2 and Rrp6 to the 5-ETS region was analyzed. These experiments showed, that both, Air2 and Rrp6, bound significantly less mRNA in $n p l 3 \Delta$ than in a wild type background, while the effect was stronger for Air2. This result suggests, that Npl3 is also involved in recruiting the TRAMP complex and the exosome machinery to rRNA (Figure 26). 
a

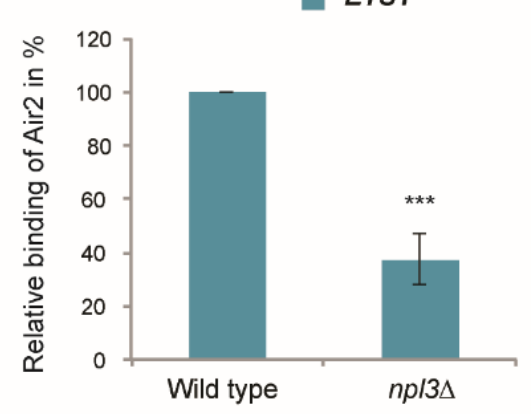

c

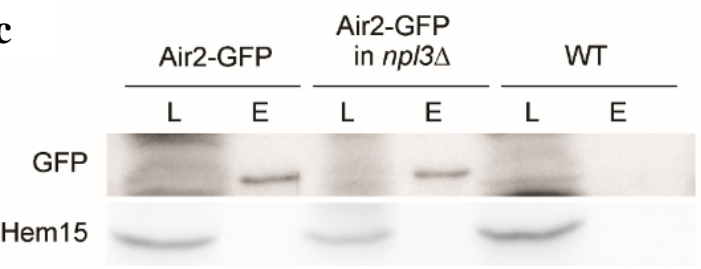

b

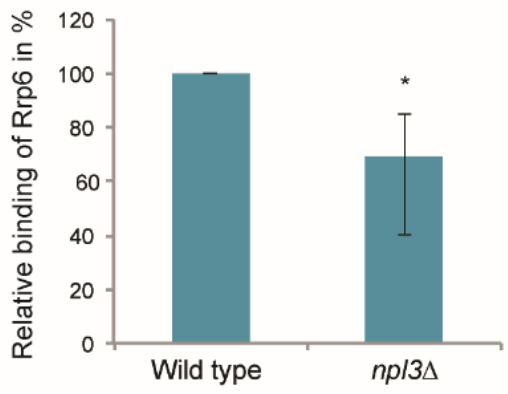

d

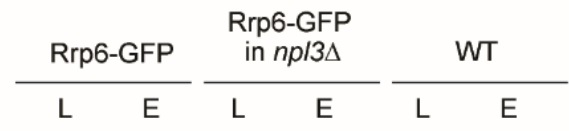

GFP

Hem15

Figure 26: $\mathrm{Npl3}$ is important to recruit the TRAMP-exosome degradation machinery to rRNAs.

Air2-GFP or Rrp6-GFP were precipitated with GFP-trap beads from wild type and $n p l 3 \Delta$ lysates. As negative control a wild type strain without any tagged protein was used and treated equally.

a,b) RNA was isolated from eluate samples and lysate controls. $200 \mathrm{ng}$ of isolated RNA were transcribed into cDNA using random hexamer primers. A two-step qPCR was performed and the resulting Cq values of lysate controls were subtracted from the corresponding eluate $\mathrm{Cq}$ value, which were then normalized to the no tag control. Furthermore, the binding of Air2 or Rrp6 in $n p l 3 \Delta$ samples was related to the wild type samples. Average and standard deviation were calculated from at least three independent samples and an unpaired twosample t-test was performed (***: $\mathrm{p} \leq 0.001,{ }^{* *}: \mathrm{p} \leq 0.01, *$ : $\left.\mathrm{p} \leq 0.05\right)$.

c,d) Proper Air2 and Rrp6-GFP pulldown was confirmed by western blot analysis. Air2-GFP or Rrp6-GFP were detected with a GFP-specific antibody. Hem15 was detected with its direct antibody.

\subsubsection{Npl3 interacts with the SSU processome}

The previous results suggest that Npl3 might, similar as for mRNA, functions in surveillance of rRNAs by recruiting the TRAMP complex and the exosome to rRNAs. The increased accumulation of the aberrant $23 \mathrm{~S}$ precursor in $\operatorname{rrp} 6 \Delta$ npl3s could either be a hint for an involvement of Npl3 for degradation of this aberrant precursor, or Npl3 might be involved in the processing itself, because impaired processing at sites $A_{0}, A_{1}$ and $A_{2}$ lead to generation of this aberrant precursor. As a delay in the SSU processome assembly also results in impaired cleavage of sites $A_{0}, A_{1}$ and $A_{2}$ and in generation of the aberrant $23 \mathrm{~S}$ precursor (Lafontaine, 
$\mathbf{a}$

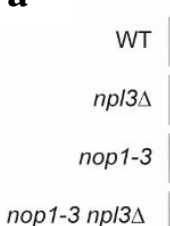

$+\mathrm{pNPL3}$

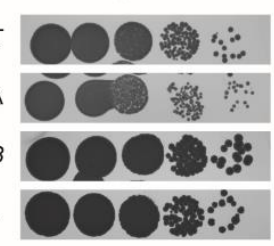

$-\mathrm{pNPL3}$

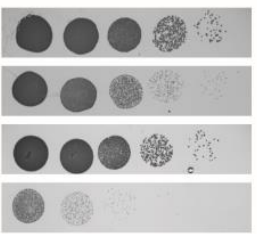

b

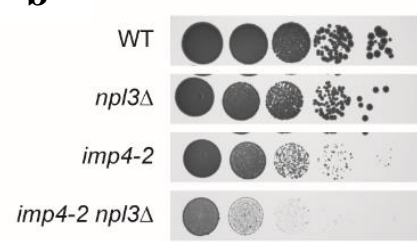

$30^{\circ} \mathrm{C}$

Figure 27: Npl3 genetically interacts with SSU processome components.

a) Serial dilutions of the indicated strains were spotted onto plates selecting for the presence of an empty or NPL3 containing plasmid (-URA). The same strains were spotted onto plates selecting for the loss of the plasmid (FOA). The plates were incubated at $30^{\circ} \mathrm{C}$ for 3 days.

b) Serial dilutions of the indicated strains were spotted on full media plates and incubated at $30{ }^{\circ} \mathrm{C}$ for 3 days.

2010), it could be also possible that Npl3 affects the assembly of the SSU processome. To test whether Npl3 interacts with the SSU processome, we performed genetic interactions studies. For that, $n p l 3 \Delta$ was crossed with nopl-3 or imp4-2 (section 3.6.1.5). The essential methyltransferase Nop1 is part of the U3 snoRNP, which is a very important component of the SSU processome and is required for processing of the $18 \mathrm{~S}$ pre-rRNA. Imp4, which is also an essential protein, forms a complex with Mpp10 and Imp3 that is important to guide the U3 snoRNP to its processing site. Furthermore, it is important for $18 \mathrm{~S}$ pre-rRNA processing. As shown in figure 27 , deletion of NPL3 in combination with mutation in either NOP1 or IMP4 result in severe growth defects. These genetic interactions confirm a functional link of Npl3 with the SSU processome.

\subsubsection{Npl3 physically interacts with several factors of the SSU processome in vivo}

It was shown previously that Npl3 is involved in nuclear export of the LSU and binds to the mature 25S and 5.8S rRNA (Hackmann et al., 2011a). Furthermore, the previous experiments showed that Npl3 is co-transcriptionally loaded to the 5'-end of emerging rRNAs and it genetically interacts with factors of SSU processome. Therefore, we asked whether Npl3 also physically interact with SSU processome components. To further investigate this, three different factors of the SSU processome, Utp18, Utp30 and Rcl1, were analyzed whether they interact physically with Np13 in vivo. Utp18 is part of the UTP-B complex that joins the 5-ETS1 region of the emerging pre-rRNA very early together with the UTP-A complex. Rcl1 belongs to another complex, the Bms1-Rcl1 complex, that joins the pre-mRNA later than UTP-A and UTP-B (Fernández-Pevida, Kressler and de la Cruz, 2015a; Zhang et al., 2016). This complex stimulates the U3 snoRNP binding activity and furthermore Rcl1 cleavage at site $A_{2}$, which 
seperates the SSU from the LSU (Henras et al., 2015). Utp30 is a factor of the SSU processome that is currently not classified to be in a subcomplex. Co-immunoprecipitation studies of these proteins with $\mathrm{Npl} 3$ were conducted using strains expressing endogenously GFP-tagged Utp18, Utp30 or Rcl1 as well as a non-tagged wild strain as negative control. GFP-tagged proteins were precipitated and co-purified Npl3 was detected. Detection of Mtr4 served as a positive control, because Mtr4 is known to be part of the SSU processome. Aco1 served as a negative control. As seen in figure 28, Npl3 co-purified with all three factors of the SSU processome and none of the interactions were RNA-dependent. This indicates, that $\mathrm{Npl} 3$ is physically interacts with the SSU processome.

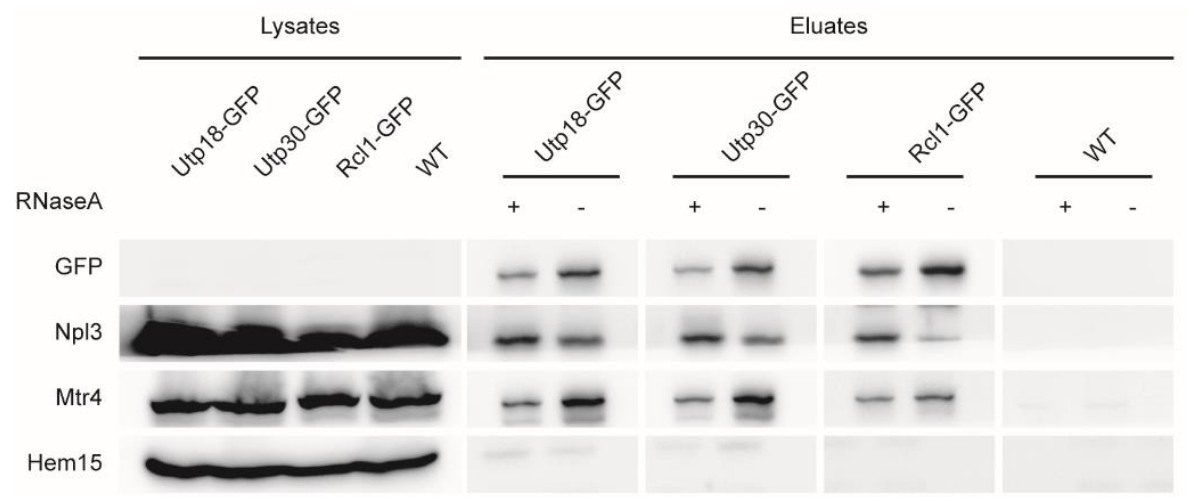

Figure 28: Npl3 physically interacts with SSU processome components in vivo.

Cells were grown to late logarithmic growth phase and subjected to co-immunoprecipitation analysis. GFP-tagged proteins were precepitated and detected in western blots with the appropriate antibodies. Co-precipitated Npl3 and Mtr4 was detected with antibodies against the proteins. One of each eluate sample was treated with RNase $(+/-)$. Antibodies against Hem 15 and precipitation from a lysate without any tagged protein served as negative controls.

\subsubsection{Npl3 is required to recruit the SSU processome component Rcl1 to pre- rRNA}

As Npl3 was shown to interact physically with SSU processome components and its deletion lead to pre-rRNA processing defects, it would be interesting to investigate whether $\mathrm{Npl3}$ also influences the assembly of the SSU processome. To analyze this, the binding of Rcl1 to either the ETS1 and ITS1 region was compared in a strain deleted for NPL3 and a wild type. GFPtagged Rcl1 was precipitated and co-precipitated RNA was analyzed and quantified using qRTPCR. The binding of Rcl1 to the 5-ETS1 and ITS1 region was analyzed. These experiments showed that Rcl1 bound significantly less to the 5-ETS1 and ITS1 regions of pre-rRNA in $n p l 3 \Delta$ than in a wild type background. This effect was stronger for the5-ETS1 region (Figure 29), 
suggesting that Npl3 influences the assembly of the SSU processome and particularly in bringing Rcl1 to its first site of action.

$\mathbf{a}$

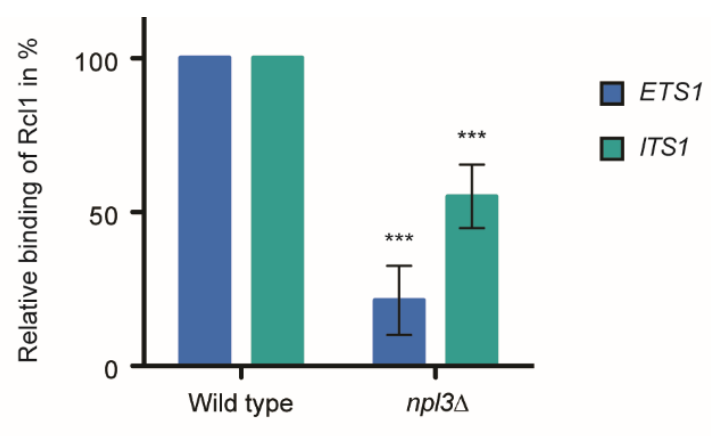

b

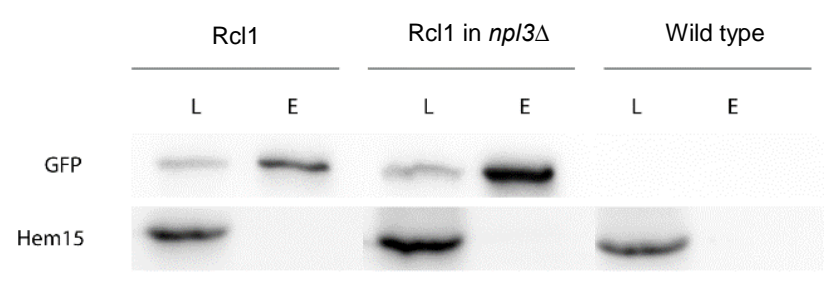

Figure 29: Npl3 is important for the SSU processome assembly.

Rcl1-GFP was precipitated with GFP-trap beads in a wildtype and a $n p l 3 \Delta$ strain. As negative control a wild type strain without any tagged protein was used and treated equally.

a) RNA was isolated from eluate samples and lysate controls. $200 \mathrm{ng}$ of isolated RNA were transcribed into cDNA using random hexamer primers. A two-step qPCR was performed and the resulting Cq values of lysate controls were subtracted from the corresponding eluate $\mathrm{Cq}$ value, which were then normalized to the no tag control. Furthermore, the binding of Rcllin $n p l 3 \Delta$ samples was related to the wild type samples. Average and standard deviations were calculated from at least three independent samples and an unpaired two-sample t-test was performed (***: $\left.\mathrm{p} \leq 0.001,{ }^{* *}: \mathrm{p} \leq 0.01, *: \mathrm{p} \leq 0.05\right)$.

b) Proper Rc11-GFP pulldown was confirmed by western blot analysis. Rcl1-GFP was detected with a GFPspecific antibody. Hem15 was detected with its direct antibody. 


\section{Discussion}

\subsection{The role of Npl3 in mRNA quality control}

Nuclear surveillance mechanisms ensure that immature or faulty mRNAs are retained in the nucleus and are immediately degraded, because export of defective mRNAs and their translation might result in products that are harmful to the cell (Lukong et al., 2008; Fasken and Corbett, 2009). Emerging mRNAs are co-transcriptionally processed and packed with assembly factors resulting in an export-competent mRNP. Pre-mRNAs require three main processing events to reach maturity: 5'-end capping, 3'-end polyadenylation, and if existing, the excision of non-coding intron sequences by splicing (Rougemaille et al., 2008; Fasken and Corbett, 2009). Capping of the 5'-end is the first processing step of nascent pre-mRNAs and it is important for mRNA stability, splicing efficiency, export, and translation initiation (Furuichi and Shatkin, 2000). During the splicing process, introns are removed from pre-mRNAs and exons are ligated to a continuous coding strand. The last step of mRNA processing is the polyadenylation of the 3 '-end including the poly (A) site cleavage, subsequent polyadenylation, and the binding of poly (A) binding proteins (Moore and Proudfoot, 2009). During all steps of mRNA maturation, faulty mRNAs can be produced. However, these aberrant or immature transcripts are recognized and degraded by the nuclear surveillance machinery. In S. cerevisiae, the exosome together with its co-factor, the TRAMP complex, recognizes faulty pre-mRNAs and degrades them in 3' to 5' direction, while the exonuclease Rat1 together with its co-factor Rail recognizes and degrades aberrant pre-mRNAs in 5' to 3' direction. However, how of faulty or immature pre-mRNAs are recognized and which additional factors are required is broadly unclear.

\subsubsection{Npl3 is a surveillance factor for pre-mRNA capping}

$\mathrm{Npl3}$ is a multifunctional RNA-binding protein and belongs to the conserved family of SR-like proteins. In S. cerevisiae, besides Npl3 two additional SR-like proteins exist: Gbp2 and Hrb1. All three SR-like proteins bind to mRNAs and functions as adaptor for the export receptor heterodimer Mex67-Mtr2 (Windgassen and Krebber, 2003; Häcker and Krebber, 2004). Interestingly, Gbp2 and Hrb1 have been identified to be key surveillance factors for introncontaining pre-mRNAs. Both bind predominantly to unspliced transcripts and retain immature transcripts in the nucleus until splicing is completed. When Gbp2 and Hrb1 recognize faulty or unspliced pre-mRNAs, they recruit the TRAMP complex via interaction with the RNA helicase 
Mtr4 and their subsequent degradation by the exosome is promoted (Hackmann et al., 2014). In contrast to Gbp2 and Hrb1, Np13 has been found to bind bulk mRNAs. While Gbp2 and Hrb1 are loaded to intron-containing transcripts via the THO complex during late steps of splicing, Npl3 is loaded to emerging transcripts via the CTD of RNAP II during transcription initiation (Lei, Krebber and Silver, 2001; Hackmann et al., 2014). It was shown, that Npl3 interacts with the $\mathrm{CBC}$ and it was suggested that Npl3 binds only to properly processed cap structures (Shen et al., 2000). These observations led to the idea, that Npl3 might be a surveillance factor for the capping reaction. Furthermore, it was shown that the thermosensitive mutant of the capping enzyme subunit Cet1, cet1-2, combined with a deletion of NPL3 result in a severe growth defect (Dr. Gesa Zander, Ph.D thesis). It suggests, that the thermosensitive mutation cet1-2 generates uncapped or aberrantly capped pre-mRNAs, but these are rapidly recognized as defective and degraded by the nuclear surveillance machinery. However, in the cet1-2 npl3s strain, these false transcripts might not being recognized as Npl3 is missing and thus leak into the cytoplasm and overwhelm the cell with faulty pre-mRNAs leading to the observed cell death. To confirm such a model, we investigated whether the mutation in cet 1-2 produces indeed uncapped or aberrant capped pre-mRNAs, which is indeed the case (Figure 14a) and whether they leak into the cytoplasm in $n p l 3 \Delta$. In fact, we show that these uncapped transcripts leak into the cytoplasm in $n p l 3 \Delta$ (Figure14b).

To identify when Npl3 is loaded to pre-mRNAs, either at the same time as the capping enzyme to somehow surveil the capping reaction, or after capping is completed to control the proper cap structure by its association with the $\mathrm{CBC}$ we determine its physical contacts. We show, that $\mathrm{Npl3}$ does not interact with either subunit of the capping enzyme Cet1 or Ceg1 (Figure 13), suggesting that Npl3 is loaded after the capping reaction has been completed and thus rather controls the presence of a properly processed cap structure.

Completion of capping requires the methylation of the terminal guanine base at position N7 which is carried out by the methyltransferase Abd1 (Mao, Schwer and Shuman, 1995). In contrast to the capping enzyme, which is loaded to emerging transcripts directly downstream the transcription start site, the methyltransferase Abd1 was suggested to be loaded further downstream (Mayer et al., 2010; Lidschreiber, Leike and Cramer, 2013). Future analyses could investigate potential physical and genetic interaction between $\mathrm{Npl3}$ and the methyltransferase Adb1. Moreover, it remains an open question if proper methylation is also controlled by Np13 and unmethylated RNAs leak into the cytoplasm in $n p l 3 \Delta$.

Once uncapped or aberrant capped mRNAs are generated, they are targeted and degraded by the essential nuclear exonuclease Rat1 in 5' to 3' direction. The important co-factor of Rat1, 
Rai1, is proposed to recognize and remove aberrant cap structures from pre-mRNAs to enable Rat1 mediated degradation (Jiao et al., 2010; Bernstein and Toth, 2012). How it recognizes them as false and which proteins participate in recognition is not known. Here, we show that Npl3 contacts this 5' to 3' degradation machinery (Figure 15). Npl3 physically interacts with both, the exonuclease Rat1 and its cofactor Rai1 (Figure 16), supporting the idea that Npl3 is indeed involved in quality control of pre-mRNA cap structures. Interestingly, the binding of Rat1 and Npl3 was severely diminished upon the addition of RNase A, while the binding between Npl3 and Rai1 was not influenced upon RNase A addition (Figure 16). This indicates, that the interaction between Rat 1 and Npl3 is mediated via RNA, while the binding between Rai1 and Npl3 is a protein-protein mediated interaction. As is was hypothesized that Rail functions in recognition of uncapped or aberrant capped pre-mRNAs but the precise mechanism of recognition is widely unclear (Jiao et al., 2010), the interaction between Rai1 and Npl3 could be a hint that Npl3 is also involved in the recognition of these faulty pre-mRNAs. In fact, we show that Npl3 is important to recruit Rail and Rat1 to mRNAs. The binding of mRNAs to both proteins was significantly reduced in an NPL3 deletion strain in comparison to a wild type strain (Figure 17). This could either mean, that Npl3 is important to actively recruit the Rat1Rai1 machinery to mRNAs or that Npl3 marks the faulty pre-mRNA and functions as a binding signal for Rat1 and Rai1.

It was found previously, that the SR-protein Gbp2 recruits the surveillance machinery to aberrantly or unspliced pre-mRNAs and the binding of either the TRAMP complex factor Mtr4 or the export factor Mex67 is mutually exclusive (Hackmann et al., 2014). It could be possible, that this mechanism is similar for the quality control of cap structures by Npl3. Here it was shown, that the mutation producing faulty capped pre-mRNAs cet1-2 indeed result in a reduced interaction between Npl3 and Mex67(Figure18). This suggests, that aberrant capped premRNAs are recognized by Npl3 and are subsequently targeted by the 5' to 3' degradation machinery. Furthermore, it suggests, that Npl3, which is associated to faulty capped premRNAs, does not recruit Mex67 to prevent export of these faulty transcripts. The mutation of Rat1, rat1-1 likewise results in decreased binding intensity of Np13 and Mex67 (Figure 18). This might be due to the fact, that in rat $1-1$ aberrantly capped transcripts accumulate and Npl3 is bound to these faulty transcripts.

Taken together, these findings lead to the following model for surveillance of the 5 '-end:

After the capping reaction is completed, Npl3 is loaded to the emerging pre-mRNAs by the CTD of RNAP II. A proper processed 5'- cap is bound by the CBC which is detected by Npl3. After complete processing and quality control of each step, the guard proteins recruit the export 
receptor heterodimer Mex67-Mtr2 leading to the subsequent nuclear export of these mature mRNPs. In case, that the 5'-cap was not properly added, Npl3 recruits the 5' to 3' degradation machinery by placing Rai1 on the pre-mRNA upon which Npl3 is released. After Rai1 has removed the faulty cap, the exonuclease Rat1 degrades the faulty transcript. When Npl3 is missing, there is no quality control at the 5 '-end and thus no degradation of faulty capped premRNAs. These faulty capped pre-mRNAs are loaded with the other guard proteins upon subsequent processing, which recruit finally the export receptor heterodimer Mex67-Mtr2, resulting in their leakage into the cytoplasm (Figure 30).

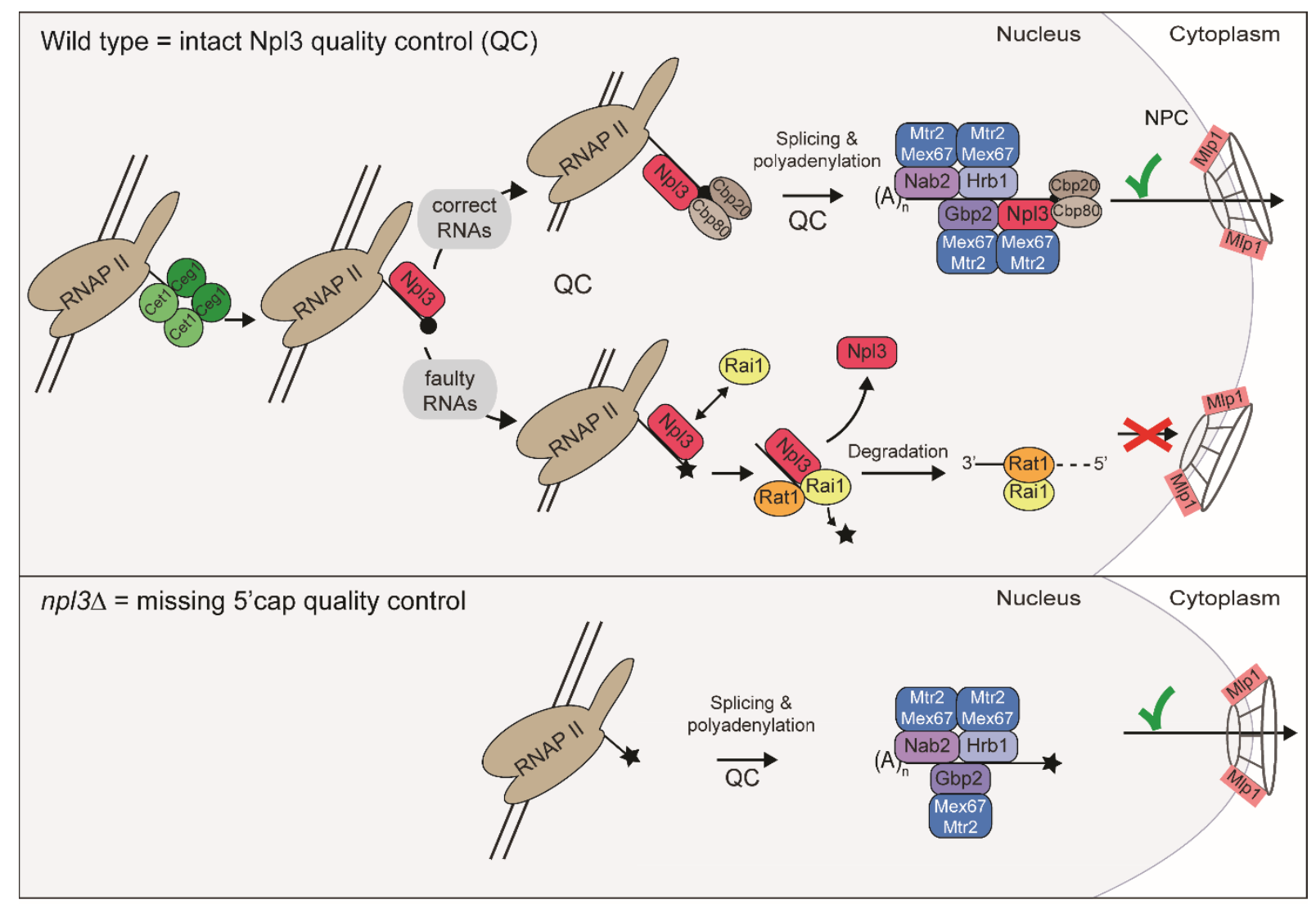

Figure 30: Model for the surveillance of 5'-capping

Top: The capping enzyme composed of the RNA triphosphatase Cet1 and the guanyltransferase Ceg1, co-

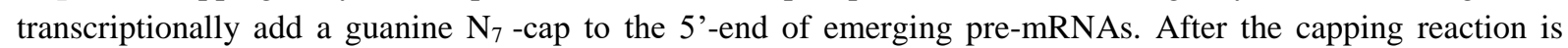
completed, Npl3 is loaded by RNAP II.

When the 5'-cap was processed correctly, the CBC can bind which is detected by Npl3, and further processing events occur. After completing processing and quality control of downstream events, the guard proteins Npl3, Gbp2, Hrb1 and Nab2 recruit the export receptor heterodimer Mex67-Mtr2 and subsequent nuclear export of these mature mRNPs is facilitated.

When the 5'-cap was not properly added, Np13 fails to detect the $\mathrm{CBC}$ and recruits the 5'-3' degradation machinery via interaction with Rai1. After Rai1 loading, Npl3 dissociates and Rai1 removes the faulty cap and subsequently the exonulease Rat1 degrades the faulty transcript.

Bottom: In case that Npl3 is missing, there is no quality control at the 5'-end and thus no degradation of faulty capped pre-mRNAs. These faulty capped transcripts proceed with downstream processing events and the guard proteins recruit the export receptor Mex67-Mtr2, resulting in their leakage into the cytoplasm. 


\subsubsection{Npl3 cooperates with the 3' to 5' TRAMP mediated degradation machinery}

In this work, it was shown that the multifunctional protein $\mathrm{Np} 13$ is required for the surveillance of the pre-mRNA capping event and for the recruitment of the 5' to 3' degradation machinery to aberrantly capped transcripts. However, Np13 does not only bind to the 5'-end of premRNAs, but it is also supposed to promote transcription elongation and prevent premature termination. It was suggested, that at final steps of transcription Npl3 is phosphorylated by CKII, which reduce its mRNA binding and enables the binding of termination factors. (Dermody et al., 1996; Bucheli and Buratowski, 2005). Additionally, the Rat1 and Rai1 machinery is involved in the poly (A) dependent transcription termination as it degrades RNA downstream of the cleavage site resulting in subsequent release of RNAP II (Kim et al., 2004; Bernstein and Toth, 2012). Here we have shown, that Npl3 recruits Rai1 and Rat1 to mRNAs (Figure 17). It could be possible that Npl3 is also important to bring this machinery to the 3'end of mRNAs to promote transcription termination.

The fact that Npl3 was identified as an antagonist for transcription termination (Bucheli and Buratowski, 2005) suggests that it is not only required for the surveillance of the capping process, but also for the surveillance of later pre-mRNA processing events. To investigate a potential contact of $\mathrm{Npl3}$ with the 3' to 5' degradation machinery, we investigated physical and genetic interactions. We show that Npl3 is required to recruit the 3' to 5' degradation machinery to mRNAs (Figure20), supporting the idea that Npl3 is a general key surveillance factor for mRNAs. Although, it is currently unclear whether faulty capped pre-mRNAs are only degraded by the 5 ' to 3 ' degradation machinery or also require the 3 ' to 5 ' degradation machinery. Interestingly, Npl3 physically interacts only with specific subunits of the TRAMP complex. We show, that Npl3 interacts with the RNA-binding proteins Air1 or Air2 and the noncanonical polymerases Trf4 or Trf5, but not with the RNA helicase Mtr4. Furthermore, Npl3 does not physically interact with the nuclear exosome component Rrp6 (Figure 19). As Npl3 is required to recruit the nuclear exosome component to mRNAs (Figure 20), the physical interaction studies suggest a stepwise assembly of the TRAMP complex onto its substrates. It might be possible that $\mathrm{Npl3}$, located on a faulty transcript, recruits the TRAMP complex via its interaction with either Air1 or Air2 and is subsequently released before the TRAMP complex completely assembles and initiates degradation. Air1 and Air2 are supposed to control the substrate specificity within the TRAMP complex (Schmidt et al., 2012), which supports the idea that the Air proteins first recognize and bind their substrates. As Npl3 physically interacts with Rai1 and Air2, but not with the exonucleases Rat1 and Rrp6 it seems likely that Npl3 recruits the degradation machineries via interaction with the co-factors of the exonucleases and 
is released before the exonucleases bind. Furthermore, it might be, that there is a mutually exclusive binding of Air2/Rail and the export receptor Mex67 to Npl3 as it was suggested for Gbp2, that binds either Mtr4 or Mex67. However, this remains to be shown.

Taken together, these results indicate that Npl3 is a general surveillance factor for mRNAs and suggest the following model for surveillance of the 3 '-end:

Npl3 covers the emerging 3'-end of pre-mRNAs. After cleavage by the poly(A) complex, the RNA downstream, which is still associated with RNAP II, is degraded by the Rat1-Rai1 5' to 3' degradation machinery. It might be, that $\mathrm{Npl3}$ is responsible to recruit Rat1-Rai1 to this processing site. When pre-mRNAs are processed and assembled correctly, polyadenylation of the 3'-end occur and subsequently the poly(A) binding protein Nab2 binds the poly(A) tail, which might be detected by Npl3. After that, Npl3 and the other guard proteins recruit the

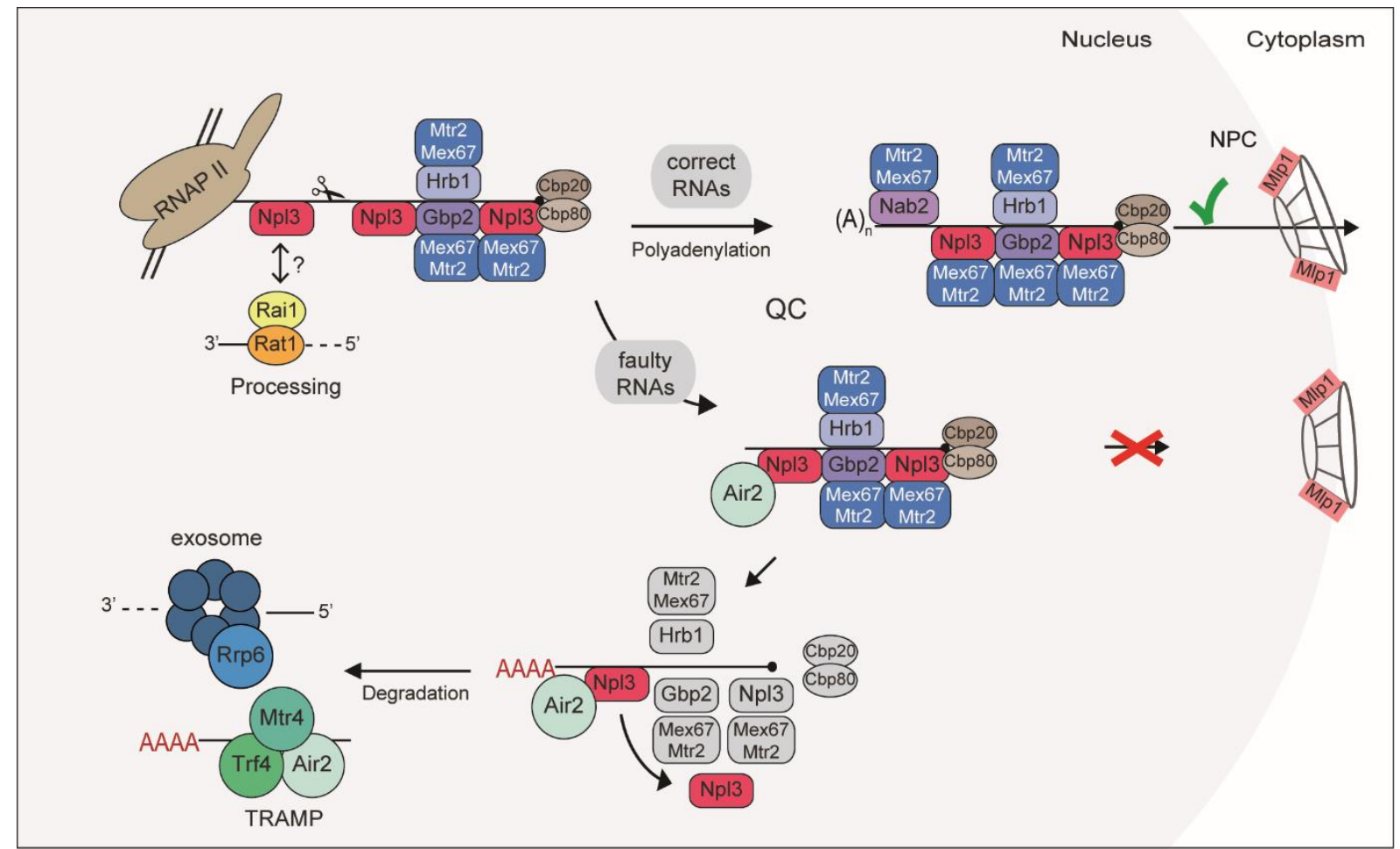

Figure 31: Model for the surveillance of the 3'end

Npl3 is loaded to the emerging 3'-end of pre-mRNAs. Upon cleavage by the poly(A) complex the RNA downstream is degraded by the Rat1-Rail degradation machinery, which might be recruited by Np13.

When pre-mRNAs are correctly processed and assembled, polyadenylation of the 3'-end occurs and the poly(A) binding protein Nab2 subsequently binds to the poly(A) tail. The guard proteins recruit the export-receptor heterodimer Mex67-Mtr2 and nuclear export of these correct mRNPs is facilitated.

In case that pre-mRNAs are not processed or assembled correctly, the TRAMP complex component Air2 is recruited to these faulty transcripts and their export is prevented. Prior to binding of the other TRAMP complex components, Np13 is released. The TRAMP complex adds an oligo(A) tail instead of a poly(A) tail to the 3'-end of faulty transcripts. This oligo(A) tail is recognized by the nuclear exosome and the faulty transcript is degraded. 
export-receptor heterodimer Mex67-Mtr2 and nuclear export of these correct mRNPs is facilitated. When pre-mRNAs are not processed or assembled correctly, Air2 is recruited to these faulty transcripts and their export is prevented. Npl3 is released prior to the assembly of the other TRAMP complex components and TRAMP complex adds an oligo(A) tail instead of a poly(A) tail to the 3 '-end of faulty transcripts. This oligo(A) tail is recognized by the nuclear exosome and the faulty transcript is degraded. (Figure 31) 


\section{$5.2 \mathrm{Npl3}$ is important for ribosome biogenesis}

\subsubsection{Npl3 is co-transcriptionally loaded to the 5'-end of pre-rRNAs and involved in rRNA processing and surveillance}

It was described earlier, that Npl3 might be involved in ribosome biogenesis, because its down regulation affects the processing of the 27S rRNA precursor to the mature $25 \mathrm{~S}$ rRNA and also the processing of the 20S rRNA precursor to the mature 18S rRNA (Russell and Tollervey, 1992). Additionally, it was shown previously that Npl3 co-purifies with mature 18S, 25S and 5S rRNA (Krogan et al., 2004) and is important for the nuclear export of the LSU independently of Mex67 (Hackmann et al., 2011). These findings suggested, that Npl3 might be involved in ribosome biogenesis and subsequent export, but its specific function is unknown. Furthermore, it is unclear whether Npl3 is not only involved in early mRNA biogenesis, but also participates in the biogenesis of rRNA.

Here, we have shown that $\mathrm{Npl3}$ is co-transcriptionally loaded to emerging rRNA at its 5'-end (Figure 23). Furthermore, Npl3 physically interacts with the largest and second largest subunit of RNAP I (Figure 22). This suggests, that Npl3 is loaded in a similar way to rRNA by RNAP I as it is loaded by RNAP II to mRNA. Additionally, we showed that a deletion of NPL3 leads to an accumulation of the large 35S rRNA precursor (Figure 24). This supports the early finding, that downregulation of Npl3 affects the processing of rRNA (Russell and Tollervey, 1992) and indicates, that Npl3 is important for early processing events. Processing of rRNAs starts with the cleavage at the cleavage sites $\mathrm{A}_{0}$ and $\mathrm{A}_{1}$ in the ETS1 spacer region and the cleavage site $\mathrm{A}_{2}$ in the ITS1 spacer region. The spacer regions are degraded by the exosome in 3'to 5' direction and by Rat1 in 5' to 3' direction (Fernández-Pevida, Kressler and de la Cruz, 2015a). Moreover, the exosome, together with the TRAMP complex, is responsible to recognize and degrade faulty pre-rRNAs (Lafontaine, 2010). Additionally, Mtr4 alone is required for rRNA processing and surveillance (Bernstein and Toth, 2012). Therefore, we asked whether Npl3 cooperates with the TRAMP complex and nuclear exosome components in a similar way as for mRNA processing and surveillance. Northern blot analyses showed, that the double deletion of RRP6 and NPL3 enhances the accumulation of the aberrant $23 \mathrm{~S}$ rRNA precursor, which emerges upon delayed or disturbed cleavage at the first cleavage sites (Figure 25). This led to the idea, that Npl3 is either important for the degradation of this faulty precursor or that it is required for early processing events at these sites. Furthermore, northern blot analysis revealed minor alterations in the rRNA pattern upon deletion of the TRAMP complex components TRF4 and AIR2 (Figure 25). Their deletion leads to the accumulation of the $35 \mathrm{~S}$ 
precursor, but double deletions of NPL3 with either AIR2 and TRF4 seems to reduce the overall amount of rRNA (Figure 25). These results suggest, that Npl3 cooperates with the TRAMP complex for rRNA processing and surveillance. Moreover, we show, that Npl3 is important to recruit Air2 and Rrp6 to the ETS1 region (Figure 26). This supports the idea, that Npl3 is required to recruit the 3 ' to 5 'degradation machinery not only to mRNA but also to rRNA.

As Npl3 interacts with the Rat1-Raildegradation machinery and is important to recruit this machinery to pre-mRNAs, it seems possible and should be analyzed whether Npl3 is required to recruit Rat1 and Rai1 to pre-rRNAs by RIP experiments.

Interestingly, Npl3 cooperates not only with the degradation machinery, but also with the SSU processome. This large mRNP complex is organized in sub-complexes which bind in a hierarchical manner to the emerging pre-rRNA and function in both, chaperoning the large 90S pre-ribosomal particle and performing the early cleavage events (Pérez-Fernández, MartínMarcos and Dosil, 2011; Zhang et al., 2016; Chaker-Margot et al., 2017) Therefore, delayed or disturbed assembly of the SSU processome results in processing defects and can also lead to the generation of the aberrant 23S precursor. Here we show, that $\mathrm{Npl3}$ genetically interacts with the methyltransferase and U3 snoRNP scaffold protein Nop1 and the Mpp10-complex component Imp4 (Figure 27). The U3 snoRNP together with the Mpp10-complex are important to coordinate the binding events of the other sub-complexes. For that, the U3 snoRNP hybridizes to several complementary sites within the ETS1 and 18S region (Pérez-Fernández, Martín-Marcos and Dosil, 2011). Moreover, co-immunoprecipitation experiments clearly revealed an RNase A insensitive physical interaction between Npl3 and components of the SSU processome (Figure 28). We show, that Npl3 interacts with SSU components of different subcomplexes: Utp18, which assembles in the UTP-B complex, Rcl1, that is part of the Bms1Rcl1 complex and Utp30, which is part of 90S pre-ribosome, but currently not classified to be part in a subcomplex (Zhang et al., 2016). These results clearly indicate that Npl3 is part of this $90 \mathrm{~S}$ pre-ribosome particle. Thus, we asked whether Npl3 is also important for the assembly of the SSU processome. Interestingly, the deletion of NPL3 leads to a significantly reduced binding of the SSU processome component Rc11 to the ETS1 and ITS1 regions (Figure 29). As Rcl1 is part of Bms1-Rcl1 complex that binds after the other sub-complexes are assembled and the 18S region becomes available (Zhang et al., 2016; Chaker-Margot et al., 2017), the reduced binding of Rcl1 to the pre-rRNA could be a hint that Npl3 is important for the assembly of the SSU processome already for the early assembly steps. However, Rcl1 performs the endonucleolytic cleavage step at site $\mathrm{A}_{2}$ which is important to separate the SSU from the LSU. Because impaired cleavage at the sites $\mathrm{A}_{0}, \mathrm{~A}_{1}$ and $\mathrm{A}_{2}$ lead to premature cleavage at the site $\mathrm{A}_{3}$ 
and thus in generation of the 23S rRNA, it seems possible that Npl3 is important to recruit Rcl1 to its cleavage site and would explain why deletion of NPL3 results in impaired processing and enhanced accumulation of the $23 \mathrm{~S}$ in the RRP6 deletion. This should be investigated by additional RIP experiments.

It was additionally shown, that Npl3 physically interacts with the RNA binding protein Rrp5, which is required for the biogenesis of both, the SSU and the LSU (Heike Krebber, unpublished results). Rrp5 was recently shown to bind first to the pre-40S particle and must be actively released to enable binding to the pre-60S particle and thus provides a quality control checkpoint (Khoshnevis et al., 2016), in which Npl3 might be involved.

In summary, Npl3 interacts with several factors of the SSU processome and the degradation machinery (Figure 32), suggesting that it has a more general function in the SSU processome assembly and quality control of rRNA. Early defects of either rRNA processing or assembly of the SSU processome can result in defects of the following maturation steps. As Npl3 is loaded early to the 5'-end Npl3 might control early processing events and thereby influences the assembly of the SSU processome.

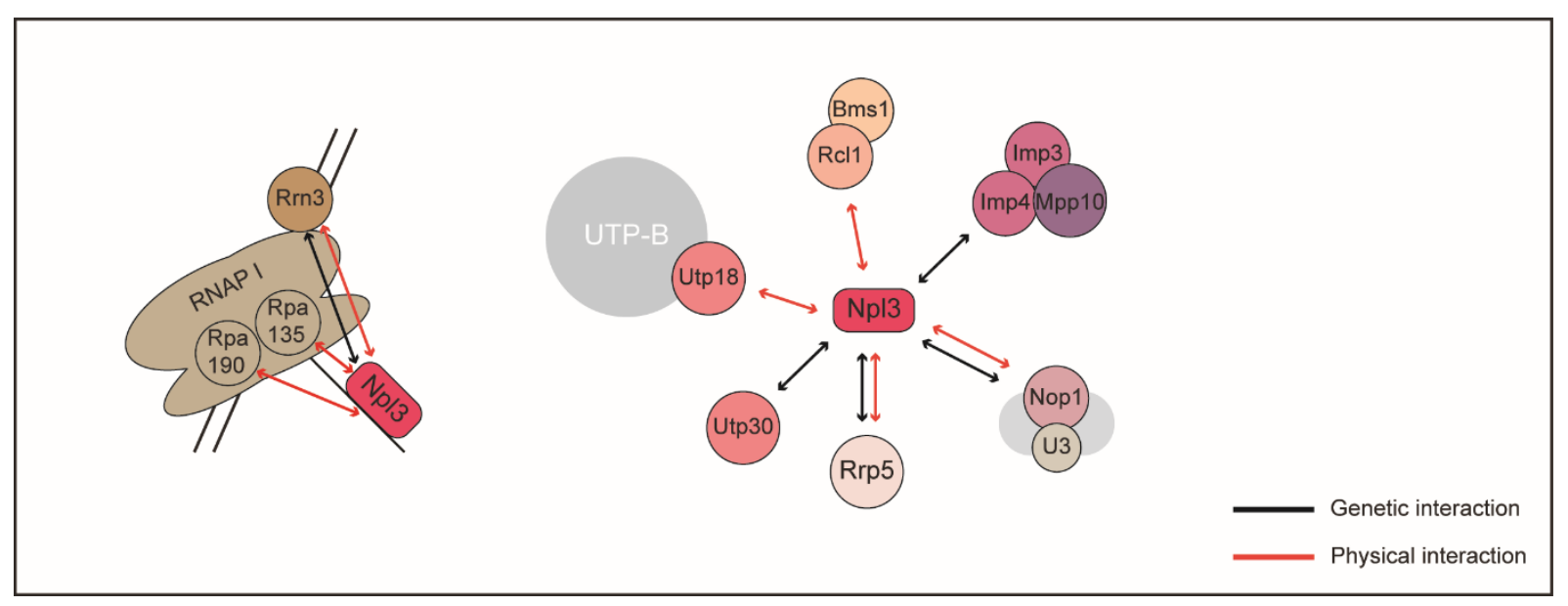

Figure 32: Npl3 interacts with RNAP I and the SSU processome.

Physical (red) and genetic (black) interactions between Npl3 and factors of RNAP I and the SSU processome.

Taken together, Npl3 is co-transcriptionally loaded to the 5 '-end of the $35 \mathrm{~S}$ rRNA precursor and binds to the ETS1 and ITS1 spacer region. Processing of rRNAs starts with the cotranscriptional assembly of the SSU processome, which is responsible for the first cleavage events at the sites $A_{0}, A_{1}$ and $A_{2}$. Cleavage at site $A_{2}$, which is carried out by the endonuclease Rcl1, results in the 20S rRNA and the 27S precursors and thereby separates the SSU from the LSU. During regular processing, the sites $\mathrm{A}_{0}, \mathrm{~A}_{1}$ and $\mathrm{A}_{2}$ are cleaved and the spacer regions are 
processed by the nuclear exosome in 3' to 5' direction and by the Rat1-Rai machinery in 5' to 3' direction. The exosome is recruited to the processing site via Mtr4, which is recruited by Utp18. As Npl3 interacts with Utp18, it might be that Npl3 is important to direct Utp18 to the processing site. Furthermore, the recruitment of the Rat1-Rai1 machinery might also be mediated by Npl3. Defects in these processing events as well as delayed assembly of the SSU processome lead to a premature cleavage at site $\mathrm{A}_{3}$ resulting in the aberrant inviable 23S rRNA precursor. Due to the fact, that missing Npl3 leads to an increase of the $23 \mathrm{~S}$ rRNA, visible in $\operatorname{rrp} 6 \Delta n p l 3 \Delta$, the protein might -similar to pre-mRNA processing- surveil the rRNA processing and recruit the TRAMP and Rat1-Rai1 complex to aberrant products, such as the 23S rRNA. (Figure33).

Overall our studies have identified novel functions of Npl3 in RNA surveillance. Both, for the degradation of faulty mRNAs and rRNAs, it interacts with the 3' to 5' and 5' to 3' degradation machineries, which are less recruited to false mRNAs when Npl3 is absent. The mechanisms by which this guard protein detects defective RNAs is still unclear, however it might be the binding of particular RNA binding proteins, as in the case of the CBC at 5'-mRNA caps. 


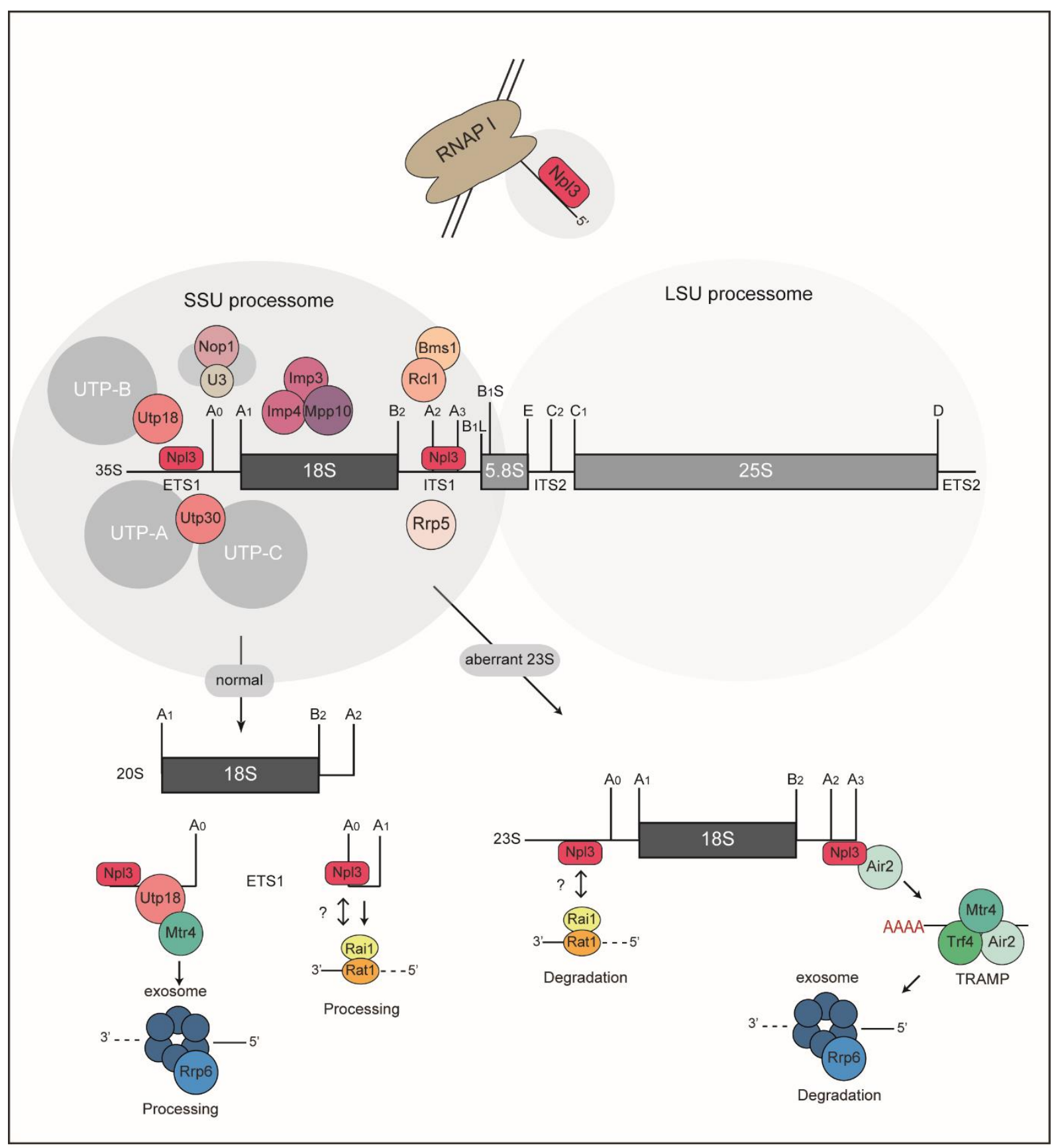

Figure 33: Npl3 in ribosome biogenesis and quality control of rRNA.

$\mathrm{Np} 13$ is co-transcriptionally loaded to the 5'-end of the 35S rRNA precursor and binds to the ETS1 and ITS1 spacer regions.

Processing of rRNAs starts with the co-transcriptional assembly of the SSU processome, which is composed of several sub-complexes that join the emerging pre-rRNA in a hierarchical manner. The SSU processome is responsible for the first cleavage events at the sites $A_{0}, A_{1}$ and $A_{2}$. Cleavage at site $A_{2}$, which is carried out by the endonuclease Rcl1, results in the 20S rRNA and the 27S precursors and thereby separates the SSU from the LSU. Delayed or impaired assembly of the SSU processome lead to a premature cleavage at site $\mathrm{A}_{3}$ resulting in the aberrant 23S rRNA precursor, which is lethal to cells.

During regular processing, the sites $\mathrm{A}_{0}, \mathrm{~A}_{1}$ and $\mathrm{A}_{2}$ are cleaved and the spacer regions are degraded by the nuclear exosome in 3' -5 ' direction and by the Rat1-Rai machinery in 5' -3 ' direction. The exosome is recruited to the processing site via Mtr4, which is recruited by Utp18. Npl3 interacts with Utp18 and might participate in Mtr4 recruitment. The recruitment of the Rat1-Rai1 machinery might also be mediated by Npl3.

In case that the aberrant $23 \mathrm{~S}$ rRNA is generated, Npl3 recruits the TRAMP complex for its subsequent degradation by the exosome. Furthermore, it might be, that Npl3 recruits also the Rat1-Rail machinery for 5'-3' directed degradation. 


\section{References}

Aitchison, J. D. and Rout, M. P. (2012) 'The yeast nuclear pore complex and transport through it', Genetics, 190(3), pp. 855-883. doi: 10.1534/genetics.111.127803.

Ares, M., Grate, L. and Pauling, M. H. (1999) 'A handful of intron-containing genes produces the lion's share of yeast mRNA', RNA, 5, pp. 1138-1139. doi: 10.1017/S1355838299991379.

Baejen, C. et al. (2014) 'Transcriptome Maps of mRNP Biogenesis Factors Define Pre-mRNA Recognition', Molecular Cell, 55(5), pp. 745-757. doi: 10.1016/j.molcel.2014.08.005.

Baierlein, C. et al. (2013) 'Monosome Formation during Translation Initiation Requires the Serine/Arginine-Rich Protein Npl3', Molecular and Cellular Biology, 33(24), pp. 4811-4823. doi: 10.1128/MCB.00873-13.

Bernstein, J. et al. (2008) 'Characterization of the essential activities of Saccharomyces cerevisiae Mtr4p, a $3^{\prime} \rightarrow 5^{\prime}$ helicase partner of the nuclear exosome', Journal of Biological Chemistry, 283(8), pp. 4930-4942. doi: 10.1074/jbc.M706677200.

Bernstein, J. and Toth, E. A. E. (2012) 'Yeast nuclear RNA processing', World journal of biological chemistry, 3(1), pp. 7-26. doi: 10.4331/wjbc.v3.i1.REVIEW.

Blattner, C. et al. (2011) 'Molecular basis of Rrn3-regulated RNA polymerase I initiation and cell growth', Genes and Development, 25(19), pp. 2093-2105. doi: 10.1101/gad.17363311.

Bucheli, M. E. and Buratowski, S. (2005) 'Npl3 is an antagonist of mRNA 3' end formation by RNA polymerase II.', The EMBO journal, 24(12), pp. 2150-60. doi: 10.1038/sj.emboj.7600687.

Callahan, K. P. and Butler, J. S. (2010) 'TRAMP complex enhances RNA degradation by the nuclear exosome component Rrp6', Journal of Biological Chemistry, 285(6), pp. 3540-3547. doi: 10.1074/jbc.M109.058396.

Chaker-Margot, M. et al. (2015) 'Stage-specific assembly events of the 6-MDa small-subunit 
processome initiate eukaryotic ribosome biogenesis.', Nature Structural \& Molecular Biology, 22(11), pp. 920-923. doi: 10.1038/nsmb.3111.

Chaker-Margot, M. et al. (2017) 'Architecture of the yeast small subunit processome', Science, 355(6321), p. eaal1880. doi: 10.1126/science.aal1880.

Chan, S., Choi, E.-A. and Shi, Y. (2011) 'Pre-mRNA 3'-end processing complex assembly and function', Wiley Interdisciplinary Reviews: RNA, 2(3), pp. 321-335. doi: 10.1002/wrna.54.

Coppola, J. A., Field, A. S. and Luse, D. S. (1983) 'Promoter-proximal pausing by RNA polymerase II in vitro: transcripts shorter than 20 nucleotides are not capped.', Proceedings of the National Academy of Sciences of the United States of America, 80(5), pp. 1251-5. doi: 10.1073/pnas.80.5.1251.

Cramer, P. (2004) 'RNA polymerase II structure: From core to functional complexes', Current Opinion in Genetics and Development, pp. 218-226. doi: 10.1016/j.gde.2004.01.003.

Davis, C. a et al. (2000) 'Test of intron predictions reveals novel splice sites, alternatively spliced mRNAs and new introns in meiotically regulated genes of yeast.', Nucleic acids research, 28(8), pp. 1700-1706. doi: 10.1093/nar/28.8.1700.

Dermody, J. L. et al. (1996) 'Unphosphorylated SR-like protein Npl3 stimulates RNA polymerase II elongation', PLOS ONE, 7(9), pp. 1233-1246. doi: 10.1101/gad.10.10.1233.

Dermody, J. L. et al. (2008) 'Unphosphorylated SR-like protein Npl3 stimulates RNA polymerase II elongation', PLoS ONE, 3(9). doi: 10.1371/journal.pone.0003273.

Dez, C., Houseley, J. and Tollervey, D. (2006) 'Surveillance of nuclear-restricted preribosomes within a subnucleolar region of Saccharomyces cerevisiae', The EMBO journal, 25(7), pp. 1534-46. doi: 10.1038/sj.emboj.7601035.

Dragon, F. et al. (2002) 'A large nucleolar U3 ribonucleoprotein required for $18 \mathrm{~S}$ ribosomal RNA biogenesis', Nature, 417(6892), pp. 967-970. doi: 10.1038/nature00769. 
Dunn, E. F. et al. (2005) 'Yeast poly(A)-binding protein, Pab1, and PAN, a poly(A) nuclease complex recruited by Pab1, connect mRNA biogenesis to export', Genes and Development, 19(1), pp. 90-103. doi: 10.1101/gad.1267005.

Fabrega, C. et al. (2003) 'Structure of an mRNA capping enzyme bound to the phosphorylated carboxy-terminal domain of RNA polymerase II', Molecular Cell, 11(6), pp. 1549-1561. doi: 10.1016/S1097-2765(03)00187-4.

Fang, F., Phillips, S. and Butler, J. S. (2005) 'Rat1p and Railp function with the nuclear exosome in the processing and degradation of rRNA precursors.', RNA (New York, N.Y.), 11(10), pp. 1571-8. doi: 10.1261/rna.2900205.

Fasken, M. B. and Corbett, A. H. (2009) 'Mechanisms of nuclear mRNA quality control.', $R N A$ biology, 6(3), pp. 237-241. doi: 10.4161/rna.6.3.8330.

Fernández-Pevida, A., Kressler, D. and de la Cruz, J. (2015a) 'Processing of preribosomal RNA in Saccharomyces cerevisiae', Wiley Interdisciplinary Reviews: RNA, 6(2), pp. 191-209. doi: 10.1002/wrna.1267.

Fernández-Pevida, A., Kressler, D. and de la Cruz, J. (2015b) 'Processing of preribosomal RNA in Saccharomyces cerevisiae', Wiley Interdisciplinary Reviews: RNA, pp. 191-209. doi: 10.1002/wrna.1267.

Freed, E. F. et al. (2010) 'When ribosomes go bad: diseases of ribosome biogenesis.', Molecular bioSystems, 6(3), pp. 481-93. doi: 10.1039/b919670f.

Furuichi, Y. and Shatkin, A. J. (2000) 'Viral and cellular mRNA capping: past and prospects.', Advances in virus research, 55, pp. 135-184. doi: 10.1016/S0065-3527(00)55003-9.

Garfin, D. E. (2009) 'Chapter 29 One-Dimensional Gel Electrophoresis1', Methods in Enzymology, pp. 497-513. doi: 10.1016/S0076-6879(09)63029-9.

Ghosh, A. and Lima, C. D. (2010) 'Enzymology of RNA cap synthesis', Wiley Interdisciplinary 
Reviews: RNA, pp. 152-172. doi: 10.1002/wrna.19.

Gietz, D. et al. (1992) 'Improved method for high efficiency transformation of intact yeast cells.', Nucl Acid Res, 20(6), p. 1425. doi: 10.1093/nar/20.6.1425.

Gilbert, W. and Guthrie, C. (2004) 'The Glc7p Nuclear Phosphatase Promotes mRNA Export by Facilitating Association of Mex67p with mRNA', Molecular Cell, 13(2), pp. 201-212. doi: 10.1016/S1097-2765(04)00030-9.

Gilbert, W., Siebel, C. W. and Guthrie, C. (2001) 'Phosphorylation by Sky1p promotes Npl3p shuttling and mRNA dissociation.', RNA (New York, N.Y.), 7(2), pp. 302-313. doi: 10.1017/S1355838201002369.

Görnemann, J. et al. (2005) 'Cotranscriptional spliceosome assembly occurs in a stepwise fashion and requires the cap binding complex', Molecular Cell, 19(1), pp. 53-63. doi: 10.1016/j.molcel.2005.05.007.

Gross, T. et al. (2007) 'The DEAD-Box RNA Helicase Dbp5 Functions in Translation Termination', Science, 315(5812), pp. 646-649. doi: 10.1126/science.1134641.

Gu, M., Rajashankar, K. R. and Lima, C. D. (2010) 'Structure of the Saccharomyces cerevisiae Cet1-Ceg1 mRNA Capping Apparatus', Structure, 18(2), pp. 216-227. doi: 10.1016/j.str.2009.12.009.

Häcker, S. and Krebber, P. (2004) 'Differential Export Requirements for Shuttling Serine/Arginine-type mRNA-binding Proteins', Journal of Biological Chemistry, 279(7), pp. 5049-5052. doi: 10.1074/jbc.C300522200.

Hackmann, A. et al. (2011a) 'The mRNA export factor Npl3 mediates the nuclear export of large ribosomal subunits', EMBO reports, 12(10), pp. 1024-1031. doi: 10.1038/embor.2011.155.

Hackmann, A. et al. (2011b) 'The mRNA export factor Npl3 mediates the nuclear export of 
large ribosomal subunits.', EMBO reports. Nature Publishing Group, 12(10), pp. 1024-31. doi: 10.1038/embor.2011.155.

Hackmann, A. et al. (2014) 'Quality control of spliced mRNAs requires the shuttling SR proteins Gbp2 and Hrb1', Nature communications, 5. doi: 10.1038/ncomms4123.

Hamill, S., Wolin, S. L. and Reinisch, K. M. (2010) 'Structure and function of the polymerase core of TRAMP, a RNA surveillance complex.', Proceedings of the National Academy of Sciences of the United States of America, 107(34), pp. 15045-15050. doi: 10.1073/pnas.1003505107.

Henras, A. K. et al. (2015) 'An overview of pre-ribosomal RNA processing in eukaryotes', Wiley Interdisciplinary Reviews: RNA, pp. 225-242. doi: 10.1002/wrna.1269.

Ho, C. K. and Shuman, S. (1999) 'Distinct roles for CTD Ser-2 and Ser-5 phosphorylation in the recruitment and allosteric activation of mammalian mRNA capping enzyme', Molecular Cell, 3(3), pp. 405-411. doi: 10.1016/S1097-2765(00)80468-2.

Hobeika, M. et al. (2009) 'Structural requirements for the ubiquitin-associated domain of the mRNA export factor Mex67 to bind its specific targets, the transcription elongation THO complex component Hpr1 and nucleoporin FXFG repeats', Journal of Biological Chemistry, 284(26), pp. 17575-17583. doi: 10.1074/jbc.M109.004374.

Houseley, J., LaCava, J. and Tollervey, D. (2006) 'RNA-quality control by the exosome', Nature Reviews Molecular Cell Biology, 7(7), pp. 529-539. doi: 10.1038/nrm1964.

Houseley, J. and Tollervey, D. (2006) 'Yeast Trf5p is a nuclear poly(A) polymerase.', EMBO reports, 7(2), pp. 205-11. doi: 10.1038/sj.embor.7400612.

Hsin, J. and Manley, J. L. (2012) 'The RNA polymerase II CTD coordinates transcription and RNA processing,, Genes and Development, pp. 2119-2137. doi: 10.1101/gad.200303.112.Transcription. 
Huang, Y. and Steitz, J. A. (2005) 'SRprises along a messenger's journey’, Molecular Cell, pp. 613-615. doi: 10.1016/j.molcel.2005.02.020.

Huertas, P. and Aguilera, A. (2003) 'Cotranscriptionally formed DNA:RNA hybrids mediate transcription elongation impairment and transcription-associated recombination', Molecular Cell, 12(3), pp. 711-721. doi: 10.1016/j.molcel.2003.08.010.

Hurt, E. et al. (2000) 'Mex67p mediates nuclear export of a variety of RNA polymerase II transcripts', Journal of Biological Chemistry, 275(12), pp. 8361-8368. doi: 10.1074/jbc.275.12.8361.

Hurt, E. et al. (2004) 'Cotranscriptional recruitment of the serine-arginine-rich (SR)-like proteins Gbp2 and Hrb1 to nascent mRNA via the TREX complex.', Proceedings of the National Academy of Sciences, USA, 101(7), pp. 1858-1862. doi: 10.1073/pnas.0308663100.

Inoue, H., Nojima, H. and Okayama, H. (1990) 'High efficiency transformation of Escherichia coli with plasmids', Gene, 96(1), pp. 23-28. doi: 10.1016/0378-1119(90)90336-P.

Jeong, S. (2017) 'SR Proteins: Binders, Regulators, and Connectors of RNA', Molecules and Cells, 40(1), pp. 1-9. doi: 10.14348/molcells.2017.2319.

Jia, H. et al. (2011) 'The RNA helicase Mtr4p modulates polyadenylation in the TRAMP complex', Cell, 145(6), pp. 890-901. doi: 10.1016/j.cell.2011.05.010.

Jia, H. et al. (2012) 'RNA unwinding by the Trf4/Air2/Mtr4 polyadenylation (TRAMP) complex', Proceedings of the National Academy of Sciences, 109(19), pp. 7292-7297. doi: 10.1073/pnas.1201085109.

Jiao, X. et al. (2010) 'Identification of a quality-control mechanism for mRNA 5'-end capping', Nature, 467(7315), pp. 608-611. doi: 10.1038/nature09338.

Jimeno-González, S. et al. (2010) 'The Yeast 5???-3??? Exonuclease Rat1p Functions during Transcription Elongation by RNA Polymerase II', Molecular Cell, 37(4), pp. 580-587. doi: 
10.1016/j.molcel.2010.01.019.

Jove, R. and Manley, J. L. (1982) 'Transcription initiation by RNA polymerase II is inhibited by Biochemistry: Jove and Manley', Proceedings of the National Academy of Sciences, 79(October), pp. 5842-5846.

Khoshnevis, S. et al. (2016) 'The DEAD-box Protein Rok1 Orchestrates 40S and 60S Ribosome Assembly by Promoting the Release of Rrp5 from Pre-40S Ribosomes to Allow for 60S Maturation', PLoS Biology, 14(6). doi: 10.1371/journal.pbio.1002480.

Kim, M. et al. (2004) 'The yeast Rat1 exonuclease promotes transcription termination by RNA polymerase II', Nature, 432(7016), pp. 517-522. doi: 10.1038/nature03041.

Kim Guisbert, K. et al. (2005) 'Functional specificity of shuttling hnRNPs revealed by genomewide analysis of their RNA binding profiles.', RNA (New York, N.Y.), 11(4), pp. 383-93. doi: 10.1261/rna.7234205.

Koš, M. and Tollervey, D. (2010) 'Yeast Pre-rRNA Processing and Modification Occur Cotranscriptionally', Molecular Cell, 37(6), pp. 809-820. doi: 10.1016/j.molcel.2010.02.024.

Kress, T. L., Krogan, N. J. and Guthrie, C. (2008) 'A Single SR-like Protein, Npl3, Promotes Pre-mRNA Splicing in Budding Yeast', Molecular Cell, 32(5), pp. 727-734. doi: 10.1016/j.molcel.2008.11.013.

Kressler, D., Hurt, E. and Baßler, J. (2010) 'Driving ribosome assembly', Biochimica et Biophysica Acta - Molecular Cell Research, 1803(6), pp. 673-683. doi: 10.1016/j.bbamcr.2009.10.009.

Krogan, N. J. et al. (2004) 'High-Definition Macromolecular Composition of Yeast RNAProcessing Complexes', Molecular Cell, 13(2), pp. 225-239. doi: 10.1016/S10972765(04)00003-6.

LAEMMLI, U. K. (1970) 'Cleavage of Structural Proteins during the Assembly of the Head of 
Bacteriophage T4', Nature, 227(5259), pp. 680-685. doi: 10.1038/227680a0.

Lafontaine, D. L. J. (2010) 'A “garbage can” for ribosomes: how eukaryotes degrade their ribosomes', Trends in Biochemical Sciences. Elsevier Ltd, 35(5), pp. 267-277. doi: 10.1016/j.tibs.2009.12.006.

Lee, M. S., Henry, M. and Pamela, A. (1996) 'A protein that shuttles between the nucleus and the cvto $\sim$ lasm is an important mediito; of RNA export', Genes \& Dev, 10, pp. 1233-1246. doi: 10.1101/gad.10.10.1233.

Lei, E. P., Krebber, H. and Silver, P. A. (2001) 'Messenger RNAs are recruited for nuclear export during transcription', Genes and Development, 15(14), pp. 1771-1782. doi: $10.1101 / \operatorname{gad} .892401$.

Lei, E. P. and Silver, P. A. (2002) 'Intron status and 3'-end formation control cotranscriptional export of mRNA', Genes and Development, 16(21), pp. 2761-2766. doi: 10.1101/gad.1032902.

Lewis, J. D. and Izaurflde, E. (1997) 'The Role of the Cap Structure in RNA Processing and Nuclear Export', European Journal of Biochemistry, 247(2), pp. 461-469. doi: 10.1111/j.14321033.1997.00461.x.

Lidschreiber, M., Leike, K. and Cramer, P. (2013) 'Cap Completion and C-Terminal Repeat Domain Kinase Recruitment Underlie the Initiation-Elongation Transition of RNA Polymerase II', Molecular and Cellular Biology, 33(19), pp. 3805-3816. doi: 10.1128/MCB.00361-13.

Livak, K. J. and Schmittgen, T. D. (2001) 'Analysis of relative gene expression data using realtime quantitative PCR and the 2(-Delta Delta C(T)) Method.', Methods (San Diego, Calif.), 25(4), pp. 402-8. doi: 10.1006/meth.2001.1262.

Lukong, K. E. et al. (2008) 'RNA-binding proteins in human genetic disease.', Trends in genetics : TIG, 24(8), pp. 416-425. doi: 10.1016/j.tig.2008.05.004.

Mao, X., Schwer, B. and Shuman, S. (1995) 'Yeast mRNA cap methyltransferase is a 50- 
kilodalton protein encoded by an essential gene.', Molecular and cellular biology, 15(8), pp. $4167-74$. Available at: http://www.pubmedcentral.nih.gov/articlerender.fcgi?artid=230655\&tool=pmcentrez\&rendert ype=abstract.

Matlin, A. J. and Moore, M. J. (2007) 'Spliceosome assembly and composition.', Advances in experimental medicine and biology, 623, pp. 14-35. doi: 10.1261/rna.1340908.

Mayer, A. et al. (2010) 'Uniform transitions of the general RNA polymerase II transcription complex', Nature Structural \& Molecular Biology, 17(10), pp. 1272-1278. doi: 10.1038/nsmb.1903.

Meinel, D. M. and Sträßer, K. (2015) 'Co-transcriptional mRNP formation is coordinated within a molecular mRNP packaging station in S. cerevisiae', BioEssays, 37(6), pp. 666-677. doi: 10.1002/bies.201400220.

Milkereit, P. and Tschochner, H. (1998) 'A specialized form of RNA polymerase I, essential for initiation and growth-dependent regulation of rRNA synthesis, is disrupted during transcription', EMBO Journal, 17(13), pp. 3692-3703. doi: 10.1093/emboj/17.13.3692.

Mitchell, P. et al. (1997) 'The exosome: a conserved eukaryotic RNA processing complex containing multiple 3' to 5' exoribonucleases', Cell, 91(4), pp. 457-466. doi: S00928674(00)80432-8 [pii].

Moehle, E. A. et al. (2012) 'The Yeast SR-Like Protein Npl3 Links Chromatin Modification to mRNA Processing', PLoS Genetics, 8(11). doi: 10.1371/journal.pgen.1003101.

Moore, M. J. and Proudfoot, N. J. (2009) 'Pre-mRNA Processing Reaches Back toTranscription and Ahead to Translation', Cell, pp. 688-700. doi: 10.1016/j.cell.2009.02.001.

Peña, C., Hurt, E. and Panse, V. G. (2017) 'Eukaryotic ribosome assembly, transport and quality control', Nature Structural \& Molecular Biology, 24(9), pp. 689-699. doi: 10.1038/nsmb.3454. 
Pérez-Fernández, J., Martín-Marcos, P. and Dosil, M. (2011) 'Elucidation of the assembly events required for the recruitment of Utp20, Imp4 and Bms1 onto nascent pre-ribosomes', Nucleic Acids Research, 39(18), pp. 8105-8121. doi: 10.1093/nar/gkr508.

Rasmussen, E. B. and Lis, J. T. (1993) 'In vivo transcriptional pausing and cap formation on three Drosophila heat shock genes.', Proceedings of the National Academy of Sciences of the United States of America, 90(17), pp. 7923-7. doi: 10.1073/pnas.90.17.7923.

Rigaut, G. et al. (1999) 'A generic protein purification method for protein complex characterization and proteome exploration.', Nature biotechnology, 17(10), pp. 1030-1032. doi: $10.1038 / 13732$.

Rose, M., Winston, F. and Hieter, P. (1991) 'Methods in Yeast Genetics - A Laboratory Course Manual', in Biochemical Education, pp. 101-102. doi: 10.1016/0307-4412(91)90039B.

Rougemaille, M. et al. (2008) 'mRNA journey to the cytoplasm: attire required.', Biology of the cell / under the auspices of the European Cell Biology Organization, 100(6), pp. 327-342. doi: 10.1042/BC20070143.

Russell, I. D. and Tollervey, D. (1992) 'NOP3 is an essential yeast protein which is required for pre-rRNA processing', Journal of Cell Biology, 119(4), pp. 737-747. doi: 10.1083/jcb.119.4.737.

Sambrook, J., Fritsch, E. F. and Maniatis, T. (1989) Molecular Cloning: A Laboratory Manual. Cold Spring Harbor laboratory press, New York. doi: 574.873224 1/1989.

San Paolo, S. et al. (2009) 'Distinct roles of non-canonical poly(A) polymerases in RNA metabolism', PLoS Genetics, 5(7). doi: 10.1371/journal.pgen.1000555.

Santos-Pereira, J. M. et al. (2014) 'Npl3, a new link between RNA-binding proteins and the maintenance of genome integrity', Cell Cycle, pp. 1524-1529. doi: 10.4161/cc.28708. 
Schmidt, K. et al. (2012) 'Air proteins control differential TRAMP substrate specificity for nuclear RNA surveillance.', RNA (New York, N.Y.), 18(10), pp. 1934-45. doi: 10.1261/rna.033431.112.

Schmidt, K. and Butler, J. S. (2013) 'Nuclear RNA surveillance: Role of TRAMP in controlling exosome specificity', Wiley Interdisciplinary Reviews: RNA, pp. 217-231. doi: 10.1002/wrna.1155.

Shen, E. C. et al. (2000) '7The yeast mRNA-binding protein Np13p interacts with the capbinding complex', Journal of Biological Chemistry, 275(31), pp. 23718-23724. doi: 10.1074/jbc.M002312200.

Sherman, F. (1991) 'Getting Started with Yeast', Methods in Enzymology, 194(C), pp. 3-21. doi: 10.1016/0076-6879(91)94004-V.

Sherman, F. and Hicks, J. (1991) 'Micromanipulation and Dissection of Asci', Methods in Enzymology, 194(C), pp. 21-37. doi: 10.1016/0076-6879(91)94005-W.

Shibagaki, Y. et al. (1992) 'messenger RNA Capping Enzyme - Isolation and Characterization of the Gene Encoding messenger RNA Guanylyltransferase Subunit from SaccharomycesCerevisiae', J Biol Chem, 267(14), pp. 9521-9528.

Sikorski, R. S. and Hieter, P. (1989) 'A system of shuttle vectors and yeast host strains designed for efficient manipulation of DNA in Saccharomyces cerevisiae.', Genetics, 122(1), pp. 19-27. doi: 0378111995000377 [pii].

Sklenar, A. R. and Parthun, M. R. (2004) 'Characterization of yeast histone H3-specific type B histone acetyltransferases identifies an ADA2-independent Gen5p activity.', $B M C$ biochemistry, 5, p. 11. doi: 10.1186/1471-2091-5-11.

Sommer, P. and Nehrbass, U. (2005) 'Quality control of messenger ribonucleoprotein particles in the nucleus and at the pore', Current Opinion in Cell Biology, pp. 294-301. doi: 10.1016/j.ceb.2005.04.007. 
Soucek, S., Corbett, A. H. and Fasken, M. B. (2012) 'The long and the short of it: The role of the zinc finger polyadenosine RNA binding protein, Nab2, in control of poly(A) tail length', Biochimica et Biophysica Acta - Gene Regulatory Mechanisms, pp. 546-554. doi: 10.1016/j.bbagrm.2012.03.006.

Sprague, G. F. (1991) 'Assay of yeast mating reaction', Methods in Enzymology, 194(C), pp. 77-93. doi: 10.1016/0076-6879(91)94008-Z.

Takase, Y. et al. (2000) 'The essential interaction between yeast mRNA capping enzyme subunits is not required for triphosphatase function in vivo.', Molecular and cellular biology, 20(24), pp. 9307-9316. doi: 10.1128/MCB.20.24.9307-9316.2000.

Takizawa, N. et al. (2013) 'The essential role for the RNA triphosphatase Cet1p in nuclear import of the mRNA capping enzyme Cet1p-Ceg1p complex of Saccharomyces cerevisiae.', PloS one, 8(10), p. e78000. doi: 10.1371/journal.pone.0078000.

Thiry, M. and Lafontaine, D. L. J. (2005) 'Birth of a nucleolus: The evolution of nucleolar compartments', Trends in Cell Biology, pp. 194-199. doi: 10.1016/j.tcb.2005.02.007.

Thomson, E., Ferreira-Cerca, S. and Hurt, E. (2013) 'Eukaryotic ribosome biogenesis at a glance', Journal of Cell Science, 126(21), pp. 4815-4821. doi: 10.1242/jcs.111948.

Tian, B. and Graber, J. H. (2012) 'Signals for pre-mRNA cleavage and polyadenylation', Wiley Interdisciplinary Reviews: RNA, pp. 385-396. doi: 10.1002/wrna.116.

Tieg, B. and Krebber, H. (2013) 'Dbp5 - From nuclear export to translation', Biochimica et Biophysica Acta - Gene Regulatory Mechanisms, 1829(8), pp. 791-798. doi: 10.1016/j.bbagrm.2012.10.010.

Towbin, H., Staehelin, T. and Gordon, J. (1979) 'Electrophoretic transfer of proteins from polyacrylamide gels to nitrocellulose sheets: procedure and some applications.', Proceedings of the National Academy of Sciences of the United States of America, 76(9), pp. 4350-4. doi: 10.1002/bies.950190612. 
Tsukamoto, T. et al. (1997) 'Isolation and characterization of the yeast mRNA capping enzyme beta subunit gene encoding RNA 5'-triphosphatase, which is essential for cell viability.', Biochemical and biophysical research communications, 239(1), pp. 116-122. doi: 10.1006/bbrc.1997.7439.

Tutucci, E. and Stutz, F. (2011) 'Keeping mRNPs in check during assembly and nuclear export.', Nature reviews. Molecular cell biology. Nature Publishing Group, 12(6), pp. 377-384. doi: 10.1038/nrm3119.

Wahl, M. C., Will, C. L. and Lührmann, R. (2009) 'The Spliceosome: Design Principles of a Dynamic RNP Machine', Cell, pp. 701-718. doi: 10.1016/j.cell.2009.02.009.

Wery, M. et al. (2009) 'The nuclear poly(A) polymerase and Exosome cofactor Trf5 is recruited cotranscriptionally to nucleolar surveillance.', RNA (New York, N.Y.), 15(3), pp. 406-19. doi: 10.1261/rna.1402709.

Will, C. L. and Lührmann, R. (2011) 'Spliceosome structure and function', Cold Spring Harbor Perspectives in Biology, 3(7), pp. 1-2. doi: 10.1101/cshperspect.a003707.

Windgassen, M. and Krebber, H. (2003) 'Identification of Gbp2 as a novel poly(A)+ RNAbinding protein involved in the cytoplasmic delivery of messenger RNAs in yeast.', EMBO reports, 4(3), pp. 278-83. doi: 10.1038/sj.embor.embor763.

Winston, F., Dollard, C. and Ricupero???Hovasse, S. L. (1995) 'Construction of a set of convenient saccharomyces cerevisiae strains that are isogenic to S288C', Yeast, 11(1), pp. 5355. doi: 10.1002/yea.320110107.

Wlotzka, W. et al. (2011) 'The nuclear RNA polymerase II surveillance system targets polymerase III transcripts', The EMBO Journal, 30(9), pp. 1790-1803. doi: 10.1038/emboj.2011.97.

Wojda, I. et al. (2002) 'Protein kinases CKI and CKII are implicated in modification of ribosomal proteins of the yeast Trichosporon cutaneum', Acta Biochimica Polonica, 49(4), pp. 947-957. doi: 024904947. 
Wolin, S. L., Sim, S. and Chen, X. (2012) 'Nuclear noncoding RNA surveillance: Is the end in sight?', Trends in Genetics. Elsevier Ltd, 28(7), pp. 306-313. doi: 10.1016/j.tig.2012.03.005.

Woolford, J. L. and Baserga, S. J. (2013) 'Ribosome biogenesis in the yeast Saccharomyces cerevisiae', Genetics, 195(3), pp. 643-681. doi: 10.1534/genetics.113.153197.

Wu, H., Becker, D. and Krebber, H. (2014) 'Telomerase RNA TLC1 shuttling to the cytoplasm requires mRNA export factors and is important for telomere maintenance', Cell Reports, 8(6), pp. 1630-1638. doi: 10.1016/j.celrep.2014.08.021.

Xiang, S. et al. (2009) 'Structure and function of the 5 ' $\rightarrow 3$ ' exoribonuclease Ratl and its activating partner Rai1', Nature, 458(7239), pp. 784-788. doi: 10.1038/nature07731.

Xue, Y. et al. (2000) 'Saccharomyces cerevisiae RAI1 (YGL246c) is homologous to human DOM3Z and encodes a protein that binds the nuclear exoribonuclease Rat1p.', Molecular and cellular biology, 20(11), pp. 4006-15. doi: 10.1128/MCB.20.11.4006-4015.2000.

Zhang, L. et al. (2016) 'Stepwise and dynamic assembly of the earliest precursors of small ribosomal subunits in yeast', Genes and Development, 30(6), pp. 718-732. doi: 10.1101/gad.274688.115. 


\section{Acknowledgement - Danksagung}

Ich möchte mich bei allen Personen ganz herzlich bedanken, die mich während meiner Doktorarbeit unterstützt und zum Gelingen dieser Arbeit beigetragen haben.

Allen voran möchte ich Prof. Dr. Heike Krebber danken, dass sie mir die Möglichkeit gegeben hat, in ihrem Labor viele interessante Themen zu bearbeiten sowie für ihr Vertrauen, die enge Betreuung und die wissenschaftliche Förderung.

Weiterhin danke ich den Mitgliedern meines Thesis Committees, Dr. Oliver Valerius und Prof. Dr. Ralf Ficner, für die Begleitung meiner Doktorarbeit und für ihre wertvollen Ratschläge.

Herzlich bedanken möchte ich mich bei der AG Braus sowie allen anderen im Methodenteil erwähnten Arbeitsgruppen für das Bereitstellen von Stämmen und Plasmiden.

Besonders möchte ich mich außerdem bei allen aktuellen und ehemaligen Mitgliedern der AG Krebber für ihre Hilfsbereitschaft, die angenehme Arbeitsatmosphäre, den starken Zusammenhalt und die hilfreichen Diskussionen bedanken. Ich bedanke mich bei den von mir betreuten Studentinnen, Kara Schneider, Carolin Stockkamp und Anika Seel für die tolle gemeinsame Zeit im Labor und ihr großartiges Engagement, dass zum Gelingen dieser Doktorarbeit beigetragen hat. Bei Dr. Gesa Zander und Dr. Alexandra Hackmann bedanke ich mich für die gute Zusammenarbeit an diesem Projekt. Dr. Wilfried Kramer danke ich für sein kritisches Nachfragen und seine guten Ideen und Ratschläge.

Für das Korrekturlesen dieser Arbeit bedanke ich mich herzlich bei Prof. Dr. Heike Krebber, Sebastian Grosse und Daniel Becker.

Abschließend möchte ich mich von ganzem Herzen bei meiner Familie, insbesondere bei meiner Mutter und Großmutter, bei meinem Freund Claas Hendrik Linskens und seiner Familie und meinen Freunden bedanken. Danke, dass ihr mir immer zur Seite standet, mich unterstützt und an mich geglaubt habt. 


\section{Curriculum Vitae}

Ulla-Maria Schneider

Date of Birth: $7^{\text {th }}$ February 1986

Place of Birth: Wolfhagen (Germany)

\section{School Education}

1992 - 1996 Grundschule Wolfsanger, Kassel

1996 - 1999 Gesamtschule Fuldatal, Kassel

1999-2002 Gesamtschule Witzenhausen

\section{Vocational education}

$2005-2006 \quad$ Vocational training as biologic technical-assistant

Elisabeth-Knipping-Schule, Kassel

\section{Scientific Education}

$2006-2007$

$2008-2011$

$2011-2013$

2014 - present
Biologie (Diplom), Universität Kassel

Bachelor of Science - Biologie, Georg-August Universität Göttingen Bachelor thesis in the group of Prof. Dr. Gerhard Braus,

Department of Molecular Microbiology and Genetics, Georg-August Universität Göttingen, entitled: "Deletion and characterization of F-box protein encoding genes $f b x 1-15$ in Aspergillus nidulans“

Master of Science - Microbiology and Biochemistry, Georg-August Universität Göttingen

Master thesis in the group of Prof. Dr. Heike Krebber,

Department of Molecular Genetics, Georg-August Universität Göttingen, entitled:" Functional importance of the TRAMP complex in mRNA quality control and mRNA transport"

$\mathrm{PhD}$ student in the group of Prof. Dr. Heike Krebber, Department of Molecular Genetics, Georg-August Universität Göttingen;

Member of the GGNB graduate school Molecular Biology of Cells

\section{Publications}

Hackmann, A., H. Wu, U.-M. Schneider, K. Meyer, K. Jung, and H. Krebber. 2014. "Quality Control of Spliced mRNAs Requires the Shuttling SR Proteins Gbp2 and Hrb1." Nature Communications 5. doi:10.1038/ncomms4123. 